Universidade de São Paulo

Escola Superior de Agricultura "Luiz de Queiroz"

Resposta de plantas de tomate (Lycopersicon esculentum cv Micro-Tom) ao cádmio

Priscila Lupino Gratão

Tese apresentada para obtenção do título de Doutor em Agronomia. Área de concentração: Genética e Melhoramento de Plantas

Piracicaba

2008 


\section{Priscila Lupino Gratão}

Bióloga

Resposta de plantas de tomate (Lycopersicon esculentum cv Micro-Tom) ao cádmio

Orientador:

Prof. Dr. RICARDO ANTUNES DE AZEVEDO

Tese apresentada para obtenção do título de Doutor em Agronomia. Área de concentração: Genética e Melhoramento de Plantas

Piracicaba

2008 


\section{Dados Internacionais de Catalogação na Publicação (CIP)}

DIVISÃO DE BIBLIOTECA E DOCUMENTAÇÃO - ESALQ/USP

\section{Gratão, Priscila Lupino}

Resposta de plantas de tomate (Lycopersicon esculentum cv Micro-Tom) ao cádmio / Priscila Lupino Gratão. - - Piracicaba, 2008.

115 p. : il.

Tese (Doutorado) - - Escola Superior de Agricultura Luiz de Queiroz, 2008.

Bibliografia.

1. Antioxidantes 2. Cádmio 3. Estresse oxidativo 4. Hormônios vegetais 5 . Metal pesado do solo 6 . Mutação genética I. Título

CDD 635.642

\section{"Permitida a cópia total ou parcial deste documento, desde que citada a fonte - O autor"}


Aos meus pais, Adélia e Moacir,

a meu irmão, Marcelo,

minha avó tão querida, Antônia,

aos meus familiares e amigos que

sempre acreditaram em mim e nunca mediram esforços

para que esse sonho um dia se concretizasse...

DEDICO

A minha estrela guia,

minha luz,

minha maior força incentivadora...

você mãezinha...

OFEREÇO 


\section{AGRADECIMENTOS}

Em primeiro lugar a Deus, por me permitir acordar todos os dias e me fazer acreditar que é possível sempre conseguir aquilo que almejamos.

Ao Prof. Dr. Ricardo Antunes de Azevedo, pela orientação, confiança e amizade. Agradeço não só pelo aprendizado e experiência ao longo destes anos, mas especialmente pela oportunidade de ter dividido momentos maravilhosos e divertidos ao lado destas duas pessoas, Ricardo e Jacqueline, que hoje são para mim, como se fossem minha segunda família. Obrigada, de coração!

A Carol, não apenas por fazer parte diária na execução deste trabalho, mas pela grande irmã que ganhei, pelo companheirismo, convivência, paciência, vitórias e por todos os passos que demos juntas desde o início do Doutorado. Obrigada amiga, que nossa amizade seja eterna!

A Salete, pela amizade, sugestões, e por toda atenção desde o início do trabalho. Obrigada Sal, sua presença e amizade foram e são muito importantes!

A Flávia, pela amizade, ótimas discussões do trabalho e pela presença não apenas durante o Mestrado, mas também durante o Doutorado. Tenho muito o que aprender com vc!

A Gicka e Paula, não só pelo apoio e atenção desde o início do trabalho, mas pela grande amizade e pela alegria que estas duas amigas deixam a cada dia de trabalho. Obrigada Gicka pelas horas na frente do computador e Paula, pelas observações importantes. Valeu meninas!

A Bertha pela amizade, incentivo e broncas durante o doutorado. Obrigada amiga, vc é muito especial!

A Luciana, pelas conversas, idéias e todo incentivo ao trabalho realizado.

A Verônica e Renata, que através da iniciação científica nos fazem reviver o começo de todo o caminho científico, bastante laborioso, mas que nos traz uma enorme satisfação diária. 
Aos amigos Fabrício, Léo, Raul e Vanderlei, os homens do laboratório! Obrigada amigos pela convivência harmoniosa e por toda atenção e apoio.

Ao Prof. Dr. Lázaro E. P. Peres pelo apoio e contribuições desde o início do desenvolvimento deste trabalho, quando decidimos trabalhar com o Micro-Tom.

A Prof. Dra Silvia M. G. Molina pelo apoio e considerações sobre o trabalho, fundamentais para o engrandecimento do Doutorado.

A Prof. Dra. Adriana P. M. Rodriguez e a Mônica L. Rossi pelo apoio, contribuições e toda estrutura concedida para a realização das técnicas de Microscopia.

Aos amigos e colegas de outros laboratórios pelos momentos de confraternização.

Aos amigos que fazem parte da minha vida, que mesmo aqueles distantes, sempre me incentivaram de alguma forma. Obrigada por nunca me deixarem esquecer que a amizade é o sentimento mais nobre que existe.

Aos professores e funcionários do Programa.

A ESALQ e ao Departamento de Genética, pela oportunidade e toda a estrutara concedida na realização do Doutorado.

Ao CNPq e a FAPESP pela concessão das bolsas de estudo.

A todos que, de alguma maneira, contribuíram para a realização desse trabalho. 
"Nós, cientistas, acreditamos que o que nós e nossos semelhantes fizermos ou deixarmos de fazer nos próximos anos determinará o destino de nossa civilização. $\mathcal{E}$ consideramos nossa tarefa explicar incansavelmente essa verdade, ajudar as pessoas a perceber tudo o que está em jogo, e trabalhar, não para contemporizar, mas para aumentar o entendimento e conseguir, finalmente, a harmonia entre os povos e nações de diferentes pontos de vista." Albert Einstein 


\section{SUMÁRIO}

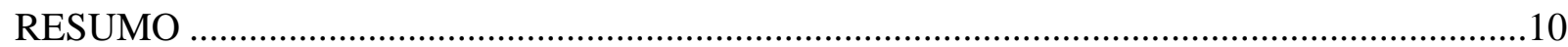

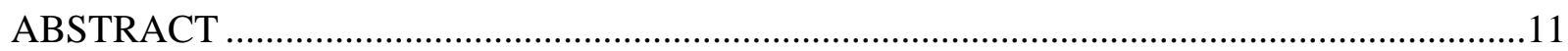

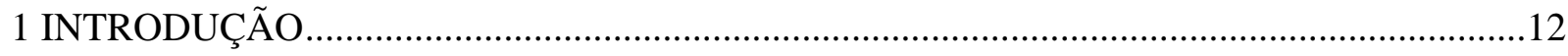

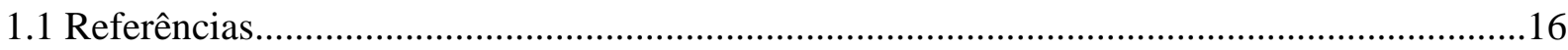

2 TORNANDO A VIDA DE PLANTAS ESTRESSADAS POR METAL PESADO UM POUCO

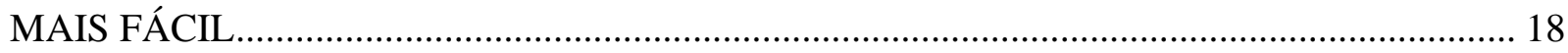

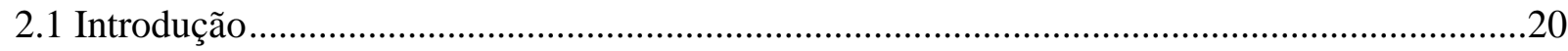

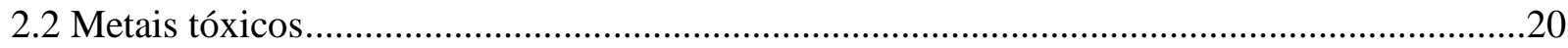

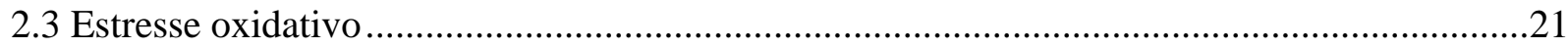

2.4 Sistemas antioxidantes de defesa: valiosos marcadores de estresse em estudos ecofisiológicos .22

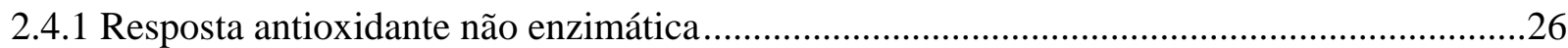

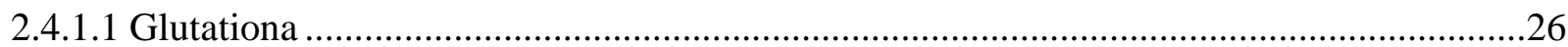

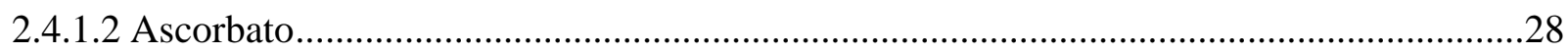

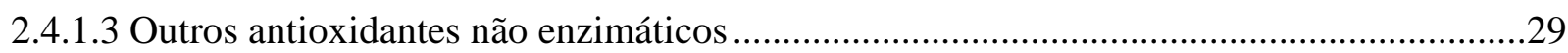

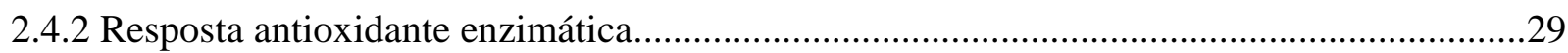

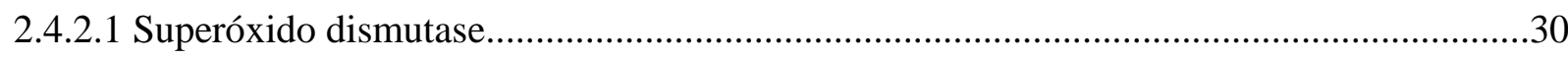

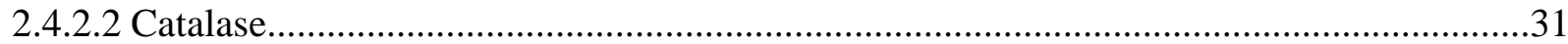

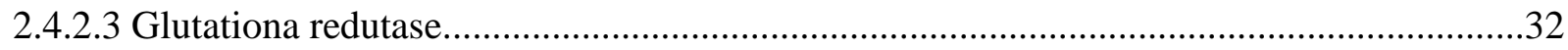

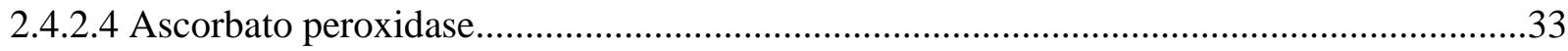

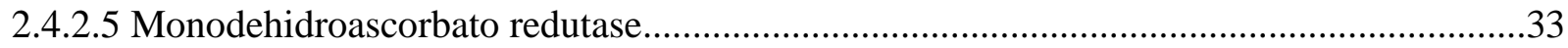

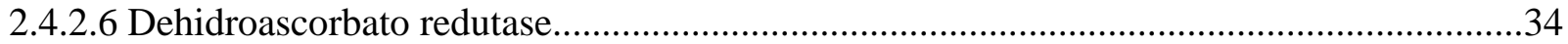




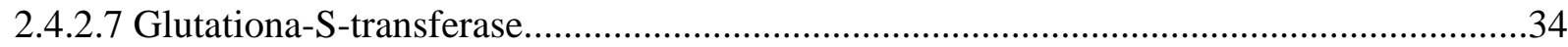

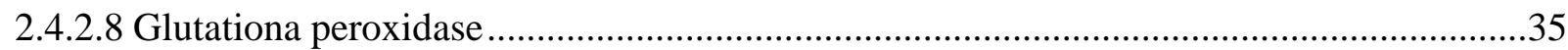

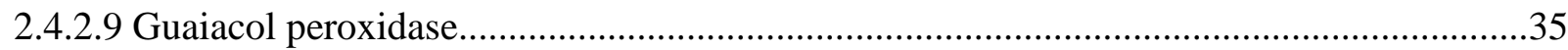

2.5 A sobrevivência das plantas: direções e perspectivas............................................................36

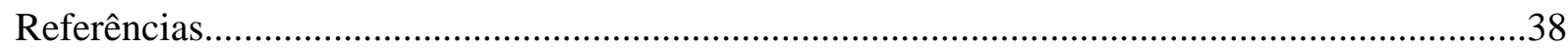

3 CARACTERIZAÇÃO DAS ENZIMAS ANTIOXIDANTES DO MICRO-TOM .....................50

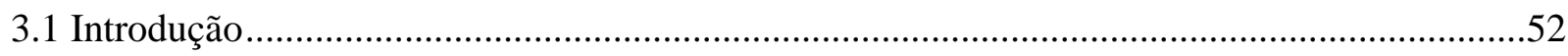

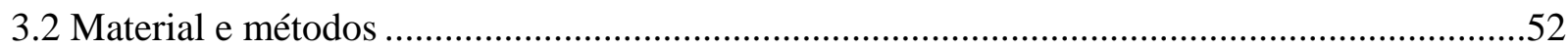

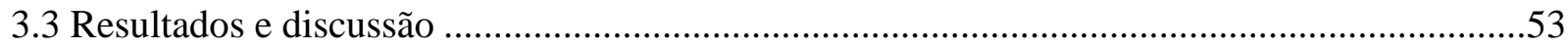

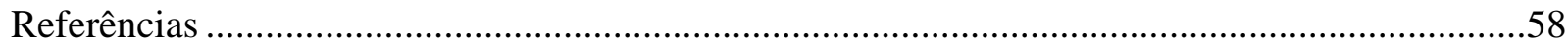

4 RESPOSTA ANTIOXIDATIVA DE LYCOPERSICON ESCULENTUM CV MICRO-TOM AO

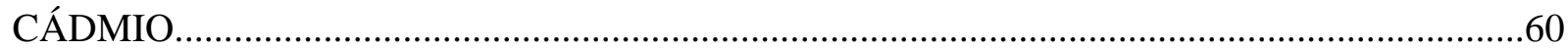

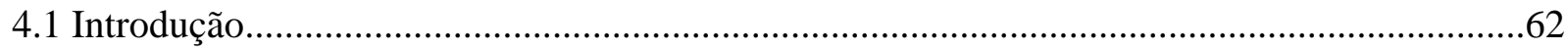

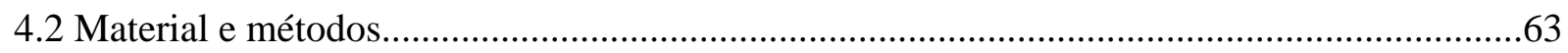

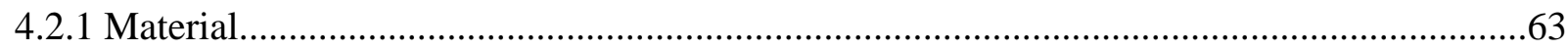

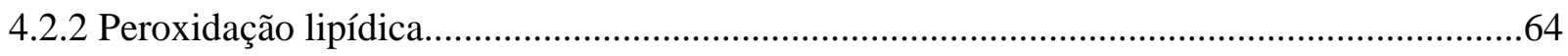

4.2.3 Extração e análises das enzimas antioxidantes.................................................................64

4.2.4 Eletroforese em gel de poliacrilamida (PAGE) e atividade enzimática...............................64

4.2.5 Determinação da concentração de proteína.........................................................................65

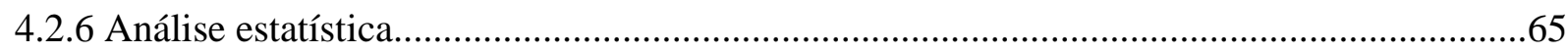

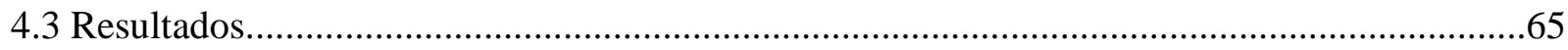

4.3.1 Crescimento das plantas e peroxidação lipídica...................................................................65

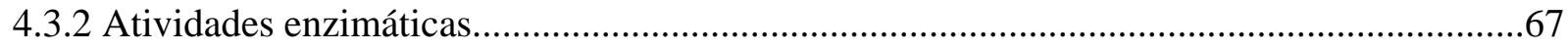

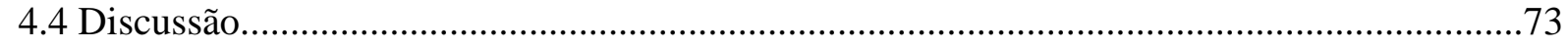


Referências .78

5. MUDANÇAS ULTRAESTRUTURAIS EM MUTANTES HORMONAIS DE TOMATE EXPOSTOS AO CÁDMIO 83

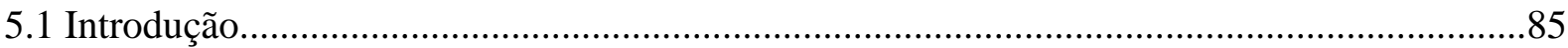

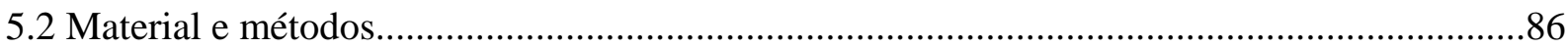

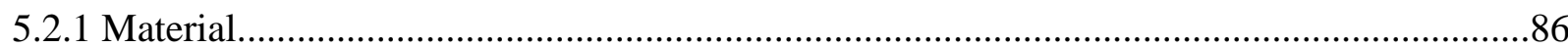

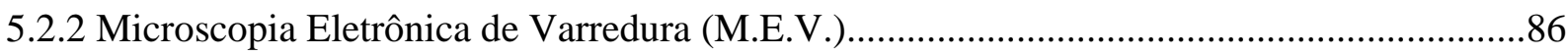

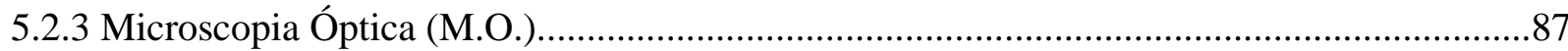

5.2.4 Microscopia Eletrônica de Transmissão (M.E.T)...................................................................87

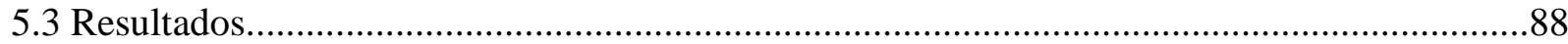

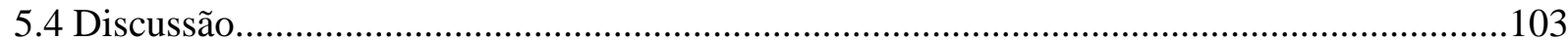

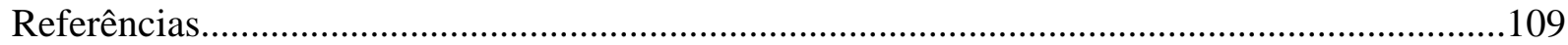




\title{
RESPOSTA DE PLANTAS DE TOMATE (Lycopersicon esculentum CV MICRO-TOM) AO CÁDMIO
}

\begin{abstract}
RESUMO
Sabe-se que dentre os principais contaminantes ambientais estão os metais pesados, decorrentes da intensa atividade agroindustrial das últimas décadas. Em especial, o cádmio (Cd) é um elemento não essencial que está entre os poluentes ambientais mais tóxicos a humanos, animais e plantas, mesmo em baixas concentrações. Considerando a relevância da problemática da toxicidade por $\mathrm{Cd}$, a caracterização da resposta de um sistema modelo largamente usado como o Micro-Tom, é essencial para o maior conhecimento dos processos fisiológicos, bioquímicos e genéticos envolvendo a toxicidade e a resistência ao $\mathrm{Cd}$. Outro fator a ser considerado é a importância econômica do tomate para a agricultura mundial, aliando as perdas de produtividade à falta de conhecimento sobre os mecanismos de toxicidade. A proposta do projeto foi o estudo do comportamento de plantas de Micro-Tom expostas ao Cd, através do processo de estresse oxidativo decorrente da exposição ao metal. Por meio de todos os parâmetros analisados ao longo do projeto, foi possível caracterizar o modelo Micro-Tom quanto à toxicidade por Cd. Após toda esta parte exploratória de caracterização dos níveis de atividade antioxidativa, foi possível a inclusão de mutantes hormonais (auxina, etileno) já introduzidos nesse cultivar, tornando o estudo mais investigativo com novas perspectivas da relação hormonal com os mecanismos de toxicidade e resistência a fatores de estresse em geral.
\end{abstract}

Palavras-chave: Tomate; Estresse oxidativo; Enzimas antioxidantes; Mutantes hormonais 


\title{
RESPONSE OF TOMATO PLANTS (Lycopersicon esculentum CV MICRO-TOM) TO CADMIUM
}

\begin{abstract}
It is known that among the main environmental contaminants are included the heavy metals, a result of the intense industrialized activity. Cadmium (Cd) is a non essential element that is among the most dangerous heavy metals, leading to considerable losses in plant productivity and hazardous health effects, even in low concentrations. Considering the high Cd toxicity, the characterization of the responses by a model system like Micro-Tom may be essential to understanding about physiological, biochemistry and genetic processes involved with the toxicity and resistance to $\mathrm{Cd}$. Another major aspect to be considered is the economical importance of tomato in world agriculture and the possible losses of productivity caused by Cd. The main objective of this part of the work was to study Cd-induced oxidative stress in MicroTom plants. Through the parameters analysed, it was possible to characterize the Micro-Tom model related to Cd toxicity. After this initial characterization based mainly on antioxidative activities, it was possible to include in the study hormonal mutants (auxin, ethylene, introduced into the Micro-Tom line), in order to investigate whether these mutants respond differently from the wild-type when Cd-induced oxidative stress is concerned.
\end{abstract}

Keywords: Tomato; Oxidative stress; Antioxidant enzymes; Hormonal mutants 


\section{INTRODUÇÃO}

O tomateiro é considerado um modelo excelente para estudos biológicos, fisiológicos e bioquímicos apresentando alta diversidade em metabólitos secundários e tecidos que facilitam análises fisiológicas e bioquímicas (LIMA et al., 2004). Considerando os estudos nas áreas de genômica e proteômica, o tomateiro apresenta a vantagem de ter um genoma pequeno $\left(7,1 \times 10^{8}\right.$ pares de bases) e mapas cromossômicos estruturados com marcadores clássicos e moleculares (LIMA et al., 2004). Além disso, é uma espécie altamente cultivada e de grande importância agrícola.

A grande diversidade de tecidos facilita a condução de análises bioquímicas, sendo também um padrão morfológico diferente do modelo Arabidopsis (LIMA et al., 2004). Isso propicia que o tomateiro seja um modelo adicional de estudos, diversificando linhas de pesquisa, resultados encontrados e padrões para estudos comparativos (MEISSNER et al., 1997). Além disso, a cultivar miniatura de tomateiro proposta por Meissner et al. (1997) como modelo genético, produz frutos e sementes viáveis em vasos contendo 50 - $100 \mathrm{~mL}$ de substrato, completando seu ciclo de vida entre 70 e 90 dias. Portanto, este cultivar pode crescer em laboratório com a mesma estrutura mínima requerida para Arabidopsis (LIMA et al., 2004).

\subsection{Estresse por metal}

Dentre os metais tóxicos, a escolha do Cd ocorreu em função de alguns aspectos principais: (1) o Cd é um dos principais contaminantes ambientais e um dos mais tóxicos dentre os metais pesados, além de apresentar um comportamento químico diferenciado; (2) o acúmulo de Cd em determinados tecidos da planta pode levar a uma rejeição comercial de certos cultivares, além de se tornar perigoso à saúde humana. Assim, o estudo do impacto do Cd sobre as culturas agrícolas tem elevada importância nas mais diversas áreas de estudo que compreendem a agronomia, medicina e biologia; (3) apesar de todos os efeitos danosos causados, os mecanismos de toxicidade e de resistência ao Cd não estão totalmente elucidados; (4) analisando a literatura pertinente ao estudo proposto, poucos estudos foram encontrados envolvendo a toxicidade e/ou resistência ao Cd em plantas de Micro-Tom. 
Diversos estudos apontam diferentes hipóteses para os mecanismos de toxicidade e resistência ao Cd em plantas: indução de estresse oxidativo via peroxidação de lipídios, interferência na sinalização celular, exclusão de Cd pela complexação com fitoquelatinas (PCs), entre outras (BENAVIDES et al., 2005; GRATÃO et al., 2005; GRATÃO et al., 2006; MOBIN; KHAN, 2007; WAHID; GHANI, 2007).

Alguns estudos mostram que o tomateiro é sensível ao $\mathrm{Cd}$ e ao cobre $(\mathrm{Cu})$, acumulando quantidades significativas dos metais diretamente relacionada à concentração fornecida. A distribuição do metal nas plantas ocorre de forma generalizada, porém o primeiro sistema a acumular os metais é o radicular (MEDIOUNI et al., 2006). A presença dos metais também afeta o crescimento das plantas e ocasiona a peroxidação lipídica, influenciando também o ciclo do nitrogênio e, com isso, todas as biomoléculas dele dependentes (MEDIOUNI et al., 2006).

Em suspensões celulares de tomate, o Cd desencadeou o processo de morte celular programada, permitindo que os autores da pesquisa iniciassem estudos de processos bioquímicos envolvidos com a sinalização celular, o bloqueio dos canais de Ca e os inibidores do ciclo de fosfolipídios e de proteínas (YAKIMOVA et al., 2005).

\subsection{Estresse oxidativo}

Uma das mais importantes funções das células das plantas é a sua habilidade em responder às modificações ambientais. Entender as conexões entre as respostas iniciais das plantas aos variados tipos de estresses que conferem a ela sucesso no ajuste às condições de crescimento alteradas, é uma das grandes metas da biologia de plantas.

Os radicais livres e outras espécies ativas de oxigênio (EAOs), como o peróxido de hidrogênio, são produzidos de forma contínua em qualquer sistema vivo. Consequentemente, os organismos desenvolveram diversos sistemas antioxidantes de defesa, visando a proteção contra os possíveis danos causados pelas EAOs (GRATÃO et al., 2005). Entretanto, plantas expostas ao estresses bióticos e abióticos podem gerar um aumento na produção das EAOs maior do que sua capacidade antioxidante celular, caracterizando o processo de estresse oxidativo. Este estresse pode ativar a morte celular programada ou aumentar a resposta sistêmica de resistência à patógenos (GRATÃO et al., 2006). Por outro lado, as EAOs podem também agir como sinalizadoras em vários processos adaptativos e sinais regulatórios intrínsicos de crescimento e desenvolvimento (PITZSCHKE et al., 2006). 
Vários mecanismos são utilizados pelas plantas para desintoxicar as células das EAOs produzidas e consequentemente interromper as cascatas de oxidação descontrolada (GRATÃO et al., 2005, PITZSCHKE et al., 2006). A identificação dos pontos de produção das EAOs, intensidade de sinal, estágio de desenvolvimento da planta e interações com outras moléculas sinalizadoras estão envolvidas com respostas biológicas específicas (GECHEV et al., 2006).

Sabe-se, porém, que a peroxidação dos lipídios das biomembranas é um dos principais indicadores da ocorrência do processo de estresse oxidativo. O malondialdeído (MDA) é um dos vários produtos de baixo peso molecular formados via a decomposição de produtos da peroxidação lipídica, sendo frequentemente utilizado como indicador de estresse oxidativo (VITORELLO et al., 2005; DEWIR et al. 2006).

\subsection{Justificativa}

Considerando a relevância da problemática da toxicidade por Cd, a caracterização da resposta de um sistema largamente usado como o Micro-Tom a este metal é essencial para o melhor conhecimento dos processos fisiológicos, bioquímicos e genéticos envolvendo a toxicidade e a resistência ao Cd. Outro fator relevante a ser considerado é a importância econômica do tomate para a agricultura mundial, aliado às perdas na produtividade e a falta de conhecimento sobre os mecanismos de toxicidade causados pelo Cd. Assim, estas observações tornam este projeto significativo dentro das áreas de estudo que envolve os temas citados.

Conhecer a dinâmica do modelo de estudos Micro-Tom também é importante por se tratar de um modelo genético de pequisa. Já existem trabalhos na literatura apontando a identificação de alguns genes responsáveis por processos específicos (SCARPECI et al., 2006), porém, pouco se sabe sobre o papel do Cd sobre tais genes.

O estudo também é relevante para propostas futuras, pois o modelo é de fácil cultivo o que permite que as informações sejam utilizadas na compreensão da resposta antioxidante a metais. Além disso, permite a elaboração de estratégias para obtenção de plantas que apresentem resistência aos efeitos causados pelo metal, relacionada à aplicação de biotecnologias como a bioacumulação e a fitorremediação.

Para isso, torna-se necessário um maior entendimento das bases fisiológicas, genéticas e bioquímicas dos mecanismos de resistência das plantas. 
Isso mostra a importância de se caracterizar um modelo genético como o tomateiro para que mais genes possam ser identificados em estudos envolvendo fatores de estresse.

\subsection{Consideração geral do projeto}

A idéia principal deste trabalho surgiu dos estudos desenvolvidos no mestrado (com fumo) e com base na possibilidade de se utilizar uma planta modelo, tomate, e na disponibilidade de mutantes hormonais, visto que praticamente nada existe na literatura relacionado estresse oxidativo por metais e metabolismo hormonal. O estudo foi então idealizado sobre mutantes hormonais de tomate na resposta antioxidativa destes materiais submetidos ao crescimento na presença de Cd. Inicialmente, foi realizado um estudo com cultivar de Micro-Tom sob diferentes concentrações do metal o que serviu como base para que experimentos posteriores fossem estabelecidos. Através deste experimento piloto foram observados efeitos danosos decorrentes de altas concentrações do metal aplicados no estágio inicial de desenvolvimento. A partir destes dados, a estratégia de aplicação do metal nos mutantes hormonais foi modificada, sendo este inserido no experimento em estágios mais tardios.

Assim, os mutantes hormonais dgt (diageotropica, apresenta alteração na via de transdução de sinal da auxina) e $N r$ (Never ripe, apresenta um gene defectivo para o receptor de etileno) foram submetidos à duas concentrações de $\mathrm{Cd}$ - 0,2 e 1,0 mM de $\mathrm{CdCl}_{2}$ de acordo com os resultados observados no experimento piloto. Pelo desenvolvimento do projeto, acredita-se que todos os resultados obtidos neste trabalho fornecem informações importantes a respeito dos efeitos do Cd e a relação entre as respostas antioxidativas e os hormônios auxina e etileno. 


\section{Referências}

BENAVIDES, M.P., GALLEGO, S.M., TOMARO, M.L. Cadmium toxicity in plants. Brazilian Journal of Plant Physiology, Piracicaba, v. 17, p. 21-34, 2005.

DEWIR, Y.H, CHAKRABARTY, D., ALI, M.B., HAHN, E.J., PAEK, K.Y. Lipid peroxidation and antioxidant enzyme activities of Euphorbia milii hyperhydric shoots. Environmental and Experimental Botany, Oxford, v. 58, p. 93-99, 2006.

GECHEV, T.S., VAN BREUSEGEM, F., STONE, J.M., DENEV, I., LALOI, C. Reactive oxygen species as signals that modulate plant stress responses and programmed cell death. Bioessays, Hoboken, v. 28, p. 1091-1101, 2006.

GRATÃO, P.L., POLLE, A., LEA, P.J., AZEVEDO, R.A. Making the life of heavy metalstressed plants a little easier. Functional Plant Biology, Collingwood, v. 32, p. 481-94, 2005.

GRATÃO, P.L., POMPEU, G.B., CARDOSO, P.F., LEA, P.J., AZEVEDO, R.A. Plant antioxidant responses to toxic elements. Current Topics in Biochemical Research, New Delhi, v. 8, p. 40-70, 2006.

LIMA, J.E., CARVALHO, R.F., TULMANN NETO, A., FIGUEIRA, A., PERES, L.E.P.: MicroMsk: a tomato genotype miniature size, short life cycle and improved in vitro shoot regeneration. Plant Science, Ireland, v. 167, p. 753-757, 2004.

MEDIOUNI, C., BENZARTI, O., TRAY, B., GHORBEL, M.H., JEMAL, F. Cadmium and copper toxicity for tomato seedlings. Agronomical and Sustainable Development, Paris, v. 26 , p.227-232, 2006.

MEISSNER, R., JACOBSON, Y., MELAMED, S., LEVYATUV, S., SHALEV, G., ASHRI, A., ELKIND, Y, LEVY, A. A new model system for tomato genetics. - Plant Journal, Oxford, v. 12, p. 1465-1472, 1997.

MOBIN, M., KHAN, N.A. Photosynthetic activity, pigment composition and antioxidative response of two mustard (Brassica juncea) cultivars differing in photosynthetic capacity subjected to cadmium stress. Journal of Plant Physiology, Jena, v. 164, p. 601-610, May. 2007.

PITZSCHKE, A., FORNAZI, C., HIRT H. Reactive oxygen species signalling in plants. Antioxidants \& Redox Signalling, Columbus, v. 8, p. 1757-1764, 2006.

SCARPECI, T.E., MARRO, M.L., BORTOLOTTI, S., BOGGIO, S.B; VALLE, E.M. Plant nutritional status modulates glutamine synthetase levels in ripe tomatoes ( Solanum lycopersicum cv. Micro-Tom). Journal of Plant Physiology, Stuttgart, v. 164, p. 137-145, 2006.

VITORELLO, V., CAPALDI, F.R., STEFANUTO, V.A. Recent advances in aluminum toxicity and resistance in higher plantas. Brazilian Journal of Plant Phisiology, Piracicaba, v. 17, p. 129-143, 2005. 
WAHID, A, GHANI, A. Varietal differences in mung bean (Vigna radiata) for growth, yield, toxicity symptoms and cadmium accumulation. Annals of Applied Biology, Oxford, 2007, in press.

YAKIMOVA, E.T., KAPCHINA-TOTEVA, V.M., LAARHOVEN, L.J., HARREN, F.M., WOLTERING, E.J. Involvement of ethylene and lipid signaling in cadmium-induced programmed cell death in tomato suspension cells. Plant Physiology and Biochemistry, Paris, v. 44, p. 581-589, 2006. 


\section{TORNANDO A VIDA DE PLANTAS ESTRESSADAS POR METAL PESADO UM POUCO MAIS FÁCIL}

\section{Resumo}

A contaminação de solos e águas por metais pesados cria um grande problema que leva as perdas consideráveis na produtividade de plantas e efeitos danosos à saúde. A exposição a metais tóxicos pode intensificar a produção de espécies ativas de oxigênio (EAOs), que são continuamente produzidas tanto em células não estressadas quanto nas estressadas. Algumas EAOs são muito tóxicas e devem ser eliminadas por defesas celulares contra o estresse para que as plantas sobrevivam e cresçam. O objetivo desta revisão é avaliar os modos de ação e o papel dos antioxidantes na proteção de plantas a estresses causados pela presença dos metais pesados no ambiente.

Palavras-chave: Enzimas antioxidantes; metais pesados; Estresse oxidativo; Fitoquelatinas; Fitotoxicidade; Espécies ativas de oxigênio 


\title{
2 MAKING THE LIFE OF HEAVY METAL-STRESSED PLANTS A LITTLE EASIER
}

\begin{abstract}
The contamination of soils and water with metals has created a major environmental problem, leading to considerable losses in plant productivity and hazardous health effects. Exposure to toxic metals can intensify the production of reactive oxygen species (ROS), which are continuously produced in both unstressed and stressed plants cells. Some of the ROS species are highly toxic and must be detoxified by cellular stress responses, if the plant is to survive and grow. The aim of this review is to assess the mode of action and role of antioxidants in protecting plants from stress caused by the presence of heavy metals in the environment.
\end{abstract}

Keywords: Antioxidant enzymes; Heavy metals; Oxidative stress; Phytochelatin; Phytotoxicity, Reactive oxygen species 


\subsection{Introdução}

Ao longo das últimas décadas, houve o reconhecimento de que a poluição ambiental é maior do que previamente havia-se assumido e que muitos contaminantes ambientais permanecem no ambiente por um longo tempo, e se acumulam a quantidades que podem prejudicar os humanos. A contaminação de solos, sedimentos e água com metais tóxicos é um dos maiores problemas do mundo industrializado de hoje. Além disso, há uma grande preocupação sobre a variedade destes compostos químicos que são introduzidos no ambiente. Os metais pesados, incluídos nas principais categorias de poluentes, são encontrados no solo, água e também em gases tóxicos formados na atmosfera por reações fotoquímicas. Alguns metais são fortemente retidos no solo que quando lixiviados podem afetar adversamente a biomassa e a fertilidade deste (SELIM; KINGERY 2003).

\subsection{Metais tóxicos}

Esta revisão concentra-se no estudo detalhado dos metais, particularmente aqueles que são danosos a maioria das espécies de plantas. O termo metal é usado com referência a metais e semi-metais que estão associados com a poluição e a toxicidade, mas também inclui alguns elementos que são nutrientes essenciais para as células em baixas concentrações.

O selênio (Se) é geralmente tóxico a plantas e outros organismos, sendo estes efeitos relacionados à sua similaridade química com o enxofre (S). Se torna tóxico a altas concentrações devido à incorporação em moléculas que contêm $S$, particularmente durante a troca específica de cisteína por Se-cisteína (MINORSKY, 2003). O alumínio (Al) é considerado um dos elemntos mais abundantes na crosta terrestre e o maior fator limitante de crescimento em solos ácidos (VITORELLO et al., 2005). O alvo do Al está provavelmente relacionado à membrana plasmática (ZHANG te al., 1996), causando também inibição na elongação de raízes e na redução da respiração e síntese de ATP (YAMAMOTO et al., 2003). Por outro lado, o requerimento de níquel (Ni) pelas plantas parece estar relacionado ao seu papel na formação do centro ativo da urease (EC 3.5.1.5), porém em altas concentrações, o Ni pode induzir indiretamente o estresse oxidativo (PANDOLFINI et al., 1996). Outros micronutrientes, como o cobre (Cu) e o manganês (Mn) também causam estresse oxidativo quando presentes em excesso (DUCIC; POLLE, 2005). Além disso, ambos são capazes de prejudicar a função fotossintética (KÜPPER ET AL., 2000; 
ST CLAIR; LYNCH, 2004). O cromo (Cr) é também um metal tóxico que pode resultar em danos severos a plantas e animais. A fitotoxicidade do Cr pode causar inibição da germinação de sementes, degradação de clorofila, alteração no cloroplasto e alterações ultraestruturais na membrana pela indução de estresse oxidativo (PANDA et al., 2003; PANDA; CHOUDHURY, 2005). O cádmio (Cd) é um elemento não essencial, considerado um dos metais pesados mais tóxicos, que causa vários efeitos danosos no metabolismo geral da planta (BENAVIDES et al AL., 2005; GRATÃO et al., 2005) e induz estresse oxidativo (SCHÜTZENDUBEL et AL., 2001; VITÓRIA et al., 2001). Vários outros metais são investigados com relação ao estresse oxidativo, a sistemas de transporte e ao influxo nas plantas e seus efeitos no metabolismo geral (BHATIA et al., 2004; QUAGHEBEUR; RENGEL, 2004; REID; 2004; MONET et al., 2005; LIU et al., 2007).

\subsection{Estresse oxidativo}

O estresse oxidativo é um fator central do fenômeno de estresses abióticos e bióticos que ocorre quando há um sério desbalanço entre a produção de espécies ativas de oxigênio (EAOs) e as defesas antioxidativas, em qualquer compartimento celular, que leva a sérias mudanças fisiológicas (FOYER; NOCTOR, 2000). As EAOs podem ser consideradas como as principais moléculas danosas, que devem ser mantidas sob baixas concentrações, embora este conceito tenha mudado em função das várias funções do oxigênio ativo. Assim, é importante que as células controlem a concentração das EAOs, mas não as eliminem completamente (SCHÜTZENDÜBEL; POLLE, 2002).

A redução do $\mathrm{O}_{2}$ a $\mathrm{H}_{2} \mathrm{O}_{2}$ envolve a transferência de um, dois ou três elétrons para o $\mathrm{O}_{2}$ na formação do superóxido $\left(\mathrm{O}_{2}{ }^{\bullet-}\right)$, peróxido de hidrogênio $\left(\mathrm{H}_{2} \mathrm{O}_{2}\right)$, e do radical hidroxila $\left({ }^{\bullet} \mathrm{OH}\right)$, repectivamente. As EAOs $\mathrm{O}_{2}{ }^{--}$e $\mathrm{H}_{2} \mathrm{O}_{2}$ apresentam baixa reatividade em comparação com outras EAOs. O excesso de energia proveniente do $\mathrm{O}_{2}$ pode conduzir a formação de oxigênio singlet $\left({ }^{1} \mathrm{O}_{2}\right)$, uma molécula altamente reativa comparada com o $\mathrm{O}_{2} \cdot \mathrm{O}_{2} \mathrm{H}_{2}$ funciona como uma molécula sinalizadora em plantas e também pode estar envolvida na regulação da expressão gênica por estresses abióticos (NEILL; GOULD, 2003). $\mathrm{O} \mathrm{H}_{2} \mathrm{O}_{2}$ pode induzir o fechamento estomático ou ser requerido para a inibição do ácido abscísico (ABA) na abertura estomática (DESIKAN et al., 2004). $\mathrm{O} \mathrm{H}_{2} \mathrm{O}_{2}$ é também um produto da ß-oxidação associada ao glioxissomo 
de ácidos graxos e nas reações de fotorespiração (SCANDALIOS, 1993; IGAMBERDIEV; LEA, 2002).

As EAOs são vistas como indicadores celulares de estresse e mensageiros secundários envolvidos em vários aspectos da expressão gênica e na tradução da química enzimática (FOYER; NOCTOR, 2003). Enquanto a maioria da atenção está centralizada nos cloroplastos, a produção de EAOs na mitocôndria é igualmente importante (BARTOLI et al., 2004). Com relação aos metais tóxicos, as oxidases localizadas na membrana plasmática parecem ter papel principal na mediação da produção de $\mathrm{O}_{2}{ }^{--}$e $\mathrm{H}_{2} \mathrm{O}_{2}$ (POLLE; SCHÜTZENDÜBEL, 2003). As várias fontes de EAOs e o complexo sistema antioxidante de defesa provêm a flexibilidade necessária para estas funções.

Os metais pesados induzem o estresse oxidativo, mas as respostas dos antioxidantes apresentam resultados variáveis e controversos (SCHÜTZENDÜBEL et al., 2001). A variação na resposta deve-se a fatores como: (1) os metais pesados exercem diferentes mecanismos de indução ao estresse, (2) os antioxidantes são compartimentalizados e ocorrem diferenças entre as respostas entre as organelas, células e tecidos, (3) a desintoxicação e complexação de metais pesados reduz seus efeitos estimulatórios sobre o estresse oxidativo.

\subsection{Sistemas antioxidantes de defesa: valiosos marcadores de estresse em estudos ecofisiológicos}

A primeira linha de defesa contra o estresse oxidativo é evitar a produção de EAOs. Assim, nas mitocôndrias a cadeia de transporte de elétrons é adequadamente oxidada para manter o balanço entre a disponibilidade do substrato, o requerimento de ATP e a ativação de oxidases alternativas (MOLLER, 2001; NOCTOR et al., 2004). Uma vez formado, as EAOs devem ser desintoxicadas eficientemente a fim de minizar os evetuais efeitos danosos. Assim, os mecanismos de desintoxicação constituem a segunda linha de defesa contra os efeitos detrimentais das EAOs (MOLLER et al., 2001). O termo antioxidante descreve qualquer composto capaz de extinguir as EAOs sem que elas se convertam em radicais destrutivos. As enzimas antioxidantes são consideradas catalizadoras de reações ou estão envolvidas no processamento direto das EAOs (MEDICI et al., 2004). Os antioxidantes não enzimáticos e os enzimáticos funcionam na interrupção de cascatas descontroladas de oxidação (NOCTOR; FOYER, 1998). Finalmente, a terceira linha de defesa contra as EAOs está relacionada ao reparo 
de danos oxidativos em proteínas (BECHTOLD et al., 2004), que está fora do escopo desta revisão.

As estratégias contra os metais tóxicos são diversas e incluem: (1) exsudação de agentes complexores na rizosfera, (2) ligação do metal na parede celular, (3) prevenção do transporte do metal para partes aéreas, (4) complexação do metal com vários ligantes, (5) transporte do complexo metal-ligante para vacúolos, (6) estocagem de íons metálicos no vacúolo pela complexação com ligantes vacuolares e (7) ação de enzimas resistentes ao metal para minimizar a injúria interna causada pela toxicidade (HALL, 2002; MCGRATH; ZHAO, 2003).

Devido a diferentes processos metabólicos descritos anteriormente que podem produzir EAOs, vários mecanismos de defesa, ambos enzimáticos e não enzimáticos têm emergido. Estes sistemas de defesa removem, neutralisam ou limpam os radicais e seus intermediários (FOYER; NOCTOR, 2003). Os estudos sugerem que o apoplasto, cloroplasto, citoplasma, mitocôndria e peroxissomos contêm mecanismos de defesa às EAOs (DEL RIO et al., 2002; PIGNOCCHI; FOYER, 2003; FOYER; NOCTOR, 2003; NOCTOR et al., 2004). Embora algumas informações estejam disponíveis em relação ao papel antioxidante de várias peroxiredoxinas (DIETZ, 2003), pouco se conhece sobre os mecanismos de defesa às EAOs no núcleo, que pode conter fatores de transcrição redox-sensíveis (DELAUNAY et al., 2000). Os mecanismos de defesa às EAOs (Figura 2.1) envolvem os seguintes ciclos:

- Ciclo água-água nos cloroplastos que inclui a enzima superóxido dismutase (SOD);

- Ciclo ascorbato glutationa nos cloroplastos, citosol, mitocôndria, apoplasto e peroxissomos;

- Glutationa peroxidase (GPX) e catalase (CAT) nos peroxissomos. 

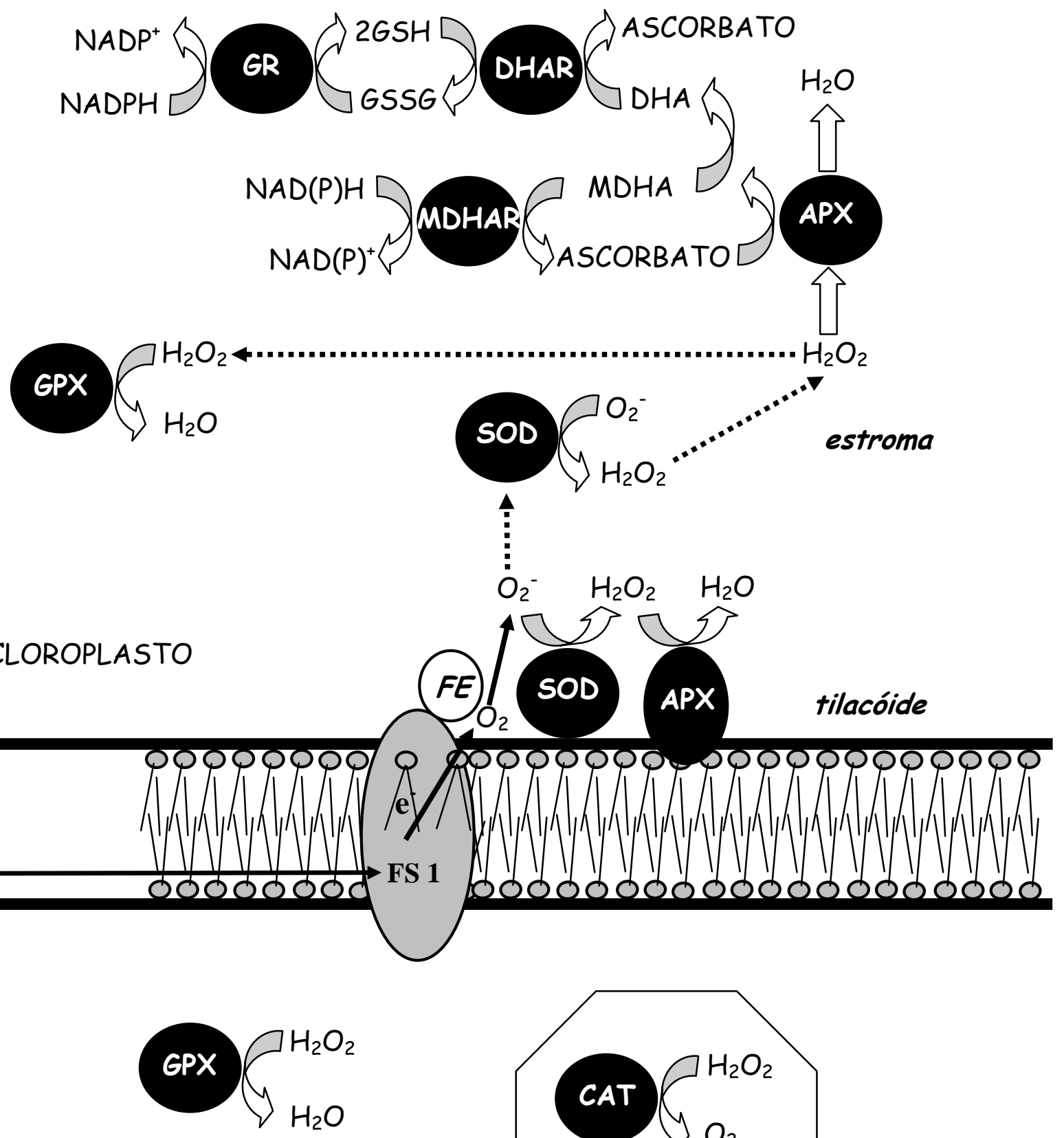

CITOSOL

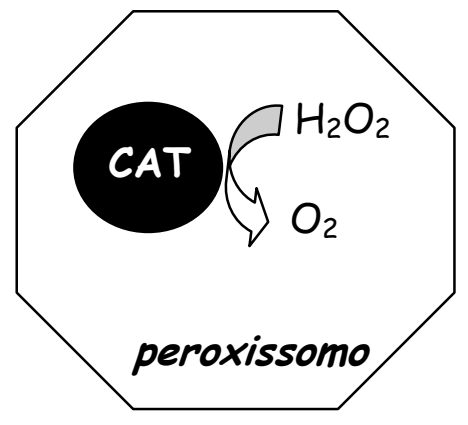

Figura 2.1 - Caminhos de defesa contra as EAOs. FE, fator do estroma; FSI, fotosistema I; GR, glutationa redutase; APX ascorbato peroxidase, GPX, glutationa peroxidase; SOD, superóxido dismutase; CAT, catalase; MDHAR, monodehidroascorbato redutase; DHAR, dehidroascorbato redutase (modificado de Asada, 1999) 
A fotoredução do $\mathrm{O}_{2}$ à água no fotosistema I (FSI) por elétrons gerados no fotosistema II (FSII) é referido como ciclo água-água nos cloroplastos. A mais importante função deste ciclo é agir contra o $\mathrm{O}_{2}{ }^{\bullet-}$ e $\mathrm{H}_{2} \mathrm{O}_{2}$ nos pontos onde são gerados, evitando a produção de ${ }^{\bullet} \mathrm{OH}$ e sua interação com moléculas nos cloroplastos (ASADA, 2000).

O ciclo ascorbato-glutationa nos cloroplastos, também referido como 'Asada-FoyerHalliwell' envolve oxidações e reduções sucessivas do ascorbato, glutationa e NADPH pelas enzimas ascorbato peroxidase (APX, EC 1.11.1.11), glutationa redutase (GR, EC 1.6.4.2), dehidroascorbato redutase (DHAR, EC 1.8.5.1) e monodehidroascorbato redutase (MDHAR, EC 1.6.5.4). Durante os estresses bióticos e abióticos, a mitocôndria pode ser danificada pelo estresse oxidativo em função de sua suscetibilidade à inibição oxidativa da sua função (MOLLER, 2001; MILLAR et al., 2003; TAYLOR et al., 2003; BARTOLI et al., 2004). A remoção do $\mathrm{H}_{2} \mathrm{O}_{2}$ produzido no cloroplasto, como resultado da dismutação do $\mathrm{O}_{2}{ }^{{ }^{-}}$, é essencial para evitar a inibição das enzimas do ciclo de Calvin (WILLEKENS ET AL., 1997). O estresse oxidativo pode causar proliferação de peroxissomos, que possuem um eficiente sistema de defesa contra as EAOs, especialmente $\mathrm{H}_{2} \mathrm{O}_{2}$ (IGAMBERDIEV; LEA, 2002). Como os cloroplastos e mitocôndrias, os peroxissomos também produzem $\mathrm{O}_{2}{ }^{\bullet-}$ e apresentam dois pontos de geração de $\mathrm{O}_{2}{ }^{--}$, um na matriz da organela e outro no local da membrana dependente de NAD(P)H (DEL RIO et al., 2002).

O sistema de peroxiredoxinas (Prx) foi recentemente descoberto (BAIER; DIETZ, 1999), mas já recebe considerável atenção como antioxidantes, tanto na redução de uma série de peróxidos tóxicos, quanto na sinalização de redox, relacionados ao ajuste do redox celular e do metabolismo antioxidante (FINKEMEIER et al., 2005). As peroxiredoxinas também apresentam papel essencial no combate aos efeitos negativos dos metais pesados na regulação do redox (FINKEMEIER et al., 2005). Neste sentido, a At-PrxII F Prx, um dos seis tipos de genes de Prx identificados no genoma de Arabidopsis thaliana e uma Prx mitocondrial, estão relacionadas à defesa antioxidante e possivelmente à sinalização de redox nas células de plantas (FINKEMEIER et al., 2005).

As plantas possuem eficientes sistemas antioxidantes enzimáticos e não enzimáticos que protegem as células contra o estresse oxidativo. Se estas defesas falham, EAOs podem causar danos significativos na célula. Em estudos com Arabidopsis thaliana tratadas com nitrato de prata, estas mostraram sintomas severos induzidos pelas EAOs que foram reduzidas consideravelmente pela aplicação de ascorbato (NAVABPOUR et al., 2003). A prata parece ter 
induzido a expressão de genes relacionados com a senescência incluindo os genes de metalotioneínas codificads por LSC54. Entretanto, apenas metade dos genes relacionados à senescência que foram testados mostrou expressão induzida. A observação de que muitos genes relacionados à senescência foram induzidos em tecidos tratados com nitrato de prata, em conjunto com a expressão reduzida do gene RBCS, pode indicar que há uma fase de senescência antes da ocorrência da morte celular. Entretanto, é difícil determinar através dos trabalhos de Navabpour et al. (2003) se a produção de EAOs induzida pelo nitrato de prata está relacionada a senescência, que requer mobilização de carbono e nitrogênio, sendo reversível (THOMPSON et al., 2004), ou à morte celular programada, que faz parte dos modos de desenvolvimento de muitas espécies (VAN DOORN; WOLTERING, 2005).

\subsubsection{Resposta antioxidante não enzimática}

As moléculas envolvidas nesta resposta incluem o ascorbato, glutationa (GSH), flavonóides, alcalóides, compostos fenólicos, amino ácidos não proteicos, tocoferóis e carotenóides. A oxidação de GSH por EAOs oxida a glutationa (GSSG), e o ascorbato é oxidado à MDHA e dehidroascorbato (DHA). Em resposta ao estresse, as plantas aumentam a atividade das enzimas de biossíntese de GSH (NOCTOR et al., 2002). Assim, GSSG, MDHA e DHA podem ser reduzidas reciclando GSH e ascorbato através do ciclo ascorbato-glutationa. As desintoxicação de EAOs em plantas por flavonóides e carotenóides ainda demanda de muita investigação quando comparados a GSH e ascorbato.

\subsubsection{Glutationa}

Alguns metais podem causar depleção de GSH e alterações nas atividades de enzimas antioxidantes. GSH, um dos maiores tampões redox na maioria das células aeróbicas, tem importante papel nas funções fisiológicas, incluindo regulação de reações redox, conjugação de metabólitos, desintoxicação de xenobióticos, homeostase e sinalização de respostas adaptativas (NOCTOR et al., 2002).

O papel da GSH no sistema antioxidante de defesa indica seu uso como um marcador de estresse, embora respostas baseadas nas concentrações de GSH e estado redox não tenham consistência nos dados disponíveis na literatura (TAUSZ et al., 2004). Recentemente, fortes 
evidências indicam que as concentrações elevadas de GSH estão correlacionadas com a habilidade das plantas de resistirem ao estresse oxidativo imposto por metais (FREEMAN et al., 2004). O aumento da demanda de GSH pode ser encontrado pela ativação de caminhos envolvidos com a assimilação do enxofre na biossíntese de cisteína. Análises de microarranjos indicam que os níveis de transcritos de cisteína sintase aumentaram em resposta ao estresse causado por Zn em A. thaliana (BECHER et al., 2004) e também foi elevado no seu parente resistente ao metal, $A$. halleri (WEBER et al., 2004).

As plantas contêm peptídeos que se ligam aos metais pesados denominados de fitoquelatinas (PCs), que consistem de três aminoácidos; cisteína, glicina e glutamato, arranjados geralmente na conformação ( $\gamma$-GluCys)n-Gly onde $n$ é o número de repetições da unidade $\gamma$-GluCys, que normalmente varia de 2 a 11. A estrutura química das PCs sugere que elas são formadas como resultado direto da expressão do gene de tolerância ao metal, mas particularmente como um produto do caminho biossintético, sendo a GSH, o provável precursor (COBBETT, 2000; INOUHE, 2005). A fitoquelatina sintase, que catalisa a conversão de GSH à PCs, é caracterizada como uma $\gamma$-glutamilcisteína dipeptidil transpeptidase (EC 2.3.2.15) (VATAMANIUK et al., 2004). A exposição ao Cd estimula a síntese de PC (SRIVASTAVA et al., 2004) que forma rapidamnte um complexo de 'baixo peso molecular' (LMW) com o Cd (Figura 2.2) (VÖGELILANGE; WAGNER, 1990). Este complexo adquire enxofre instável $\left(\mathrm{S}^{2-}\right)$ no tonoplasto e forma um novo complexo de 'alto peso molecular'(HMW), que tem grande afinidade por íons de Cd (HU et al., 2001). Os íons de Cd livres entram no vacúolo por sistemas antiporte $\left(\mathrm{Cd}^{2+} / 2 \mathrm{H}^{+}\right)$ (GRIES; WAGNER, 1998). No vacúolo, o complexo HMW se dissocia e o Cd liberado pode ser complexado por ácidos orgânicos vacuolares (MEMON et al., 2001). A formação de complexos com fosfatos ou enxofre também são relatados (KÜPPER et al., 2000; OTT et al., 2002). 

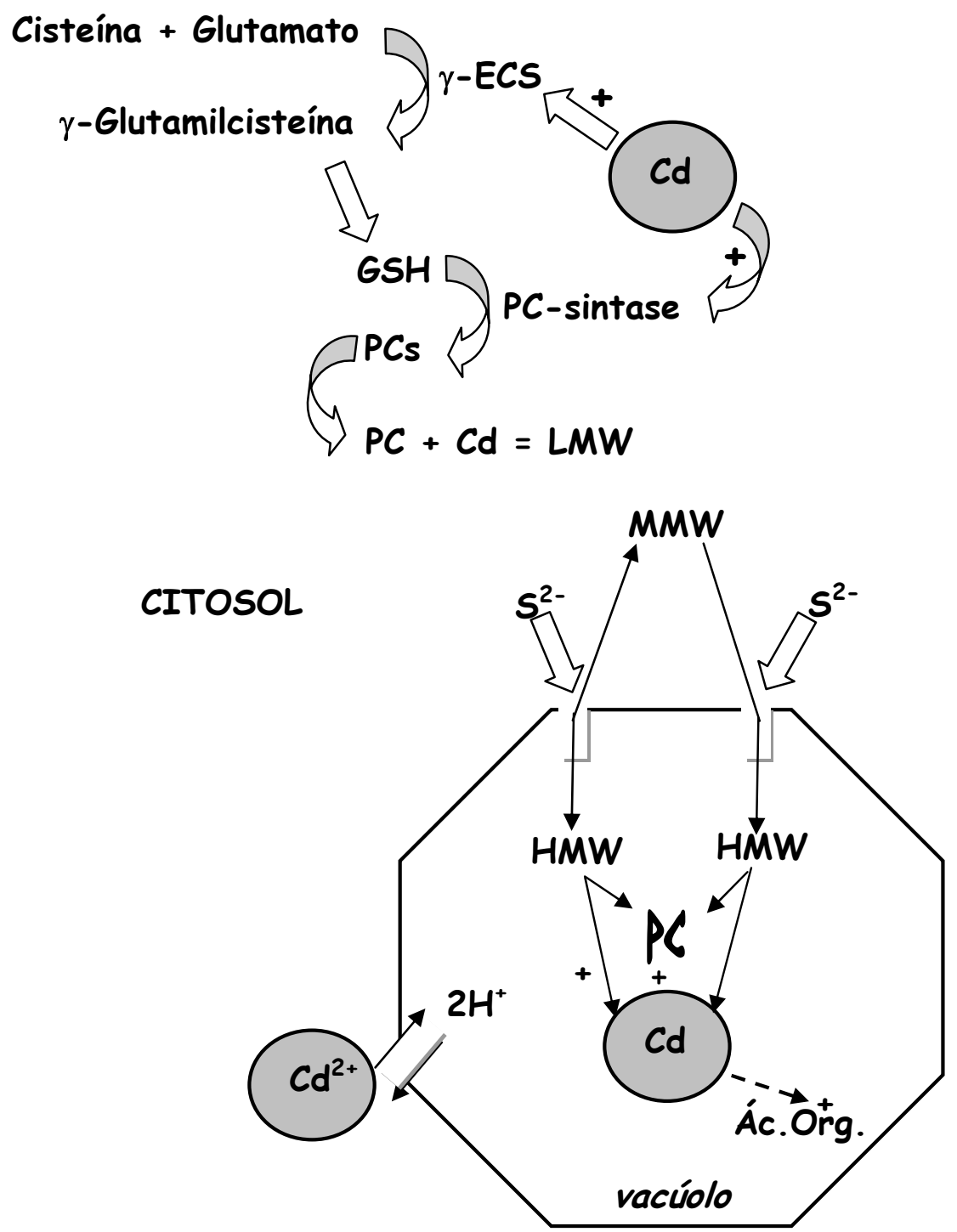

Figura 2.2 - Mecanismos envolvidos na desintoxicação e compartimentalização do Cd. LMW, complexo de baixo peso molecular; HMW, complexo de alto peso molecular; MMW, complexo de médio peso molecular; GSH, glutationa; Ac. Org., ácidos orgânicos e PC, fitoquelatina [modificado de Sanitá di Toppi and Gabrielli (1999)]

\subsubsection{Ascorbato}

$\mathrm{O}$ ascorbato é um antioxidante chave na reação com radicais ${ }^{\circ} \mathrm{OH}, \mathrm{O}_{2}{ }^{\bullet-}$ e ${ }^{1} \mathrm{O}_{2}(\mathrm{CHEN}$; GALLIE, 2004). O ascorbato é um metabólito essencial envolvido nas funções celulares vitais, considerado como o maior e provavelmente o único tampão antioxidante no apoplasto. A maior rota da biossíntese de ascorbato nas células é via intermediários de GDP-manose e L-galactose 
(SMIRNOFF et al., 2001). A ascorbato oxidase (AO, EC 1.10.3.3) regula o estado redox do pool de ascorbato apoplástico e, tanto a explosão oxidativa quanto a AO modificam o estado redox do apoplasto (PIGNOCCHI; FOYER, 2003). O sistema redox do ascorbato consiste de L-ascorbato, MDHA e DHA. As concentrações de ascorbato vacuolares são relativamente baixas (RAUTENKRANZ et al., 1994), entretanto foram sugeridas altas valores para os compartimentos do cloroplasto e do citosol (RAUTENKRANZ et al., 2003). Além disso, o $\mathrm{H}_{2} \mathrm{O}_{2}$ e o estado redox do ascorbato estão provavelmente relacionados a sinalização do estresse fotoxidativo (HERNÁNDEZ et al., 2004).

\subsubsection{Outros antioxidantes não enzimáticos}

Cisteína, hidroquinonas, manitol, vitamina E, alguns alcalóides, compostos fenólicos e ßcarotenos são também importantes antioxidantes. Os carotenóides, que são componentes essenciais de membranas de tilacóides, podem efetivamente extinguir o estado excitado da clorofila e/ou ${ }^{1} \mathrm{O}_{2}$ (SCANDALIOS, 1993). Os compostos fenólicos, metabólitos secundários com capacidade antioxidativa protegem contra o estresse provocado por Al (YAMAMOTO et al., 1998). Outro potente mecanismo de proteção está relacionado com o aminoácido não proteico nicotianamina, provavelmente através do seu potencial efeito quelante à metais (WEBER et al., 2004). As antocianinas são consideradas importantes antioxidantes na atenuação da injúria fotoxidativa em folhas (NEIL; GOULD, 2003). Krupa et al. (1996) demonstraram que o efeito do $\mathrm{Cd}, \mathrm{Ni}, \mathrm{Pb}$ e Zn no conteúdo de antocianinas não está diretamente relacionado com a toxicidade individual, desde que pequenas concentrações de antocianina foram acumuladas após o tratamento de plântulas de centeio com diversos metais tóxicos (KRUPA et al., 1996).

\subsubsection{Resposta antioxidativa enzimática}

Os maiores mecanismos de defesa contra EAOs nas plantas incluem enzimas como superóxido dismutase (SOD, ec 1.15.1.1), catalase (CAT, EC 1.11.1.6), glutationa peroxidase (GPX, EC 1.11.1.9), APX e GR. Os níveis de estresse oxidativo são determinados pelas quantidades de $\mathrm{O}_{2}{ }^{\bullet-}, \mathrm{H}_{2} \mathrm{O}_{2}$ e radicais ${ }^{\bullet} \mathrm{OH}$ (FOYER; NOCTOR, 2003). $\mathrm{O}_{2} \mathrm{H}_{2}$ pode ser diretamente metabolizado por peroxidases, particularmente aquelas presentes no apoplasto 
(ZOLLER et al., 2003), e por CAT nos peroxissomos (DEL RIO et al., 2002; IGAMBERDIEV; LEA, 2002).

As superóxidos dismutases agem como a primeira linha de defesa contra as EAOs, dismutando $\mathrm{O}_{2}{ }^{\bullet-}$ à $\mathrm{H}_{2} \mathrm{O}_{2}$. APX, GPX e CAT subsequentemente desintoxicam o $\mathrm{H}_{2} \mathrm{O}_{2}$. A desintoxicação do $\mathrm{H}_{2} \mathrm{O}_{2}$ à $\mathrm{H}_{2} \mathrm{O}$ pela $\mathrm{APX}$ ocorre através da oxidação do ascorbato à MDHA, que pode ser regenerado pela MDHAR usando $\mathrm{NAD}(\mathrm{P}) \mathrm{H}$ como equivalente redutor. O MDHA pode ser espontaneamente dismutado em dehidroascorbato. A regeneração do ascorbato é mediada pela DHA seguida pela oxidação de GSH a GSSG. APX e CAT pertencem a duas classes diferentes de enzimas em função das suas afinidades ao $\mathrm{H}_{2} \mathrm{O}_{2}$. A APX é de ordem micromolar e a CAT, milimolar. Assim, enquanto a APX pode ser responsável por uma fina modulação da resposta às EAOs, a CAT é provavelmente responsável pela remoção do excesso de EAOs durante o estresse (MITTLER, 2002).

O equilíbrio das atividades da SOD, APX e CAT é essencial para determinar o nível fixo de $\mathrm{O}_{2}{ }^{\bullet-}$ e $\mathrm{H}_{2} \mathrm{O}_{2}$ (BOWLER et al., 1991). Mecanismos compensatórios são induzidos se o balanço das enzimas de defesa é modificado. Quando a atividade da CAT é reduzida em plantas, outras enzimas como APX, GPX mitocondriais são super reguladas (WILLEKENS et al., 1997; YOSHIMURA et al., 2002; VANDENABEELE et al., 2004).

\subsubsection{Superóxido dismutase}

A superóxido dismutase é responsável pela dismutação do $\mathrm{O}_{2}{ }^{\bullet-}$ em $\mathrm{H}_{2} \mathrm{O}_{2}$ e $\mathrm{O}_{2}$, sendo considerada a primeira linha de defesa contra EAOs que influencia as concentrações de $\mathrm{O}_{2}{ }^{\bullet-}$ e $\mathrm{H}_{2} \mathrm{O}_{2}$, os dois substratos da reação de Haber-Weiss. Três tipos distintos de isoenzimas de SOD foram detectados em plantas, classificadas de acordo com seu cofator metálico; $\mathrm{Mn}$, Fe e $\mathrm{Cu} / \mathrm{Zn}$ (ALSCHER et al., 2002). As Mn-SODs estão localizadas nas mitocôndrias e peroxissomos (DEL RIO et al., 2003), mas também foram relatadas nos cloroplastos de algumas plantas (HAYAKAWA et al., 1984). As Fe-SODs não são encontradas em todas as plantas (FERREIRA et al., 2002) mas estão associadas com os cloroplastos (ALSCHER et al., 2002), enquanto as Cu/Zn-SODs estão localizadas no citosol, cloroplastos e peroxissomos (DEL RIO et al., 2002).

As respostas da SOD ao estresse por metal pesado varia consideravelmente dependendo da espécie, tecido, estágio de desenvolvimento, metal utilizado e tempo de exposição. Aumentos na atividade total da SOD foram detectadas seguindo a aplicação de Cd em várias espécies de 
plantas (SCHICKLER; CASPI, 1999; SEN RAYCHAUDHURI; DENG, 2000; SCHÜTZENDÜBEL et al., 2001; VITÓRIA et al, 2001), permanecendo constante em outras espécies (FERREIRA ET AL., 2002; FORNAZIER et al., 2002a; FORNAZIER et al., 2002b), e declinando nas demais (LÉON et al., 2002; SCHÜTZENDÜBEL; POLLE, 2002). O aumento na produção de EAOs devido ao estresse por $\mathrm{Al}$ estimulou mudanças nas atividades das enzimas antioxidantes como a SOD, que parece ser dose-dependente (GUO et al., 2004). Diferentes formas da SOD foram exibidas em plantas submetidas ao $\mathrm{Ni}$, dependendo da espécie e tecido (SCHICKLER; CASPI, 1999; BACCOUCH et al., 2001), enquanto o Se induziu a atividade da SOD (SREEKALA et al., 1999; XUE et al., 2001).

\subsubsection{Catalase}

A catalase metaboliza o $\mathrm{H}_{2} \mathrm{O}_{2}$ liberado nos peroxissomos em $\mathrm{H}_{2} \mathrm{O}$ e $\mathrm{O}_{2}$ (IGAMBERDIEV; LEA, 2002). A CAT pode também decompor o $\mathrm{H}_{2} \mathrm{O}_{2}$ formado durante a ß-oxidação de ácidos graxos nos glioxissomos de tecidos que estocam lipídeos. Isoenzimas de CAT foram estudadas extensivamente em plantas superiores (POLIDOROS; SCANDALIOS, 1999) sendo três delas geneticamente distintas, caracterizadas em plantas de milho (SCANDALIOS et al., 2000), duas em cevada (SKADSEN et al., 1995) e em pêssego (BAGNOLI et al., 2004). Em Arabidopsis thaliana, a família multigência de cat consiste de três genes que são altamente expressos em inflorescências, mas apenas cat2 e cat3 sendo expressas em folhas (FRUGOLI et al., 1996). Além disso, seis diferentes isoenzimas foram descritas em A. thaliana (MICHAEL; MCCLUNG, 2002). Linhagens transgências de $A$. thaliana com baixos níveis de atividade de CAT2 foram construídos e mostraram ter mudanças na expressão gênica induzida por alta luminosidade (VANDENABEELE et al., 2004). Outra classe de CAT está localizada nos tecidos vasculares e pode estar envolvida na proteção contra estresse ambiental (WILLEKENS et al., 1994). As isoenzimas de CAT são reguladas temporariamante e espacialmente e respondem diferentemente a luz (SKADSEN et al., 1995) e ao $\mathrm{CO}_{2}$ (AZEVEDO et al., 1998). A presença de CAT em mitocôndrias de plantas ainda não foi relatada, contrariamente ao observado na matriz mitocondrial do coração de rato (MOLLER, 2001).

De forma similar a SOD, a atividade de CAT varia consideravelmente em resposta ao estresse por metal pesado. A atividade de CAT declinou na presença de Cd em Phaseolus vulgaris (SOMASHEKARAIH et al., 1992), Lemna minor (MOHAN; HOSETTI, 1997) e 
pimenta (LÉON et al., 2002) e também na presença de altas concentrações de NaCl (FIDALGO et al., 2004). Em contraste, a atividade de CAT aumentou consideravalmente em Agropyron repens (BREJ, 1998), Raphanus sativus (VITÓRIA et al., 2001) e cana-de-açúcar (FORNAZIER ET AL., 2002a), mas permaneceu inalterada em soja (FERREIRA et al., 2002) na presença de Cd. A resposta da atividade de CAT ao Al é também dependente das espécies de plantas e tecidos analisados. Plântulas de soja exibiram decréscimo na atividade de CAT (CAKMAK; HORST, 1991), enquanto o aumento na atividade de CAT foi detectada em folhas de arroz em resposta ao Al, que coincidiu com a indução da peroxidação lipídica (KUO; KAO, 2003). Espécies de plantas expostas ao Ni (BREJ, 1998) e Cu (JOUILI; EL FERJANI, 2003) exibiram aumento na atividade de CAT.

\subsubsection{Glutationa redutase}

A glutationa redutase (GR) é uma flavoproteína que cataliza a redução da forma oxidada GSSG dependente de NADPH para a forma reduzida GSH. A enzima, embora sintetizada no citoplasma, é também encontrada no cloroplasto e na mitocôndria (MULLINEAUX; CREISSEN, 1997). Em plantas superiores, a GR está envolvida na defesa contra estresse oxidativo, enquanto a GSH tem importante papel dentro do sistema celular, que inclue a paticipação no ciclo ascorbato glutationa, manutenção de grupos sulfidrilasde cisteínas na forma reduzida, estocagem de enxofre reduzido e substrato para glutationa-S-transferases (NOCTOR et al., 2002). A maioria dos estudos na determinação das respostas de GR à exposição ao Cd demonstram que a atividade de GR aumenta como parte da defesa contra o estresse causado pelo Cd (FORNAZIER et al., 2002a), como observado em Raphanus sativus (VITÓRIA et al., 2001), Crotalaria juncea (PERREIRA et al., 2002), Phaseolus vulgaris (CHAOUI et al., 1997), pimenta (LÉON et al., 2002) e soja (FERREIRA et al., 2002). O aumento da atividade de GR foi mais alta na concentração de $40 \mu \mathrm{M}$ do que na de $4 \mu \mathrm{M}$ de Cd em Pisum sativum (DIXIT et al., 2001). Entretanto, um decréscimo da atividade de GR após a aplicação de Cd foi relatado para poucas espécies, como o girassol (GALLEGO et al., 1996). O Ni não afetou significativamente a atividade da GR em Betula pendula (KORICHEVA et al., 1997) e nas raízes de milho (BACCOUCH et al., 2001). Entretanto, plantas do gênero Alyssum exibiram elevada atividade de GR em resposta ao tratamento com Ni (SCHICKLER; CASPI, 1999). Um declínio da atividade da GR de $50-60 \%$ foi detectado em ambas as fraçoes solúveis e mitocondriais de plantas tratadas 
com Se, enquanto o aumento foi obervado na mitocôndria e na fração solúvel em plantas tratadas com mimosina (SANTOSH et al., 1999).

\subsubsection{Ascorbato peroxidase}

A família da ascorbato peroxidase consiste ao menos de cinco diferentes isoformas (ASADA, 1992), incluindo isoformas do tilacóide, estroma, citosol, peroxissomo e apoplasto (MIYAKE; ASADA, 1992; JIMÉNEZ et al., 1997). As várias isoformas de APX respondem diferencialmente a sinais matabólicos e sinais ambientais (KUBO et al., 1995). Em estudos subseqüentes, a APX de membranas de glioxissomos mostrou-se ser uma enzima constitutiva em diferentes tipos de peroxissomos de plântulas de pepino, provavelmente protegendo a membrana dos efeitos tóxicos do $\mathrm{H}_{2} \mathrm{O}_{2}$ produzido nos caminhos metabólicos de peroxissomos (CORPAS; TRELEASE, 1998). A atividade de APX aumentou após tratamento com Cd, Zn, Al ou Ni. Resultados obtidos com Ceratophyllum demersum indicaram um efeito positivo da atividade da APX submetida ao Cd e Zn (ARAVIND; PRASAD, 2003). Entretanto, a APX exibiu intenso aumento na atividade em plantas de Ceratophyllum demersum tratadas com Cd mais Zn, comparadas às plantas tratadas com Cd ou Zn separadamente (ARAVIND; PRASAD, 2003). O estresse por Cd induziu aumento na atividade da APX em plântulas de cevada, entretanto, em raízes, a atividade da APX foi reduzida a altas concentrações do metal (HEGEDUS et al., 2001). Foi observado aumento na atividade de APX nas folhas de ervilha (ROMERO-PUERTAS, 1999) e nas partes superiores de Phaseolus vulgaris na presença de Cd (CHAOUI et al., 1997). No caso do Al, trigo tolerante a este metal exibiu maior atividade de APX comparado a planta sensível (DARKO et al., 2004). Plantas de milho crescendo na presença de Ni exibiram estímulo de atividade de APX e MDHAR sugerindo que a desordem oxidativa observada pode estar relacionada à toxicidade do Ni em raízes de milho (BACCOUCH et al., 2001).

\subsubsection{Monodehidroascorbato redutase}

A monodehidroascorbato redutase (MDHAR, EC 1.6.5.4) é uma flavina adenina dinucleotídeo (FAD) que está presente como isoenzimas cloroplasmáticas e citosólicas, que dividem propriedades enzimáticas similares. MDHAR exibe alta especificidade para MDHA como aceptor de elétrons, utilizando NADH e não NADPH como doador de elétrons. O primeiro 
passo é a redução da enzima FAD para formar um complexo de transferência de carga com a enzima reduzida que doa elétrons sucessivamente ao MDHA que por sua vez, produz duas moléculas de ascorbato (ASADA, 1999).

A MDHAR também está localizado nos peroxissomos e mitocôndrias e atua na remoção do $\mathrm{H}_{2} \mathrm{O}_{2}$ que possa ter escapado da ação da CAT (DEL RIO et al., 2002). Em contraste com outras enzimas antioxidantes, o papel da MDHAR em resposta ao estresse oxidativo induzido por metais pesados não foi estudada detalhadamente. O aumento de atividade da MDHAR em plantas de Pinus silvestris pode estar relacionado com a resposta ao estresse induzido por Cd (SCHÜTZENDÜBEL et al., 2001).

\subsubsection{Dehidroascorbato redutase}

O MDHA produzido no lúmen pode não ser reduzido pela ferrodoxina or $\mathrm{NAD}(\mathrm{P}) \mathrm{H}$, sendo espontaneamente disproporcionado a dehidroascorbato (DHA) e ascorbato. O DHA é um composto não dissociado que facilmente penetra nas membranas celulares como membranas do tilacóide, diferentemente do MDHA (ASADA, 1999). A razão de disproporção espontânea da MDHA é maior a baixo pH. Assim, no lúmen, onde o pH é 5-6, o MDHA é rapidamente convertido a DHA e ascorbato, mas no estroma, onde o pH é 7-8, a vida média do MDHA é mais longa e pode ser reduzida em redFd ou NAD(P)H (ASADA, 1999). A importância da DHAR na tolerância a metais pesados não está clara. Em cevada, por exemplo, níveis de transcritos de RNAm não foram afetados pelo estresse ao Cd (METWALLY et al., 2003), assim como em raízes de pinheiro (SCHÜTZENDÜBEL et al., 2001).

\subsubsection{Glutationa-S-transferase}

A glutationa-S-transferase (GST, EC 2.5.1.18) cataliza a conjugação do tripeptídeo glutationa (GSH) a uma variedade de substratos hidrofóbicos, eletrofílicos e citotóxicos (MARRS, 1996). As GSTs podem usar GSH para reduzir peróxidos e formarem uma família heterogênea de proteínas que removem potencialmente compostos citotóxicos que reagem com DNA, RNA e proteínas (NOCTOR et al., 2002). Uma GST de planta (BI-GST) foi identificada como um potente inibidor da letalidade de Bax (proteína pró-apoptótica) que está associada com o estresse oxidativo e a disrupção de funções mitocondriais (KILILI et al., 2004). 
A atividade da GST é consideravelmente aumentada pelo estresse ao Cd em raízes e folhas de ervilha (DIXIT et al., 2001) e raízes de plântulas de arroz (MOONS, 2003). A exposição ao Cd causa a super regulação de vários fatores transcricionais relacionados ao estresse (SUZUKI et al., 2001). A GST também parece ter papel importante na desintoxicação de EAOs em plantas de trigo tolerantes ao Al, desde que a atividade de GST foi significativamente maior quando comparada a plantas de trigo sensíveis ao Al (DARKO et al., 2004). De uma maneira similar, a atividade da GST foi também maior em resposta ao Se em Lolium multiflorum L. (XUE; HARTIKAINEN, 2000), enquanto a quantidade de transcritos de RNAm de vários genes, incluindo GST, foram substancialmente maiores em A. halleri após a exposição a baixas e altas concentrações de Zn em culturas hidropônicas (BECHER et al., 2004).

\subsubsection{Glutationa peroxidase}

A GPX (EC, 1.11.1.9) de plantas metaboliza o $\mathrm{H}_{2} \mathrm{O}_{2}$ gerado em plantas (NOCTOR et al., 2002). Uma família de sete proteínas relacionadas (AtGPX1-AtGPX7) em Arabidopsis foi identificada no citosol, cloroplasto, mitocôndria e retículo endoplasmático (MILLAR et al., 2003). Além disso, foi possível isolar um gene de tomate que codifica uma GPX que protege os tecidos de plantas sob uma variedade de estresses (CHEN et al.,m 2004). O cDNA (OsGPX1) de Oryza sativa está relacionado a proteção das células contra o estresse oxidativo (KANG et al., 2004). Aumentos na atividade de GPX induzidos por Se foram demonstrados em Lolium multiflorum L. (HARTIKAINEN et al., 2000) e em cloroplastos de alface (SEPPANEN et al., 2003). A adição de Cd também conduziu a um aumento da atividade de GPX em cultivares de pimenta (LEÓN et al., 2002), enquanto a atividade de GPX decresceu em raízes e permaneceu quase inalterada em folhas de ervilha (DIXIT et al., 2001). Embora tenha ocorrido o acúmulo de Ni nas raízes de plantas de milho, a atividade de GPX neste tecido permaneceu inalterada (BACCOUCH et al., 2001).

\subsubsection{Guaiacol peroxidase}

A guaiacol peroxidase (GPOX, Ec 1.11.1.7) participa de reações metabólicas como a decomposição do ácido indol acético (AIA), biossíntese de lignina e defesa contra patógenos. A GOPX é diferente da APX na sequência de aminoácidos e nas funções fisiológicas (CHEN et al., 
1992). O mecanismo de ação da GPOX é o mesmo da APX, embora a GPOX utilize doadores de elétrons aromáticos como guaiacol e pirogalol (ASADA, 1999). Entretanto, uma peroxidase que oxida ascorbato com um aminoácido similar a GPOX foi encontrado em Camellia sinensis (KVARATSKHELIA et al., 1997). A GPOX tem quatro pontes dissulfeto ligadas a oito resíduos conservados de cisteína para a ligação de carboidatros e $\mathrm{Ca}^{2+}$. A APX não contém carboidrato e não apresenta sequências correspondentes para glicosilação e ligação ao $\mathrm{Ca}^{2+}$ (ASADA, 1999).

A resposta da GPOX a metais pesados varia consideravelmente dependendo da espécie de planta e do metal utilizado, embora seu papel no metabolismo de plantas ainda necessite de investigações. O aumento na atividade total de GPOX foi detectado em A. thaliana (CHO; SON, 2004) e Ceratophyllum demersum (ARAVIND; PRASAD, 2003) após adição de Cd, contrariamente ao observado em plantas de ervilha expostas ao Cd, que exibiram decréscimo na atividade de GPOX (SANDALIO et al., 2001). No caso de pinácea submetida ao Cd, a atividade de GPOX aumentou inicialmente, seguida de decréscimo (RADOTIC et al., 2000). No caso de Cr, análises da resposta em Xanthoria parietina thalli indicaram aumento na atividade de GPOX (DI TOPPI; GABRIELLE et al., 2004). Em contraste, análises de toxicidade em raízes de milho revelaram que a GPOX não respondeu as disordens induzidas por Ni (BACCOUCH et al., 2001).

\subsection{A sobrevivência das plantas: direções e perspectivas}

A poluição ambiental é um importante fator que expõe as plantas a condições estressantes que acarretam em impacto direto no metabolismo através de danos celulares. As intensas pesquisas sobre os sistemas antioxidantes, particularmente com relação aos papéis biológicos, acrescentam no conhecimento de diferentes mecanismos envolvidos nas respostas aos estresses. Além disso, o desenvolvimento de técnicas de manipulação de plantas auxiliam consideravelmente no ganho de novas descobertas biotecnológicas, como o uso de plantas transgênicas no estudo de respostas antioxidativas induzidas por metais. O estudo de mecanismos que conduzem à tolerância ao estresse contribuem para a criação de um novo cenário, o qual engloba a utilização da técnica de fitorremediação, alternativa mais barata do que métodos tradicionais na limpeza de ambientes contaminados (GRATÃO et al., 2005).

Estamos vivenciando avanços significativos nas análises das técnicas das 'ômicas', que contribuem na identificação de genes alvos. O que falta é a consideração de estudos que envolvam simultaneamente a expressão gênica, tradução de proteínas e a atividade enzimática. Os sistemas antioxidantes são mecanismos importantes que apresentam o potencial de controlar 
as cascatas de oxidação nas células sob condições normais, ou quando estimuladas por qualquer condição de estresse. Nosso conhecimento sobre as respostas ao estresse é considerável, mas este conhecimento ainda permanece complexo e variável quando diferentes condições celulatres são analisadas. O uso de antioxidantes como marcadores de estresse são essenciais no acesso às respostas de plantas à condições adversas que interferem na homeostase celular, mas os aspectos relacionados as espécies de plantas e tecidos devem ser considerados.

A corrente mudança ambiental ocasionada naturalmente ou por causas antropogênicas, adiciona uma tremenda escala de condições de estresses que tornam a vida das plantas cada vez mais difícil. Está claro que há alternativas, seja elas através de ações políticas e sociais, no combate a liberação de poluentes no ambiente, na construção de plantas geneticamnte alteradas ou no uso da plantas tolerantes que ocorrem naturalmente. Assim, espera-se que a informação disponível na literatura, que é claramente extensa, possa melhorar nosso entendimento sobre os efeitos básicos da fitotoxicidade causada por metais pesados e na indução de estresse oxidativo em plantas. 


\section{Referências}

ALSCHER, R.G., ERTURK, N., HEATH, L.S. Role of superoxide dismutases (SODs) in controlling oxidative stress in plants. Journal of Experimental Botany, Oxford, v. 53, p. 13311341, 2002.

ARAVIND, P., PRASAD, M.N.V. Zinc alleviates cadmium-induced oxidative stress in Ceratophyllum demersum L.: a free floating freshwater macrophyte. Plant Physiology and Biochemistry, Paris, v. 41, p. 391-397, 2003.

ASADA, K. Ascorbate peroxidase - a hydrogen peroxide scavenging enzyme in plants. Physiologia Plantarum, Copenhagen, v. 85, p. 235-241, 1992.

ASADA, K. The water cycle in chloroplast: scavenging of active oxygens and dissipation of excess photons. Annual Review of Plant Physiology and Plant Molecular Biology, California, v. 50, p. 601-639, 1999.

ASADA, K. The water-water cycle as alternative photon and electron sinks. Philosophical Transactions of the Royal Society of London Series B-Biological Sciences, New York, v. 355, p. 1419-1430, 2000.

AZEVEDO, R.A., ALAS, R.M., SMITH, R.J., LEA, P.J. Response of antioxidant enzymes to transfer from elevated carbon dioxide to air and ozone fumigation, in leaves and roots of wildtype and a catalase-deficient mutant of barley. Physiologia Plantarum, Copenhagen, v. 104, p. 280-292, 1998.

BACCOUCH, S., CHAOUI, A., EL FERJANI, E. Nickel toxicity induces oxidative damage in Zea mays roots. Journal of Plant Nutrition, Philadelphia, v. 24, p. 1085-1097, 2001.

BAGNOLI, F., DANTI, S., MAGHERINI, V., COZZA, R., INNOCENTI, A.M., RACCHI, M.L. Molecular cloning, characterization and expression of two catalase genes from peach. Functional Plant Biology, Collingwood, v. 31, p. 349-357, 2004.

BAIER, M., DIETZ, K.J. Alkyl hydroperoxide reductases: the way out of the oxidative breakdown of lipids in chloroplasts. Trends in Plant Science, London, v. 4, p. 166-168, 1999.

BARTOLI, C.G., GOMEZ, F., MARTINEZ, D.E., GUIAMET, J.J. Mitochondria are the main target for oxidative damage in leaves of wheat (Triticum aestivum L.). Journal of Experimental Botany, Oxford, v. 55, p. 1663-1669, 2004.

BHATIA, N.P., WALSH, K.B., ORLIC, I., SIEGELE, R., ASHWATH, N., BAKER, A.J.M. Studies on spatial distribution of nickel in leaves and stems of the metal hyperaccumulator Stackhousia tryonii Bailey using nuclear microprobe (micro-PIXE) and EDXS techniques. Functional Plant Biology, Collingwood, v. 31, p. 1061-1074, 2004.

BECHER, M., TALKE, I.N., KRALL, L., KRÄMER, U. Cross-species microarray transcript profiling reveals high constitutive expression of metal homeostasis genes in shoots of the zinc hyperaccumulator Arabidopsis halleri. The Plant Journal, Washington, v. 37, p. 251-258, 2004. 
BECHTOLD, U., MURPHY, D.J., MULLINEAUX, P.M. Arabidopsis peptide methionine sulfoxide reductase 2 prevents cellular oxidative damage in long nights. Plant Cell, Rockville, v. 16, p. 908-919, 2004.

BENAVIDES, M.P., GALLEGO, S.M., TOMARO, M.L. Cadmium toxicity in plants. Brazilian Journal of Plant Physiology, Piracicaba, v. 17, p. 21-34, 2005.

BOWLER, C., SLOOTEN, L., VANDENBRANDEN, S., DERYCKE, R., BOTTERMAN, J., SYBESMA, C., VAN MONTAGU, M., INZÉ, D. Manganese superoxide-dismutase can reduce cellular-damage mediated by oxygen radicals in transgenic plants. EMBO Journal, Oxford, v. 10, p. 1723-1732, 1991.

BREJ, T. Heavy metal tolerance in Agropyron repens (L.) P. Bauv. Populations from the Legnica copper smelter area, Lower Silesia. Acta Societatis Botanicorum Poloniae, Warsaw, v. 67, p. 325-333, 1998.

CAKMAK, I., HORST, W.J. Effect of aluminum on lipid-peroxidation, superoxide-dismutase, catalase, and peroxidase-activities in root-tips of soybean (Glycine max). Physiologia Plantarum, Copenhagen, v. 83, p. 463-468, 1991.

CHAOUI, A., MAZHOUDI, S., GHORBAL, M.H., EL FERJANI, E. Cadmium and zinc induction of lipid peroxidation and effects on antioxidant enzymes activities in bean (Phaseolus vulgaris). Plant Science, Clare, v. 127, p. 139-147, 1997.

CHEN, G.X., SANO, S., ASADA, K. The amino acid sequence of ascorbate peroxidase from tea has high degree of homology to that of cytochrome c peroxidase from yeast. Plant Cell Physiology, Oxford, v. 33, p. 109-116, 1992.

CHEN, S.R., VAGHCHHIPAWALA, Z., LI, W., ASARD, H., DICKMAN, M.B. Tomato phospholipid hydroperoxide glutathione peroxidase inhibits cell death induced by Bax and oxidative stresses in yeast and plants. Plant Physiology, Rockville, v. 135, p. 1630-1641, 2004.

CHEN, Z., GALLIE, D.R. The ascorbic acid redox state controls guard cell signaling and stomatal movement. Plant Cell, Rockville, v.16, p. 1143-1162, 2004.

CHO, U.H., SOHN, J.Y. Cadmium-induced changes in antioxidative systems, hydrogen peroxide content, and lipid peroxidation in Arabidopsis thaliana. Journal of Plant Biology, Okford, v. 47, p. 262-269, 2004.

COBBETT, C.S. Phytochelatins and their roles in heavy metal detoxification. Plant Physiology, Rockville, v. 123, p. 825-832, 2000.

CORPAS, F.J., TRELEASE, R.N. Differential expression of ascorbate peroxidase and a putative molecular chaperone in the boundary membrane of differentiating cucumber seedling peroxisomes. Journal of Plant Physiology, Stuttgart, v. 153, p. 332-338, 1998. 
DARKO, E., AMBRUS, H., STEFANOVITS-BANYAI, E., FODOR, J., BAKOS, F., BARNABA, B. Aluminium toxicity, Al tolerance and oxidative stress in an Al-sensitive wheat genotype and in Al-tolerant lines developed by in vitro microspore selection. Plant Science, Clare, v. 166, p. 583-591, 2004.

DIETZ, K.J. Plant peroxiredoxins. Annual Review of Plant Biology, Oxford, v. 54, p. 93-107, 2003.

DEL RIO, L.A., CORPAS, F.J., SANDALIO, L.M., PALMA, J.M., GOMEZ, M., BARROSO, J.B. Reactive oxygen species, antioxidant systems and nitric oxide in peroxisomes. Journal of Experimental Botany, Oxford, v. 53, p. 1255-1272, 2002.

DEL RIO, L.A., SANDALIO, L.M., ALTOMARE, D.A., ZILINSKAS, B.A. Mitochondrial and peroxisomal manganese superoxide dismutase: differential expression during leaf senescence. Journal of Experimental Botany, Oxford, v. 54, p. 923-933, 2003.

DELAUNAY, A., ISNARD, A.-D., TOLEDANO, M.B. $\mathrm{H}_{2} \mathrm{O}_{2}$ sensing through oxidation of the Yap1 transcription factor. EMBO Journal, Oxford, v. 19, p. 5157-5166, 2000.

DESIKAN, R., CHEUNG, M.K., CLARKE, A., GOLDING, S., SAGI, M., FLUHR, R., ROCK, C., HANCOCK, J., NEILL, S. Hydrogen peroxide is a common signal for darkness- and ABAinduced stomatal closure in Pisum sativum. Functional Plant Biology, Collingwood, v. 31, p. 913-920, 2004.

DI TOPPI, S., GABRIELLI, R. Response to cadmium in higher plants. Environmental and Experimental Botany, Oxford, v. 41, p. 105-130, 1999.

DIXIT, V., PANDEY, V., SHYAM, R. Differential antioxidative responses to cadmium in roots and leaves of pea (Pisum sativum L. cv. Azad). Journal of Experimental Botany, Oxford, v. 52, p. 1101-1109, 2001.

DUCIC, T., POLLE, A. Transport and detoxification of $\mathrm{Mn}$ and $\mathrm{Cu}$ in plants. Brazilian Journal of Plant Physiology, Piracicaba, v. 17, p. 103-112, 2005.

FERREIRA, R.R., FORNAZIER, R.F., VITÓRIA, A.P., LEA, P.J., AZEVEDO, R.A. Changes in antioxidant enzyme activities in soybean under cadmium stress. Journal of Plant Nutrition, Philadelphia, v. 25, p. 327-342, 2002.

FIDALGO, F., SANTOS, A., SANTOS, I., SALEMA, R. Effects of long-term salt stress on antioxidant defence systems, leaf water relations and chloroplast ultrastructure of potato plants. Annals of Applied Biology, Cambridge, v. 145, p. 185-192, 2004.

FINKEMEIER, I., GOODMAN, M., LAMKEMEYER, P., KANDLBINDER, A., SWEETLOVE, L.J., DIETZ, K.J. The mitochondrial type II peroxiredoxin F is essential for redox homeostasis and root growth of Arabidopsis thaliana under stress. Journal of Biological Chemistry, Bethesda, v. 280, p. 12168-12180, 2005. 
FORNAZIER, R.F., FERREIRA, R.R., PEREIRA, G.J.G., MOLINA, S.M.G., SMITH, R.J., LEA, P.J., AZEVEDO, R.A. Cadmium stress in sugar cane callus cultures: effect on antioxidant enzymes. Plant Cell, Tissue and Organ Culture, Dordrecht, v, 71, p. 125-131, 2002b.

FORNAZIER, R.F., FERREIRA, R.R., VITÓRIA, A.P., MOLINA, S.M.G., LEA, P.J., AZEVEDO, R.A. Effects of cadmium on antioxidant enzyme activities in sugar cane. Biologia Plantarum, Netherlands, v. 45, p. 91-97, 2002a.

FOYER, C.H., NOCTOR, G. Oxygen processing in photosynthesis: regulation and signalling. New Phytologist, London, v. 146, p. 359-388, 2000.

FOYER, C.H., NOCTOR, G. Redox sensing and signalling associated with reactive oxygen in chloroplasts, peroxisomes and mitocondria. Physiologia Plantarum, Copenhagen, v. 119, p. 355-364, 2003.

FREEMAN, J.L., PERSAN, M.W., NIEMAN, K., ALBRECHT, C., PEER, W., PICKERING, I.J., SALT, D.E. Increased glutathione biosynthesis plays a role in nickel tolerance in Thlaspi nickel hyperaccumulators. Plant Cell, Rockville, v. 16, p. 2176-2191, 2004.

FRUGOLI, J.A., ZHONG, H.H., NUCCIO, M.L., MCCOURT, P., MCPEEK, M.A., THOMAS, T.L., MCCLUNG, C.R. Catalase is encoded by a multigene family in Arabidopsis thaliana (L.) Plant Physiology, Rockville, v. 112, p. 327-336, 1996.

GERENDÁS, J., POLACCO, J.C., FREYERMUTH, S.K., SATTELMACHER, B. Significance of nickel for plant growth and metabolism. Journal of Plant Nutrition and Soil Science, Philadelphia, v. 162, p. 241-256, 1999.

GALLEGO, S.M., BENAVÍDES, M.P., TOMARO, M.L. Effects of heavy metal ion excess on sunflower leaves: evidences for involvement of oxidative stress. Plant Science, Clare, v. 121, p. 151-159, 1996.

GRATÃO, P.L., PRASAD, M.N.V., CARDOSO, P.F., LEA, P.J., AZEVEDO, R.A. Phytoremediation: green technology for the clean up of toxic metals in the environment. Brazilian Journal of Plant Physiology, Piracicaba, v. 17, p. 53-64, 2005.

GRIES, G.E., WAGNER, G.J. Association of nickel versus transport of Cd and calcium in tonoplast vesicles of oat roots. Planta, New York, v. 204, p. 390-396, 1998.

GUO, T.R., ZHANG, G.P., ZHOU, M.X., WU, F.B., CHEN, J.X. Effects of aluminum and cadmium toxicity on growth and antioxidant enzyme activities of two barley genotypes with different Al resistance. Plant and Soil, Dordrecht, v. 258, p. 241-248, 2004.

HALL, J.L. Cellular mechanisms for heavy metal metal detoxification and tolerance. Journal of Experimental Botany, Oxford, v. 53, p. 1-11, 2002.

HARTIKAINEN, H., XUE, T.L., PIIRONEN, V. Selenium as an antioxidant and pro-oxidant in ryegrass. Plant and Soil, Dordrecht, v. 225, p. 193-200, 2000. 
HAYAKAWA, T., KANEMATSU, S., ASADA, K. Occurrence of Cu-Zn-superoxide dismutase in the intrathylakoid space of spinach-chloroplasts. Plant and Cell Physiology, Kyoto, v. 25, p. 883-889, 1984.

HEGEDUS, A., ERDEI, S., HORVATH, G. Comparative studies of $\mathrm{H}_{2} \mathrm{O}_{2}$ detoxifying enzymes in green and greening barley seedlings under cadmium stress. Plant Science, Clare, v. 160, p. 1085-1093, 2001.

HERNÁNDEZ, J.A., ESCOBAR, C., CREISSEN, G., MULLINEAUX, P.M. Role of hydrogen peroxide and the redox state of ascorbate in the induction of antioxidant enzymes in pea leaves under excess light stress. Functional Plant Biology, Collingwood, v. 31, p. 359-368, 2004.

IGAMBERDIEV, A.U., LEA, P.J. The Role of peroxisomes in the integration of metabolism and evolutionary diversity of photosynthetic organism. Phytochemistry, Oxford, v. 60, p. 651-674, 2002.

INOUHE, M. Phytochelatins. Brazilian Journal of Plant Phisiology, Piracicaba, v. 17, p. 65-78, 2005.

JIMÉNEZ, A., HERNÁNDEZ, J.A., DEL RÍO, L.A., SEVILLA, F. Evidence for the presence of the ascorbate-glutathione cycle in mitochondria and peroxisomes of pea leaves. Plant Physiology, Rockville, v. 114, p. 275-284, 1997.

JOUILI, H., EL FERJANI, E. Changes in antioxidant and lignifying enzyme activities in sunflower roots (Helianthus annuus L.) stressed with copper excess. Comptes Rendus Biologies, New York, v. 326, p. 639-644, 2003.

KANG, S.G., JEONG, H.K., SUH, H.S. Characterization of a new member of the glutathione peroxidase gene family in Oryza sativa. Molecules and Cells, New York, v. 17, p. 23-28, 2004.

KILILI, K.G., ATANASSOVA, N., VARDANYAN, A., CLATOT, N., AL-SABARNA, K., KANELLOPOLOS, P.N., MAKRIS, A.M., KAMPRANIS, S.C. Differential roles of Tau class glutathione S-transferases in oxidative stress. Journal of Biological Chemistry, Bethesda, v. 279, p. 24540-24551, 2004.

KORICHEVA, J., ROY, S., VRANJIC, J.A., HAUKIOJA, E., HUGHES, P.R., HANNINEN, O. Antioxidant responses to simulated acid rain and heavy metal deposition in birch seedlings. Environmental Pollution, London, v. 95, p. 249-258, 1997.

KRUPA, Z., BARANOWSKA, M., ORZOT, D. Can anthocyanins be considered as heavy metal stress indicator in higher plants? Acta Physiologiae Plantarum, Warsaw, v. 18, p. 147-151, 1996.

KUBO, A., SAJI, H., TANAKA, K., KONDO, N. Expression of Arabidopsis cytosolic ascorbate peroxidase gene in response to ozone or sulfur dioxide. Plant Molecular Biology, Netherlands, v. 29, p. 479-489, 1995. 
KUO, M.C., KAO, C.H. Aluminum effects on lipid peroxidation and antioxidative enzyme activities in rice leaves. Biologia Plantarum, Netherlands, v. 46, p. 149-152, 2003.

KÜPPER, H., LOMBI, E., ZHAO, F.J., MCGRATH, S. Cellular compartmentation of cadmium and zinc in relation to other elements in the hyperaccumulator Arabidopsis halleri. Planta, New York, v. 212, p. 75-84, 2000.

KVARATSKHELIA, M., WINKEL, C., THORNELEY, R.N.F. Purification and characterization of a novel class in peroxidase isoenzyme from tea leaves. Plant Physiology, Rockville, v. 114, p. 1237-1245, 1997.

LEÓN, A.M., PALMA, J.M., CORPAS, F.J., GOMEZ, M., ROMERO-PUERTAS, M.C., CHATTERJEE, D., MATEOS, R.M., DEL RIO, L.A., SANDALIO, L.M. Antioxidative enzymes in cultivars of peppers plants with different sensitivity to cadmium. Plant Physiology and Biochemistry, Paris, v. 40, p. 813-820, 2002.

MARRS, K.A. The functions and regulation of glutathione S-transferases in plants. Annual Review of Plant Physiology and Plant Molecular Biology, California, v. 47, p. 127-158, 1996.

MCGRATH, S.P., ZHAO, F.J. Phytoextraction of metals and metalloids from contaminated soils. Current Opinion in Biotechnology, Oxford, v. 14, p. 277-282, 2003.

MEDICI, L.O., AZEVEDO, R.A., SMITH, R.J., LEA, P.J. The influence of nitrogen supply on antioxidant enzymes in plant roots. Collingwood, v. 31, p. 1-9, 2004.

MEMON, A.R., OZDEMIR, A., AKTOPRAKLIGIL, D. Heavy metal accumulation in plants. Biotechnology \& Biotechnological Equipment, Oxford, v. 15, p. 44-48, 2001.

METWALLY, A., FINKEMEIER, I., GEORGI, M., DIETZ, K.J. Salicylic acid alleviates the cadmium toxicity in barley seedlings. Plant Physiology, Rockville, v. 132, p. 272-281, 2003.

MICHAEL, T.P., MCCLUNG, C.R. Phase-specific circadian clock regulatory elements in Arabidopsis. Plant Physiology, Rockville, v. 130, p. 627-638, 2002.

MILLAR, A.H., MITTOVA, V., KIDDLE, G., HEAZLEWOOD, J.L., BARTOLI, C.G., THEODOULOU, F.L., FOYER, C.H. Control of ascorbate synthesis by respiration and its implication for stress responses. Plant Physiology, Rockville, v. 133, p. 443-447, 2003.

MINORSKY, P.V. The hot and the classic. Plant Physiology, Rockville, v. 133, p. 14-15, 2003.

MITTLER, R. Oxidative stress, antioxidants and stress tolerance. Trends in Plant Science, London, v. 7, p. 405-410,2002.

MIYAKE, C., ASADA, K. Thylakoid-bound ascorbate peroxidase in spinach chloroplasts and photoreduction of its primary oxidation product the monodehydroascorbate radicals in thylakoids. Plant Cell Physiology, Oxford, v. 33, p. 541-553, 1992. 
MOHAN, B.S., HOSETTI, B.B. Potential phytotoxicity of lead and cadmium to Lemna minor grown in sewage stabilization ponds. Environmental Pollution, London, v. 98, p. 233-238, 1997.

MOLLER, I.M. Plant mitochondria and oxidative stress: electron transport, NADPH turnover, and metabolism of reactive oxygen species. Annual Review of Plant Physiology and Plant Molecular Biology, California, v. 52, p. 561-591, 2001.

MONNET, F., VAILLANT, N., HITMI, A., SALLANON, H. Photosynthetic activity of Lolium perenne as a function of endophyte status and zinc nutrition. Functional Plant Biology, Collingwood, v. 32, p. 131-139, 2005.

MOONS, A. Osgstu3 and osgstu4, encoding tau class glutathione S-transferase, are heavy metal - and hypoxic stress-induced and differentially salt stress-responsive in rice roots. FEBS Letters, Amsterdan, v. 553, p. 427-432, 2003.

MULLINEAUX, P.M., CREISSEN, G.P. Glutathione reductase: regulation and role in oxidative stress.Oxidative. In: SCANDALIOS, J.C. (Ed.). Stress and the Molecular Biology of Antioxidant Defenses. New York: Cold Spring Harbor Laboratory Press, 1997, p. 667-713.

NAVABPOUR, S., MORRIS, K., ALLEN, R., HARRISON, E., A-H MACKERNESS, S., BUCHANAN-WOLLASTON, V. Expression of senescence-enhanced genes in response to oxidative stress. Journal of Experimental Botany, Oxford, v. 54, p. 2285-2292, 2003.

NEILL, S.J., DESIKAN, R., CLARKE, A., HURST, R.D., HANCOCK, J.T. Hydrogen peroxide and nitric oxide as signalling molecules in plants. Journal of Experimental Botany, Oxford, v. 53, p. 1237-1247, 2002.

NEILL, S.O., GOULD, K.S. Anthocyanins in leaves: light attenuators or antioxidants? Functional Plant Biology, Collingwood, v. 30, p. 865-873, 2003.

NOCTOR, G., DUTILLEUL, C., DE PAEPE, R., FOYER, C.H. Use of mitochondrial electron transport mutants to evaluate the effects of redox state on photosynthesis, stress tolerance and the integration of carbon/nitrogen metabolism. Journal of Experimental Botany, Oxford, v. 55, p. 49-57, 2004.

NOCTOR, G., FOYER, C. Ascorbate and glutathione: keeping active oxygen under control. Annual Review of Plant Physiology and Plant Molecular Biology, California, v. 49, p. 249279, 1998.

NOCTOR, G., GOMEZ, L., VANACKER, H., FOYER, C.H. Interactions between biosynthesis, compartmentation and transport in the control of glutathione homeostasis and signalling. Journal of Experimental Botany, Oxford, v. 53, p. 1283-1304, 2002. 
OTT, T., FRITZ, E., POLLE, A., SCHÜTZENDÜBEL, A. Characterisation of antioxidative systems in the ectomycorrhiza-building basidiomycete Paxillus involutus (Bartsch.) FR. and its reaction to cadmium. FEMS Microbiology Ecology, New York, v. 42, p. 359-366, 2002.

PANDA, S.K., CHOUDHURY, I., KHAN, M.H. Excess heavy metal toxicity induces lipid peroidation and affects antioxidants in wheat (Triticum aestivum L.) leaves. Biologia Plantarum, Netherlands, v. 46, p. 289-294, 2003.

PANDA, S.K., CHOUDHURY, S. Chromium stress in plants. Brazilian Journal of Planta Phisiology, Piracicaba, v. 17, p.95-102, 2005.

PANDOLFINI, T., GABBRIELLI, R., CISCATO, M. Nickel toxicity in two durum wheat cultivars differing in drought sensitivity. Journal of Plant Nutrition, New York, v. 19, p. 16111627, 1996.

PIGNOCCHI, C., FOYER, C.H. Apoplastic ascorbate metabolism and its role in the regulation of cell signalling. Current Opinion in Plant Biology, London, v. 6, p. 379-389, 2003.

POLIDOROS, N.A., SCANDALIOS, J.G. Role of hydrogen peroxide and different classes of antioxidants in the regulation of catalase and glutathione S-transferase gene expression in maize (Zea mays L.). Physiologia Plantarum, Copenhagen, v. 106, p. 112-120, 1999.

POLLE, A., SCHÜTZENDÜBEL, A. Heavy metal signalling in plants: linking cellular and organismic responses. Topics in Current Genetics, Berlin, v. 4, p. 187-215, 2003.

QUAGHEBEUR, M., REHGEL, Z. Phosphate and arsenic interactions in the rhizosphere of canola (Brassica napus). Functional Plant Biology, Collingwood, v. 31, p. 1085-1094, 2004.

RADOTIC, K., DUCIC, T., MUTAVDZIC, D. Changes in peroxidase activity and isoenzymes in spruce needles after exposure to different concentrations of cadmium. Environmental and Experimental Botany, Oxford, v. 44, p. 105-113, 2000.

RAUTENKRANZ, A.A.F., LI, L.J., MACHLER, F., MARTINOIA, E., OERTLI, J.J. Transport of ascorbic and dehydroascorbic acids across protoplast and vacuole membranes isolated from barley (Hordeum-vulgare 1 cv gerbel) leaves. Plant Physiology, Rockville, v. 106, p. 187-193, 1994.

REID, R., LIU, J. Measurement od trace metal influx in plants: a case study with Co. Functional Plant Biology, Collingwood, v. 31, p. 941-947, 2004.

ROMERO-PUERTAS, M.C., MCCCARTHY, I., SANDALIO, L.M., PALMA, J.M., CORPAS, F.J., GOMEZ, M., DEL RIO, L.A. Cadmium toxicity and oxidative metabolism of pea leaf peroxisomes. Free Radical Research, London, v. 31, p. 25-31, June. 1999. 
SANDALIO, L.M., DALURZO, H.C., GOMEZ, M., ROMERO-PUERTAS, M.C., DEL RIO, L.A. Cadmium-induced changes in the growth and oxidative metabolism of pea plants. Journal of Experimental Botany, Oxford, v. 52, p. 2115-2126, 2001.

SANTOSH, T.R., SREEKALA, M., LALITHA, K. Oxidative stress during selenium deficiency in seedlings of Trigonella foenum-graecum and mitigation by mimosine - Part II. Glutathione metabolism. Biological Trace Element Research, Oxford, v. 70, p. 209-222, 1999.

SCANDALIOS, J.G. Oxygen stress and superoxide dismutases. Plant Physiology, Rockville, v. 101, p. 7-12, 1993.

SCANDALIOS, J.G., ACEVEDO, A., RUZSA, S. Catalase gene expression in response to chronic high temperature stress in maize. Plant Science, Clare, v. 156, p. 103-110, 2000.

SCHICKLER, H., CASPI, H. Response of antioxidative enzymes to nickel and cadmium stress in hyperaccumulator plants of the genus Alyssum. Physiologia Plantarum, Copenhagen, v. 105, p. 39-44, 1999.

SCHÜTZENDÜBEL, A., POLLE, A. Plant responses to abiotic stresses: heavy metal induced oxidative stress and protection by mycorrhization. Journal of Experimental Botany, Oxford, v. 53, p. 1351-1365, 2002.

SCHÜTZENDÜBEL, A., SCHWANZ, P., TEICHMANN, T., GROSS, K., LANGENFELDHEYSER, R., GODBOLD, D.L., POLLE, A. Cadmium-induced changes in antioxidant systems, hydrogen peroxide content and differentiation in Scots pine roots. Plant Physiology, Rockville, v. 127, p. 887-898, 2001.

SELIM, H.M., KINGERY, W.L. Geochemical and Hydrological Reactivity of Heavy Metals in Soils. In: _ Geochemical and Hydrological Reactivity of Heavy Metals in Soils. Florida: Lewis Publishers, Boca Raton, 2003, p. 360.

SEN RAYCHAUDHURI, S., DENG, X.W. The role of superoxide dismutase in combating oxidative stress in higher plants. Botanical Review, New York, v. 66, p. 89-98, 2000.

SEPPANEN, M., TURAKAINEN, M., HARTIKAINEN, H. Selenium effects on oxidative stress in potato. Plant Science, Clare, v. 165, p. 311-319, 2003.

SKADSEN, R.W., SCHULZE-LEFERT, P., HERBST, J.M. Molecular cloning, characterization and expression analysis of two catalase isozyme genes in barley. Plant Molecular Biology, Netherlands, v. 29, p. 1005-1014, 1995.

SMIRNOFF, N., CONKLIN, P.L., LOEWUS, F.A. Biosynthesis of ascorbic acid in plants: a renaissance. Annual Review of Plant Physiology and Plant Molecular Biology, Palo Alto, v. 52, p. 437-467, 2001. 
SOMASHEKARAIAH, B.V., PADMAJA, K., PRASAD, A.R.K. Phytotoxicity of cadmium ions on germinating seedlings of mung bean (Phaseolus vulgaris): involvement of lipid peroxides in chlorophyll degradation. Physiologia Plantarum, Copenhagen, v. 85, p. 85-89, 1992.

SREEKALA, M., SANTOSH, T.R., LALITHA, K. Oxidative stress during selenium deficiency in seedlings of Trigonella foenum-graecum and mitigation by mimosine - Part I. Hydroperoxide metabolism. Biological Trace Element Research, Oxford, v. 70, p. 193-207, 1999.

SRIVASTAVA, S., TRIPATHI, R.D., DWIVEDI, U.N. Synthesis of phytochelatins and modulation of antioxidants in responses to cadmium stress in Cuscuta reflexa - an angiospermic parasite. Journal of Plant Physiology, Stuttgart, v. 161, p. 665-674, 2004.

ST CLAIR, S.B., LYNCH, J.P. Photosynthetic and antioxidant enzyme responses of sugar maple and red maple seedlings to excess manganese in contrasting light environments. Functional Plant Biology, Collingwood, v. 31, p. 1005-1014, 2004.

SUZUKI, N., KOIZUMO, N., SANO, H. Screening of cadmium-responsive genes in Arabidopsis thaliana. Plant Cell and Environment, Oxford, v. 24, p. 1177-1188, 2001.

TAUSZ, M., PILCH, B., RENNENBERG, H., GRILL, D., HERSCHBACH, C. Root uptake, transport, and metabolism of externally applied glutathione in Phaseolus vulgaris seedlings. Journal of Plant Physiology, Stuttgart, v. 161, p. 347-349, 2004.

TAYLOR, N.L., DAY, D.A., MILLAR, A.H. Targets of stress-induced oxidative damage in plant mitochondria and their impact on cell carbon/nitrogen metabolism. Journal of Experimental Botany, Oxford, v. 55, p. 1-10, 2003.

THOMPSON, J.E., HOPKINS, M.T., TAYLOR, C., WANG, T.W. Regulation od senescence by eukaryotic translation initiation factor 5A: implications for plant growth and development. Trends in Plant Science, London, v. 9, p. 174-179, 2004.

VANDENABEELE, S., VANDERAUWERA, S., VUYLSTEKE, M., ROMBAUTS, S., LANGEBARTELS, C., SEIDLITZ, H.K., ZABEAU, M., VAN MONTAGU, M., INZÉ, D., VAN BREUSEGEM, F. Catalase deficiency drastically affects gene expression induced by high light in Arabidopsis thaliana. Plant Journal, Oxford, v. 39, p. 45-58, 2004.

VAN DOORN, W.G., WOLTERING, E.J. Many ways to exit? Cell death categories in plants. Trends in Plant Science, London, v. 10, p.117-122, 2005.

VATAMANIUK, O.K., MARI, S., LANG, A., CHALASANI, S., DEMKIV, L.O., REA, P.A. Phytochelatin synthase, a dipeptidyltranferase that undergoes multisite acylation with gammaglutamylcysteine during catalysis - Stoichiometric and site-directed mutagenic analysis of Arabidopsis thaliana PCS1-catalyzed phytochelatin synthesis. Journal of Biological Chemistry, Bethesda, v. 279, p. 22449-22460, 2004. 
VITORELLO, V., CAPALDI, F.R., STEFANUTO, V.A. Recent advances in aluminum toxicity and resistance in higher plantas. Brazilian Journal of Plant Phisiology, Piracicaba, v. 17, p. 129-143, 2005.

VITÓRIA, A.P., LEA, P.J., AZEVEDO, R.A. Antioxidant enzymes responses to cadmium in radish tissues. Phytochemistry, Oxford, v. 57, p. 701-710, 2001.

VÖGELI-LANGE, R., WAGNER, G.J. Subcellular-localization of cadmium and cadmiumbinding peptides in tobacco-leaves - implication of a transport function for cadmium-binding peptide. Plant Physiology, Rockville, v. 92, p. 1086-1093, 1990.

WEBER, M., HARADA, E., VESS, C., VON ROEPENACK-LAHAYE, E., CLEMENS, S. Comparative microarray analysis of Arabidopsis thaliana and Arabidopsis halleri roots identifies nicotianamine synthase, a ZIP transporter and other genes as potential hyperaccumulation factors. The Plant Journal, Washington, v. 37, p. 269-281, 2004.

WILLEKENS, H., CHAMNONGPOL, S., DAVEY, M., SCHRAUDNER, M., LANGEBARTELS, C., VANMONTAGU, M., INZÉ, D., VANCAMP, W. Catalase is a sink for $\mathrm{H}_{2} \mathrm{O}_{2}$ and is indispensable for stress defence in C-3 plants. EMBO Journal, Oxford, v. 16, p. 4806-4816, 1997.

WILLEKENS, H., LANGEBARTELS, C., TIRÉ, C., VAN MONTAGU, M., INZÉ, D., VAN CAMP, W. Differential expression of catalase genes in Nicotiana plumbaginifolia (L.). Proceedings of the National Academy of Sciences of the United States of America, Washington, v. 91, p. 10450-10454, 1994.

XUE, T.L., HARTIKAINEN, H. Association of antioxidative enzymes with the synergistic effect of selenium and UV irradiation in enhancing plant growth. Agricultural and Food Science in Finland, Finland, v. 9, p. 177-186, 2000.

XUE, T.L., HARTIKAINEN, H., PIIRONEN, V. Antioxidative and growth-promoting effect of selenium on senescing lettuce. Plant and Soil, Dordrecht, v. 237, p. 55-61, 2001.

YAMAMOTO, Y., HACHIA, A., HAMADA, H., MATSUMOTO, H. Phenylpropanoids as a protectant of aluminium toxicity in cultured tobacco cells. Plant Cell Physiology, Oxford, v. 39, p. 950-957, 1998.

YAMAMOTO, Y., KOBAYASHI, Y., DEVI, S.R., RIKIISHI, S., MATSUMOTO, H. Oxidative stress triggered by aluminum in plant roots. Plant and Soil, Dordrecht, v. 255, p. 239-243, 2003.

YOSHIMURA, K., YABUTA, Y., ISHIKAWA, T., SHIGEOKA, S. Identification of a cis element for tissue-specific alternative splicing of chloroplast ascorbate peroxidase. Journal of Biological Chemistry, Bethesda, v. 277, p. 40623-40632, 2002. 
ZHANG, G.C., SLASKI, J.J., ARCHAMBAULT, D.J., TAYLOR, G.J. Aluminum-induced alterations in lipid composition of microsomal membranes from an aluminum-resistant and an aluminum-sensitive cultivar of Triticum aestivum. Physiologia Plantarum, Copenhagen, v. 96, p. 683-691, 1996.

ZOLLER, T., SKROPPA, T., JOHNSEN, O., POLLE, A. Apoplastic peroxidases in needles of Norway spruce (Picea abies) progenies from different crossing environments. Forstwissenschaftliches Centralblatt, Oxford, v. 122, p. 153-159, 2003. 


\section{CARACTERIZAÇÃO DAS ENZIMAS ANTIOXIDANTES DO MICRO-TOM}

\section{Resumo}

A atividade da catalase (CAT), guaiacol peroxidase (GPOX), ascorbato peroxidase (APX), glutationa redutase (GR) e as isoenzimas da superóxido dismutase (SOD) foram determinadas nos tecidos das plantas do cultivar de tomate (Lycopersicon esculentum) MicroTom a 104 dias de desenvolvimento. As atividades totais de CAT, GPOX e GR foram maiores no caule do que nos outros tecidos analisados, enquanto a atividade da APX foi mais baixa neste tecido. As análises de SOD revelaram a existência de quatro isoenzimas nas folhas, três nos frutos, mas apenas duas nas raízes e caules. Esta caracterização é essencial para a investigação do efeito de estresses abióticos e bióticos nas respostas de estresse oxidativo por esta planta modelo.

Palavras-chave: Enzimas antioxidantes; Catalase; Micro-Tom; Superóxido dismutase 


\title{
3 ANTIOXIDANT ENZYMES CHARACTERIZATION OF TOMATO CV MICRO-TOM
}

\begin{abstract}
The activity of catalase (CAT), guaiacol peroxidase (GPOX), ascorbate peroxidase (APX), glutathione reductase (GR) and the isoenzymes of superoxide dismutase (SOD) were determined in plant tissues of tomato (Lycopersicon esculentum) cultivar Micro-Tom at 104 days of development activities. Total activity of CAT, GPOX and GR was shown to be higher in the shoot than in others tissues, whereas the shoot exhibited the lowest APX activity. Activity staining analysis revealed the existence of four SOD isoenzymes in leaves, three in fruits, but only two in the roots and shoots. This characterization is essential for the investigation of the effect of abiotic and biotic stresses on the oxidative stress responses by this plant system model.
\end{abstract}

Keywords: Antioxidant enzymes; Catalase; Micro-Tom; Superoxide dismutase 


\subsection{Introdução}

Vários sistemas modelo são utilizados para entender os fenômenos biológicos, tornando possível que estas informações sejam estendidas a outros organismos. Por este motivo, o tomate pode ser considerado um excelente material, que além de apresentar alta diversidade em metabólitos secundários, é considerado um modelo alternativo comparado a Arabidopsis (LIMA et al., 2004) e para estudos com frutos carnosos (SUN et al., 2006). Dentro deste propósito, o cultivar miniatura de tomate Micro-Tom pode ser usado como modelo genético, baseado no seu tamanho pequeno e na produção de frutos e sementes viáveis em vasos com 50-100 mL de substrato (MEISSNER et al., 1997). Além disso, o Micro-Tom apresenta um ciclo de desenvolvimento curto, entre 70 e 100 dias e cresce em laboratório com a mesma estrutura mínina usada para Arabidopsis. Entretanto, este cultivar é pouco caracterizado, particularmente com relação às enzimas antioxidantes.

Assim, as informações básicas sobre os mecanismos antioxidantes são essenciais e melhoram o entendimento sobre alguns mecanismos fisiológicos relacionados ao controle de espécies ativas de oxigênio (EAOs), que são produzidas nas células sob condições normais ou ou sob condições de estresse. Embora exista uma vasta complexidade de sistemas antioxidantes, algumas enzimas como a catalase (CAT), guaiacol peroxidase (GPOX), ascorbato peroxidase (APX), glutationa redutase (GR) e superóxido dismutase (SOD) foram centralizadas neste estudo.

\subsection{Material e métodos}

O cultivar Micro-Tom foi gentilmente fornecido pelo Dr A. Levy (Weizmann Institute of Science, Israel). As sementes foram distrobuídas em caixas contendo uma mistura de substrato orgânico inerte (Plantmax HT Eucatex, Brazil) e vermiculita, na proporção 1:1, suplementado com 1 g de NPK 10. 10. 10 por litro de substrato e 4 g de calcário dolomítico (Ca + Mg) por litro de substrato.

Posteriormente, o trasplantio foi realizado com plântulas contendo no mínimo um par de folhas bem desenvolvidas, além das cotiledonares. As plântulas foram retiradas com o máximo possível de substrato aderido às raízes e colocadas em vasos de $150 \mathrm{~mL}$.

Após 104 dias de desenvolvimento, raízes, fohas e frutos foram coletados e estocados a $-80{ }^{\circ} \mathrm{C}$ para análises posteriores. As amostras foram homogeinizadas (2:1 volume do tampão de 
extração para o peso fresco do tecido) num mortar com tampão fosfato de potássio $100 \mathrm{mM}$ (pH 7.5) contendo $1 \mathrm{mM}$ de ácido etilenodiamino tetra-acético (EDTA), $3 \mathrm{mM}$ de ditiotreitol (DTT) e 5\% de polivinilpolipirrolidona (PVPP) (AZEVEDO et al., 1998).

O homogeinizado foi centrifugado a 10.000 g por 30 minutos e o sobrenadante foi mantido estocado em alíquotas a $-80^{\circ} \mathrm{C}$. As atividades de CAT, GPOX, APX e GR foram determinadas como decritas por Gomes-Junior et al. (2007). A atividade de SOD foi determinada por eletroforese em gel de poliacrilamida (PAGE) não desnaturante de acordo com Gomes-Junior et al. (2006b). Os tampões e géis foram preparados como decritos por Vitória et al. (2001) com a exclusão do dodecil sulfato de sódio (SDS). O delineamento experimental utilizado foi inteiramente casualizado com três repetições para cada vaso. Os resultados foram apresentados através de média e desvio padrão.

\subsection{Resultados e discussão}

Embora tóxicas, as EAOS são normalmente produzidas e metabolizadas pelos sistemas celulares. Entretanto, sob condições de estresse, algumas EAOs são produzidas em excesso e devem ser rapidamente desintoxicadas por mecanismos celulares enzimáticos e não enzimáticos, que protegem as células da oxidação descontrolada e da conversão destas EAOs em radicais destrutivos (GRATÃO, et al., 2005; PAULY et al., 2006; PITZSCHKE et al., 2006).

O crescente número de trabalhos relacionados ao estudo destes mecanismos de defesa ressalta a importância de estudos com fatores estressantes em diferentes espécies de plantas. O tomate, que é uma planta modelo, pode dessa forma, ser utilizado para o melhor entendimento destes mecanismos.

As plantas de Micro-Tom com 104 dias de desenvolvimento exibiram alguns padrões distintos de atividade para as enzimas testadas. As atividades de CAT e GPOX foram maiores nos caules do que nos demais tecidos (Figura 3.1). A CAT representa o maior constituinte da matrix de peroxissomos (REUMANN; WEBER, 2006), usando $\mathrm{H}_{2} \mathrm{O}_{2}$ para oxidar toxinas como fenóis, ácido fórmico e formaldeído, enquanto a GPOX metaboliza o $\mathrm{H}_{2} \mathrm{O}_{2}$ a níveis que são mais baixos comparados aos altos níveis de $\mathrm{H}_{2} \mathrm{O}_{2}$ gerados em plantas (NOCTOR et al., 2002). $\mathrm{O}$ número de isoenzimas de CAT pode variar entre as espécies de plantas, como uma delas encontrada em suspensões celulares de café (GOMES-JUNIOR et al., 2006a) e três em milho (SCANDALIOS, 2000). Entretanto, o número de isoenzimas para a GPOX varia entre os 
deiferentes tecidos, como observado em algumas espécies, como na cenoura (LEPEDUS et al., 2004).

A atividade de APX foi contrária àquela observada para as outras duas peroxidases analisadas, CAT e GPOX, exibindo atividade mais baixa nos caules e mais alta nos frutos (Figura 3.1). A APX é relacionada à conversão do $\mathrm{H}_{2} \mathrm{O}_{2}$ a $\mathrm{H}_{2} \mathrm{O}$, protegendo cloroplastos e outros constituintes celulares dos danos causados por $\mathrm{H}_{2} \mathrm{O}_{2}$ e ${ }^{\bullet} \mathrm{OH}$. Esta reação enzimática utiliza ascorbato (AsA) como o doador específico de elétrons (TEIXEIRA et al., 2006).

A APX está localizada no estroma e nos tilacóides nos cloroplastos de plantas superiores e pode ser inativada por $\mathrm{H}_{2} \mathrm{O}_{2}$ se AsA for totalmente consumido, enquanto a APX citosólica de plantas superiores são relativamente tolerantes (KITAJIMA et al., 2006). Durante a senescência, a expressão dos genes individuais de APX é diferentemente regulada indicando o controle dos níveis de $\mathrm{H}_{2} \mathrm{O}_{2}$ nos diferentes compartimentos celulares (PANCHUK et al., 2005).

A atividade de GR foi maior no caule, mas consideravelmente reduzida no tecido foliar (Figura 3.1). A GR pode estar envolvida na defesa contra o estresse oxidativo, enquanto a GSH tem um importante papel na quebra do $\mathrm{H}_{2} \mathrm{O}_{2}$ (AZEVEDO et al., 1998), mantendo os grupos sulfidrilas da cisteína na forma reduzida (NOCTOR et al., 2002). Em Arabidopsis thaliana, dois genes que codificam a GR foram identificados, gr1 e gr2 (XIANG; OLIVER, 1998). Entretanto, o número de isoenzimas pode ser maior, como observado em suspensões celulares de café (GOMES-JUNIOR et al., 2007). 

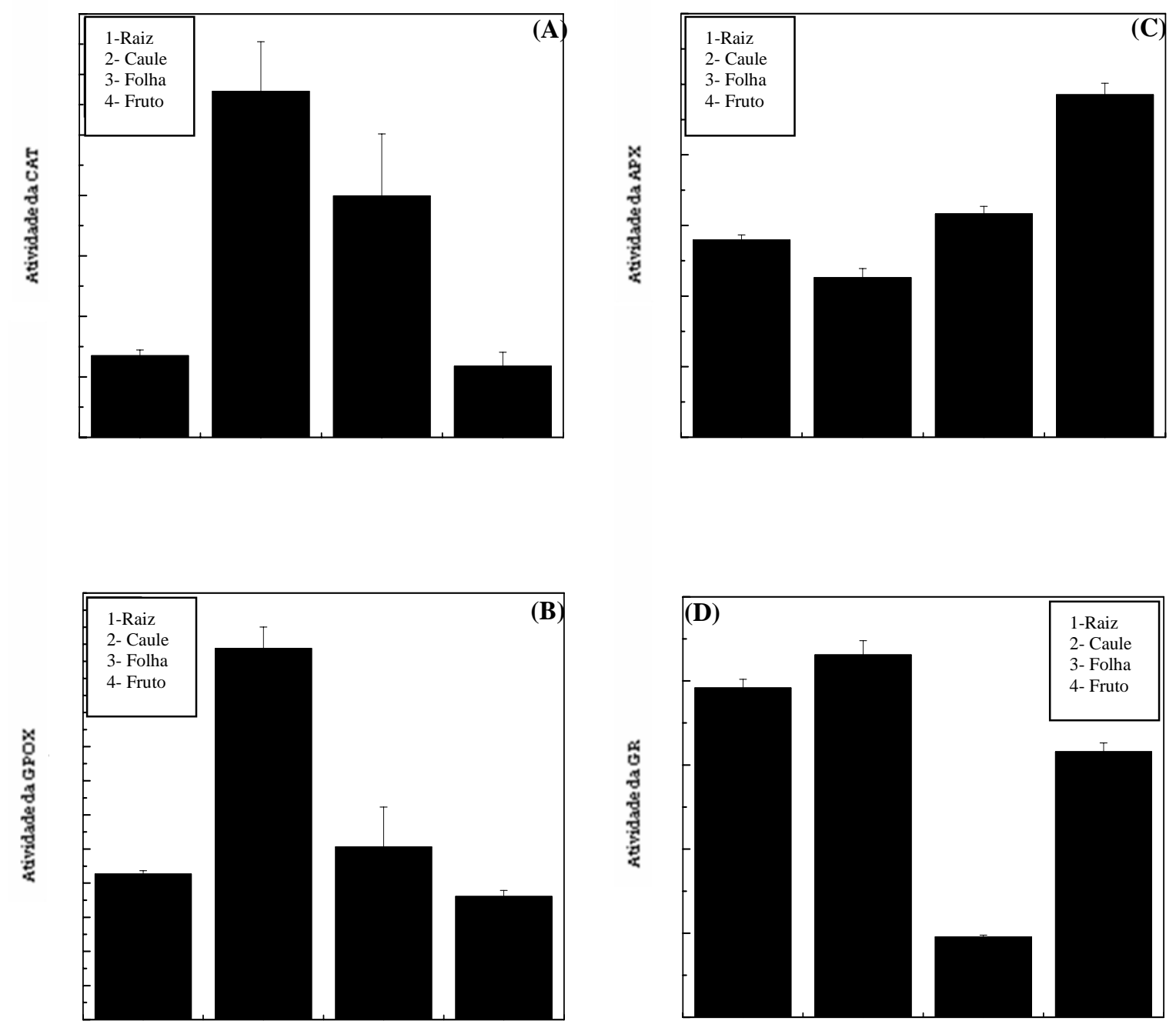

Figura 3.1 - Atividade específica de CAT ( $\mu \mathrm{mol} \mathrm{min}^{-1} \mathrm{mg}^{-1}$ proteína) (A), GOPX (u mg ${ }^{-1}$ proteína) (B), APX ( $\mu$ mol min ${ }^{-1} \mathrm{mg}^{-1}$ proteína) (C) e GR ( $\mu \mathrm{mol} \mathrm{min}^{-1} \mathrm{mg}^{-1}$ proteína) (D). Os valores são as médias de 3 repetições

No caso da enzima SOD, cinco isoenzimas foram identificadas entre os quatro tecidos de tomate analisados (Figura 3.2). A SOD I foi observada em todos os tecidos, enquanto a SOD II e a SOD IV foram observados apenas nos tecidos foliares. A SOD III foi obervada na raiz, caule e fruto, mas não no tecido foliar, enquanto a SOD V esteve presente na folha e no fruto. Embora isoenzimas distintas foram detectadas nos tecidos testados, a atividade total de SOD determinada pela análise densitométrica (dados não mostrados) foi maior no caule e fruto, sendo a SOD I, a maior responsável por esta atividade em todos os tecidos (Figura 3.2). A SOD é responsável pela dismutação do $\mathrm{O}_{2}{ }^{\bullet-}$ à $\mathrm{H}_{2} \mathrm{O}_{2}$, influenciando a concentração de $\mathrm{O}_{2}{ }^{\bullet-}$ e $\mathrm{H}_{2} \mathrm{O}_{2}$ nas células. As fontes de 
geração de $\mathrm{O}_{2}{ }^{\bullet-}$ podem ser naturais ou através de produtos das atividades metabólicas que inclui por exemplo, a cadeia transportadora de elérons (SEN RAYCHAUDHURI; DENG, 2000). Três tipos distintos de isoenzimas de SOD foram detectadas em plantas, classificadas de acordo com o cofator metálico Fe, Mn e Cu/Zn (GRATÃO et al., 2005). A Fe-SOD está associada com os cloroplastos; a Mn-SOD está localizada nas mitocôndrias e peroxissomos, enquanto a Cu/Zn está localizada no citosol, cloroplastos e peroxissomos (GRATÃO et al., 2005).

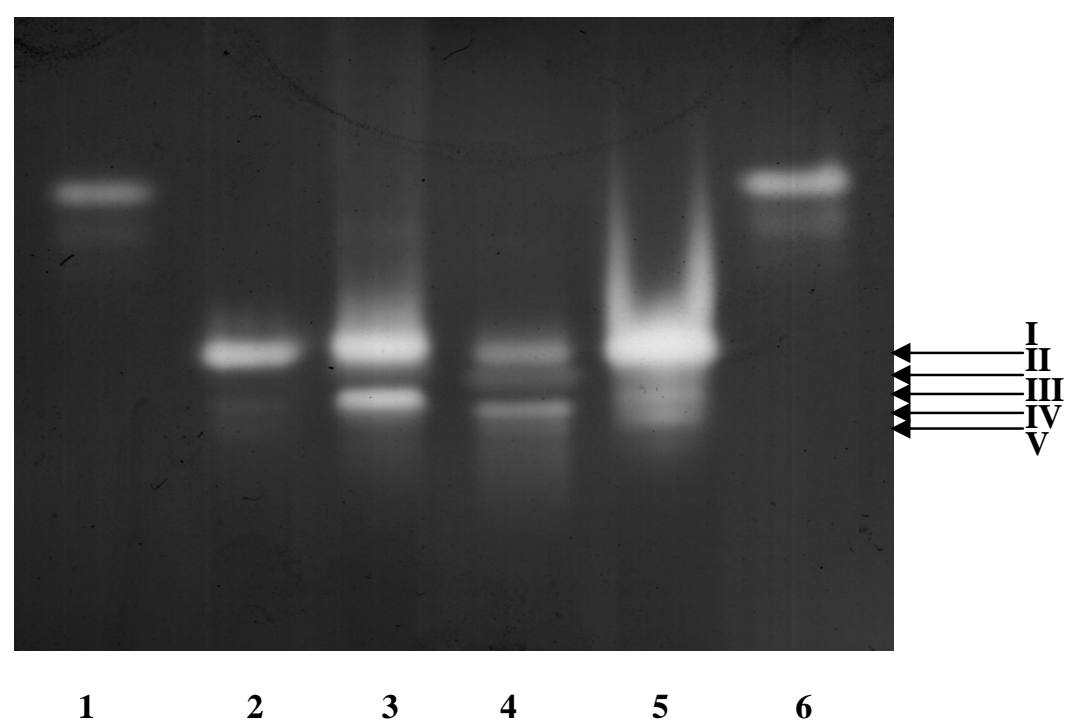

Figura 3.2 - Atividade da superóxido dismutase (SOD). Linha 1 e 6, padrão de SOD bovina; linha 2, raiz; linha 3, caule; linha 4, folha e linha 5, fruto

De acordo com os resultados observados, as enzimas CAT e GPOX apresentaram importantes papéis na dismutação do $\mathrm{H}_{2} \mathrm{O}_{2}$ nos caules, enquanto a APX foi mais importante nos frutos. Estas informações são essenciais para o entendimento de que enzimas antioxidantes distintas apresentam diferentes contribuições para o estado oxidativo da célula, que pode ser esperado também para outros estágios de desenvolvimento. Em conclusão, respostas diferentes da CAT, GPOX, APX, GR e SOD podem ser correlacionadas com o fenômeno fisiológico celular específico devido à especificidade tecidual. Baseado nestas informações, que são provenientes de um modelo de estudo como o tomate, as respostas antioxidativas de plantas sob situações de estresse poderão ser melhor compreendidas. Estas informações são importantes quando um experimento é planejado e analisado quanto à contaminação de metais pesados nas espécies de plantas em que o metal pode ser translocado e acumulado nos frutos. Neste sentido, um 
importante projeto está em andamento em nosso laboratório, em que plantas de Micro-Tom foram submetidas a metais pesados até a maturidade de seus frutos. 


\section{Referências}

AZEVEDO, R.A., ALAS, R.M., SMITH, R.J., LEA, P.J. Response of antioxidant enzymes to transfer from elevated carbon dioxide to air and ozone fumigation, in leaves and roots of wildtype and a catalase-deficient mutant of barley. Physiologia Plantarum, Copenhagen, v. 104, p. 280-292, 1998.

GOMES-JUNIOR, R.A., GRATÃO, P.L., GAZIOLA, S.A., MAZZAFERA, P., LEA, P.J., AZEVEDO, R.A. Selenium-induced oxidative stress in coffee cell suspension cultures. Functional Plant Biology, Collingwood, v. 34, p. 449-456, 2007.

GOMES-JUNIOR, R.A., MOLDES, C.A., DELITE, F.S., GRATÃO, P.L., MAZZAFERA, P., LEA, P.J., AZEVEDO, R.A. Nickel elicits a fast antioxidant response in Coffea arabica cells. Plant Physiology and Biochemistry, Paris, v. 44, p. 420-29, 2006a.

GOMES-JUNIOR, R.A., MOLDES, C.A., DELITE, F.S., POMPEU, G.B., GRATAO, P.L., MAZZAFERA, P., LEA, P.J., AZEVEDO, R.A. Antioxidant metabolism of coffee cell suspension cultures in response to cadmium. Chemosphere, Fukuoka, v. 65, p. 1330-1337, 2006b.

GRATÃO, P.L., POLLE, A., LEA, P.J., AZEVEDO, R.A. Making the life of heavy metalstressed plants a little easier. Functional Plant Biology, Collingwood, v. 32, p. 481-494, 2005.

KITAJIMA, S., TOMIZAWA, K., SHIGEOKA, S., YOKOTA, A. An inserted loop region of stromal ascorbate peroxidase is involved in its hydrogen peroxide-mediated inactivation. Febs Journal, Oxford, v. 73, p. 2704-2710, 2006.

LEPEDUS, H., CESAR, V., KRSNIK-RASOL, M. Guaiacol Peroxidases in carrot (Daucus carota L.) root. Food Technology and Biotechnology, Zagreb, v. 42, p. 33-36, 2004.

LIMA, J. E., CARVAlHO, R. F., TUlMANN NETO, A., FIGUEIRA, A., PERES, L. E. P. Micro-Msk: a tomato genotype miniature size, short life cycle and improved in vitro shoot regeneration. Plant Science, Clare, v. 167, p. 753-757, 2004.

MEISSNER, R., JACOBSON, Y., MELAMED, S., LEVYATUV, S., SHALEV, G., ASHRI, A., ELKIND, Y., LEVY, A. A new model system for tomato genetics. Plant Journal, Oxford , v. 12, p. 1465-1472, 1997.

NOCTOR, G., GOMEZ, L., VANACKER, H., FOYER, C.H. Interactions between biosynthesis, compartmentation and transport in the control of glutathione homeostasis and signalling. Journal of Experimental Botany, Oxford, v. 53, p. 1283-1304, 2002.

PANCHUK, I.I., ZENTGRAF, U., VOLKOV, R.A. Expression of the Apx gene family during leaf senescence of Arabidopsis thaliana. Planta, New York, v. 222, p. 926-932, 2005. 
PAULY, N., PUCCIARIELLO, C., MANDON, K., INNOCENTI, G., JAMET, A., BAUDOUIN, E., HEROUART, D., FRENDO, P., PUPPO, A. Reactive oxygen and nitrogen species and glutathione: key players in the legume - Rhizobium symbiosis. Journal of Experimental Botany, Oxford, v. 57, p. 1769-1776, 2006.

PITZSCHKE, A., FORNAZI, C., HIRT H. Reactive oxygen species signaling in plants. Antioxidant \& Redox Signalling, Columbus, v. 8, p. 1757-1764, 2006.

REUMANN, S., WEBER, A.P.M. Plant peroxisomes respire in the light: some gaps of the photorespiratory C-2 cycle have become filled - others remain. BBA-Mol.ecular Cell Research, New York, v. 1763, p. 1496-1510, 2006.

SCANDALIOS, J.G., ACEVEDO, A., RUZSA, S. Catalase gene expression in response to chronic high temperature stress in maize. Plant Science, Clare, v. 156, p. 103-110, 2000.

SEN RAYCHAUDHURI, S., DENG, X.W. The role of superoxide dismutase in combating oxidative stress in higher plants. Botanical Review, New York, v. 66, p. 89-98, 2000.

SUN, H.J., UCHII S., WATANABE S., EZURA H. A high efficient transformation protocol for Micro-Tom, a Model cultivar for tomato functional genomics. Plant Cell Physiology, Oxford, v. 47, p. 426-431, 2006.

TEIXEIRA, F.K., MENEZES-BENAVENTE, L., GALVÃO, V.C., MARGIS, R., MARGISPINHEIRO, M. Rice ascorbate perooxidase gene family encondes functionally diverse isoforms localized in different subcellular compartments. Planta, New York, v. 224, p. 300-314, 2006.

VITÓRIA, A.P., LEA, P.J., AZEVEDO, R.A. Antioxidant enzymes responses to cadmium in radish tissues. Phytochemistry, Oxford, v. 57, p. 701-710, 2001.

XIANG, C., OLIVER, D.J. Glutathione metabolic genes coodinately respond to heavy metals and jasmonic acid in Arabidopsis. Plant Cell, Rockville, v. 10, p. 1539-1550, 1998. 
4 RESPOSTA ANTIOXIDATIVA DE Lycopersicon esculentum CV MICRO-TOM AO CÁDMIO

\section{Resumo}

O efeito do Cd em plantas de Lycopersicon esculentum cv Micro-Tom foi identificado nos estágios de 40 e 104 dias de desenvolvimento. A inibição de crescimento e a peroxidação lipídica ocorreram principalmente quando as plantas foram submetidas a $0,5 \mathrm{mM}$ e $1,0 \mathrm{mM} \mathrm{CdCl}$. $\mathrm{O}$ aumento nas atividades de todas as enzimas antioxidantes testadas foi diferentemente induzido para cada concentração do metal. As respostas antioxidativas ao Cd foram aparentemente suficientes para evitar o estresse oxidative. A atividade de GR foi contrária àquela observada para as duas peroxidases analisadas, CAT e GPOX, exibindo a atividade mais baixa nas raízes para as baixas concentrações do metal e atividade mais alta nas folhas. No caso dos frutos, as atividades de CAT, GPOX e GR foram mais intensas nas plantas submetidas às concentrações crescentes do metal $(0,0 \mathrm{mM}-1,0 \mathrm{mM} \mathrm{CdCl})_{2}$.

Palavras chave: Enzimas antioxidantes; Cádmio; Tomate; Estresse oxidativo 


\title{
4 ANTIOXIDANT RESPONSE OF Lycopersicon esculentum CV MICRO-TOM TO CADMIUM
}

\begin{abstract}
We have determined the effects of Cd on plants of Lycopersicon esculentum cv MicroTom at 40 and 104-days after sowing. Inhibition of growth and lipid peroxidation occurred principally when plants were grown at $0.5 \mathrm{mM}$ and $1.0 \mathrm{mM} \mathrm{CdCl}_{2}$. Increases in the activities of all of the four enzymatic antioxidant defence systems tested were induced, but at different concentrations of metal. Overall, the cellular antioxidant responses to Cd were apparently sufficient to avoid oxidative stress. The activity trend GR was contrary to that observed for the two peroxidises analyzed, CAT and GPOX, exhibiting the lowest activity in the roots for low Cdconcentrations and the highest in the leaves. In the case of fruits, CAT, GPOX and GR were more intense at crescent concentration $\left(0.0 \mathrm{mM}-1.0 \mathrm{mM} \mathrm{CdCl}_{2}\right)$.
\end{abstract}

Keywords: Antioxidant enzymes; Cadmium, Tomato; Oxidative stress 


\subsection{Introdução}

A poluição ambiental tornou-se muito mais importante do que previamente havia-se assumido. Neste sentido, os metais pesados podem permanecer no ambiente por um longo período de tempo, causando danos severos ao ambiente e à saúde humana (AZEZEDO; AZEVEDO, 2006; PRZEDPELSKA; WIERZBICKA, 2007). A contaminação de solos, sedimentos e água com o cádmio (Cd), que está entre um dos metais pesados mais tóxicos, provoca grandes perdas na produtividade de plantas e efeitos danosos na saúde (GRATÃO et al., 2005; GRATÃO et al., 2006b).

O Cd é tóxico aos humanos, animais e plantas mesmo em baixas concentrações (MOBIN; KHAN, 2007; WAHID; GHANI, 2007), afetando o metabolismo de plantas e induzindo o estresse oxidativo (BENAVIDES et al., 2005; GOMES-JUNIOR et al., 2006). Entretanto, a intensidade do estresse depende da espécie, concentração do metal e duração da exposição (BENAVIDES et al., 2005). Embora toda a informação centralizada no estresse oxidativo causado pelo Cd seja foco de muita pesquisa nos últimos anos, ainda é difícil tirar uma conclusão geral sobre as concentrações tóxicas nos solos.

Sob condições normais de crescimento, ocorre baixa produção de espécies ativas de oxigênio (EAOs) nas células. Entretanto, condições adversas que interferem na homeostase celular, pode levar ao estresse oxidativo e eventualmente à danos nas membranas celulares, proteínas e DNA (GRATÃO et al., 2006a; PITZSCHKE et al., 2006). Uma vez formadas, estas EAOs devem ser desintoxicadas com eficiência através de mecanismos antioxidantes que são capazes de evitar que estas EAOs se convertam em radicais destrutivos. Assim, a toxicidade das EAOs pode estar relacionada com a evolução de complexos arranjos de mecanismos antioxidantes não enzimáticos e enzimáticos que interrompem as cascatas descontroladas de oxidação (GRATÃO et al., 2005, PITZSCHKE et al., 2006).

Os mecanismos de defesa às EAOs nas plantas incluem enzimas como superóxido dismutase (SOD, EC 1.15.1.1) que dismuta $\mathrm{O}_{2}{ }^{\bullet-}$ à $\mathrm{H}_{2} \mathrm{O}_{2}$. Subsequentemente, o $\mathrm{H}_{2} \mathrm{O}_{2}$ pode ser desintoxicado pela ascorbato peroxidase (APX, EC 1.11.1.11), catalase (CAT, 1.11.1.6) particularmente nos peroxissomos (IGAMBERDIEV; LEA, 2002) e glutationa peroxidase (GPX, EC 1.11.1.9) (GRATÃO et al., 2005). Para a desintoxicação do $\mathrm{H}_{2} \mathrm{O}_{2}$, compostos fitofenólicos agem como antioxidantes pela doação de elétrons a guaiacol peroxidase (GPOX, EC 1.11.1.7) (SAKIHAMA et al., 2002). No ciclo ascorbato-glutationa, ocorre a regeneração da glutationa 
reduzida (GSH) através da glutationa oxidada (GSSG) mediado pela glutationa redutase (GR, EC 1.6.4.2) que usa NAD(P)H como agente redutor (MOLLER et al., 2007).

Sistemas modelos são bem utilizados para explorar fenômenos biológicos, que são estendidos a outros sitemas. Com esta finalidade, o tomate é considerado um material excelente para análises bioquímicas e fisiológicas (LIMA et al., 2004). Além disso, o tomate pode ser um modelo importante para o estudo de frutos carnosos (SUN et al., 2006). Com este propósito, foi proposta a utilização do cultivar miniatura do tomate Micro-Tom como modelo genético, em função do seu pequeno tamanho, da produção de frutos e sementes viáveis e ciclo de desenvolvimento curto, variando entre 70 e 100 dias (MEISSNER et al., 1997). Além disso, este cultivar (cv) pode crescer em laboratório com a mesma estrutura mínima requerida pela Arabidopsis.

Assim, o objetivo deste trabalho foi o estudo dos efeitos do Cd no metabolismo do cv Micro-Tom, através das análises de parâmetros relacionados à peroxidação lipídica e ao sistema antioxidante enzimático. A informação preveniente deste estudo será utilizada para melhorar nosso entendimento sobre os mecanismos básicos relacionados à fitotoxicidade causada por este metal através do uso destes antioxidantes como marcadores de estresse.

\subsection{Material e métodos}

\subsubsection{Material}

O cultivar Micro-Tom foi gentilmente fornecido pelo Dr A. Levy (Weizmann Institute of Science, Israel). As sementes foram semeadas em caixas contendo uma mistura de substrato orgânico inerte (Plantmax HT Eucatex, Brazil) e vermiculita, na proporção 1:1, suplementado com 1 g de NPK 10. 10. 10 por litro de substrato e 4 g de calcário dolomítico $(\mathrm{Ca}+\mathrm{Mg}$ ) por litro de substrato.

Posteriormente, o trasplantio foi realizado com plântulas contendo pelo menos um par de folhas bem desenvolvidas, além das cotiledonares. As plântulas foram transplantas para vasos de Leonard (VINCENT, 1975), preenchidos com areia e isopor (na proporção de 4:3, repectivamente) e solução nutritiva de Hoagland's (HOAGLAND; ARNON, 1950). Após seis dias, plantas uniformes foram selecionadas para o crescimento na mesma solução contendo 0,0 $\mathrm{mM}$ (controle), 0,05 mM, 0,1 mM, 0,2 mm, 0,5 mm e 1,0 $\mathrm{mM} \mathrm{CdCl}_{2}$, sendo que algumas plantas 
foram submetidas a soluções crescentes do metal $(0,0 \mathrm{mM}$ à $1,0 \mathrm{mM} \mathrm{CdCl} 2)$. A solução foi trocada a cada seis dias, mantendo os níveis da concentração do metal e da evaporação constantes. Após 40 e 104 dias de desenvolvimento, raízes, folhas e frutos foram coletados, lavados e estocados a $-80{ }^{\circ} \mathrm{C}$ para análises posteriores.

\subsubsection{Peroxidação lipídica}

A peroxidação lipídica foi determinada pela estimativa do conteúdo de substânica reativas ao ácido tiobarbitúrico (TBARS) seguindo o método de Heath e Packer (1968). A concentração do equivalente malondialdeído (MDA) foi calculada usando o coeficiente de extinção molar de $155 \mathrm{mM} \mathrm{cm}^{-1}$.

\subsubsection{Extração e análise das enzimas antioxidantes}

As amostras foram homogeinizadas (2:1 volume do tampão de extração para o peso fresco do tecido) num mortar com tampão fosfato de potássio $100 \mathrm{mM}$ (pH 7.5) contendo $1 \mathrm{mM}$ de ácido etilenodiamino tetra-acético (EDTA), $3 \mathrm{mM}$ de ditiotreitol (DTT) e 5\% de polivinilpolipirrolidona (PVPP) (AZEVEDO et al., 1998). O homogeinizado foi centrifugado a 10.000 g durante 30 minutos e o sobrenadante foi mantido estocado em alíquotas separadas a -80 ${ }^{\circ} \mathrm{C}$, para as análises de CAT, GPOX e GR (GOMES-JUNIOR et al., 2007). A atividade de GPOX foi avaliada pela monitoração da absorbância à $450 \mathrm{~nm}$. Uma unidade de atividade da enzima (u) correspondeu ao aumento de 0,001 na absorbância por minuto.

Os frutos e raízes submetidos à concentração de $1,0 \mathrm{mM}$ de $\mathrm{CdCl}_{2}$ não foram utilizadas para os ensaios das enzimas antioxidantes. Este fato deve-se aos efeios tóxicos do metal, que impossibilitou a obtenção de raízes e frutos viáveis para estas análises.

\subsubsection{Eletroforese em gel de poliacrilamida (PAGE) e atividade enzimática}

As análises de eletroforese foram conduzidas em condições não desnaturante sob $10 \%$ de poliacrilamida, com a mesma quantidade de proteína aplicada em cada canaleta. Posteriormente, os géis foram submetidos a soluçãoes reveladoras espefícicas para a SOD de acordo como descrito por Gomes-Junior et al. (2006). Os tampões de eletroforese e géis de eletroforese fioram 
preparados como descritos por Vitória et al. (2001), com a exceção do dodecil sulfato de sódio (SDS).

\subsubsection{Determinação da concentração de proteína}

A concentração de proteína para todas as amostras foi determinada pelo método de Bradford (1976), utilizando-se a albumina de soro bovina (BSA) como padrão proteico.

\subsubsection{Análise estatística}

O delineamento experimental utilizado foi em blocos casualizados com três repetições para cada vaso, sendo que os resultados foram apresentados através de média e desvio padrão de três replicatas independentes para MDA, CAT, GPOX e GR.

\subsection{Resultados}

\subsubsection{Crescimento das plantas e peroxidação lipídica}

Experimentos preliminares com diferentes concentrações de Cd foram realizados para a determinação das concentrações de Cd que causavam inibição de crescimento. As duas maiores concentrações do metal utilizadas $\left(0,5\right.$ e $1,0 \mathrm{mM}$ de $\left.\mathrm{CdCl}_{2}\right)$ resultaram em inibição do crescimento, particularmente na concentração mais alta (Figura 4.1). Baseado nestas análises, experimentos posteriores foram conduzidos para as análises das enzimas antioxidantes. 

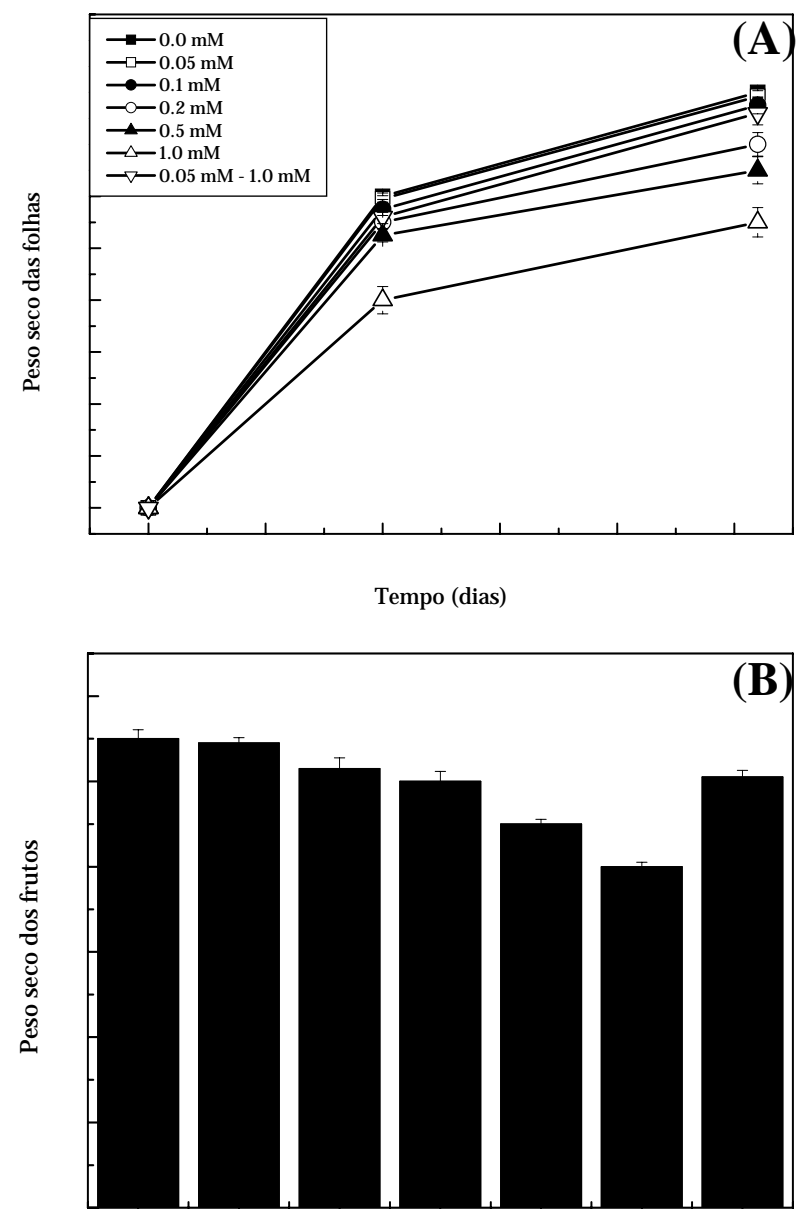

Concentracõos de Cd

Figura 4.1 - Crescimento (peso seco em g) das folhas (A) e frutos (B). Os valores são as médias de 3 repetições. 1 - $0.0 \mathrm{mM} \mathrm{CdCl}_{2} ; 2$ - 0,05 $\mathrm{mM} \mathrm{CdCl}_{2} ; 3$ - 0,1 $\mathrm{mM} \mathrm{CdCl}_{2 ;} 4$ - 0,2 $\mathrm{mM} \mathrm{CdCl}_{2 ;} 5$ $0,5 \mathrm{mM} \mathrm{CdCl}_{2 ;} 6$ - 1,0 $\mathrm{mM} \mathrm{CdCl}_{2}$ e 7 - (0,0 $\left.\mathrm{mM} \mathrm{CdCl}_{2}-1,0 \mathrm{mM} \mathrm{CdCl}_{2}\right)$

As EAOs reagem com ácidos graxos insaturados e causam a peroxidação de lipídeos nas membranas (GRATÃO et al., 2005). A provável indução de Cd na peroxidação lipídica foi determinada pela concentração de TBARS nas raízes, folhas e frutos. O aumento da concentração de TBARS foi observado para todas os tecidos, sendo mais proeminente para a concentração mais alta do metal aplicado (1,0 mM de $\mathrm{CdCl}_{2}$ ) (Figura 4.2).

O grau de peroxidação lipídica variou pouco nas folhas tratadas com Cd no período de 40 dias (Figura 4.2), diferentemente ao observado para as raízes, durante o mesmo tempo (Figura 4.2). Estas observações demonstram claramente que desordens oxidativas causadas pelo Cd faz parte da expressão da toxicidade do metal nas raízes de tomate em função do aumento da 
peroxidação lipídica. As plantas submetidas às concentrações crescentes $(0,0 \mathrm{mM}-1,0 \mathrm{mM}$ $\mathrm{CdCl}_{2}$ ) mostraram valores similares aos controles e às concentrações mais baixas nas raízes, folhas e frutos (Figura 4.2).
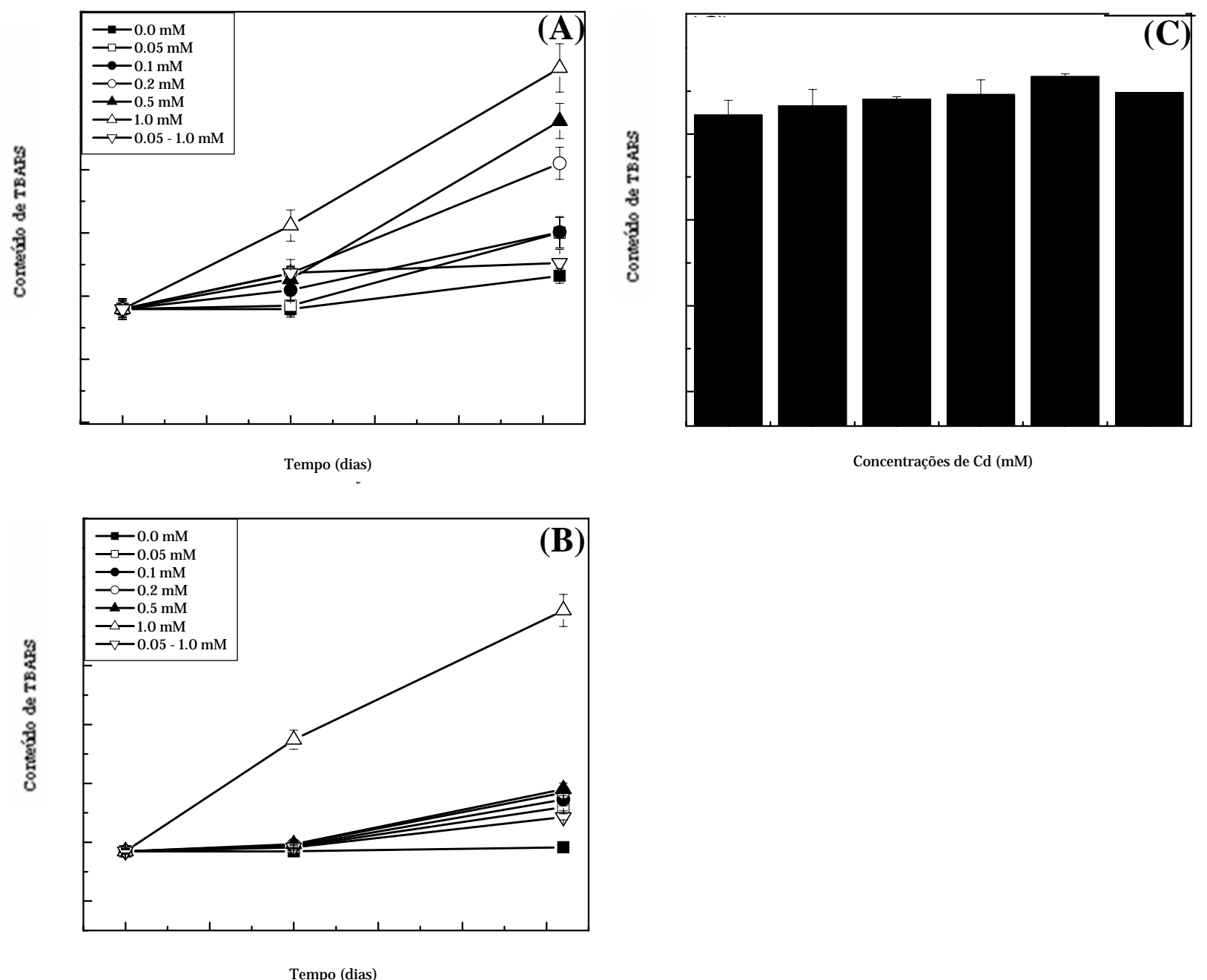

Figura 4.2 - Conteúdo de TBARS (nmol g ${ }^{-1}$ tecido fresco) nas raízes (A); folhas (B) e frutos (C). 1 - 0.0 $\mathrm{mM} \mathrm{CdCl} ; 2$ - $0,05 \mathrm{mM} \mathrm{CdCl}_{2} ; 3-0,1 \mathrm{mM} \mathrm{CdCl}_{2 ;} 4$ - 0,2 $\mathrm{mM} \mathrm{CdCl}_{2 ;} 5$ - 0,5 $\mathrm{mM} \mathrm{CdCl}_{2 ;} 6-$ $0,0 \mathrm{mM}-1,0 \mathrm{mM} \mathrm{CdCl}_{2}$ Os valores são as médias de três repetições

\subsubsection{Atividades enzimáticas}

A atividade de CAT determinada nos ensaios espectrofotométricos mostrou-se variável nos diferentes tecidos analisados. A atividade de CAT nas raízes não exibiu maiores variações na concentração de $0,5 \mathrm{mM} \mathrm{CdCl}_{2}$ durante o experimento, diferentemente do observado para as 
menores concentrações do metal $\left(0,05 \mathrm{mM}\right.$ e 0,1 $\left.\mathrm{mM} \mathrm{CdCl}_{2}\right)$ (Figura 4.3). Contrariamente, nas folhas, a concentração de 0,5 mM induziu aumento na atividade quando comparadas com o controle após 40 dias de exposição. Entretanto, a maior atividade de CAT nas folhas foi aquela observada na concentração de 0,2 mM Cd (Figura 4.3). Nos frutos, a atividade de CAT foi maior nas plantas submetidas às concentrações crescentes do metal (0,0 mM - 1,0 mM Cd) (Figura 4.3).

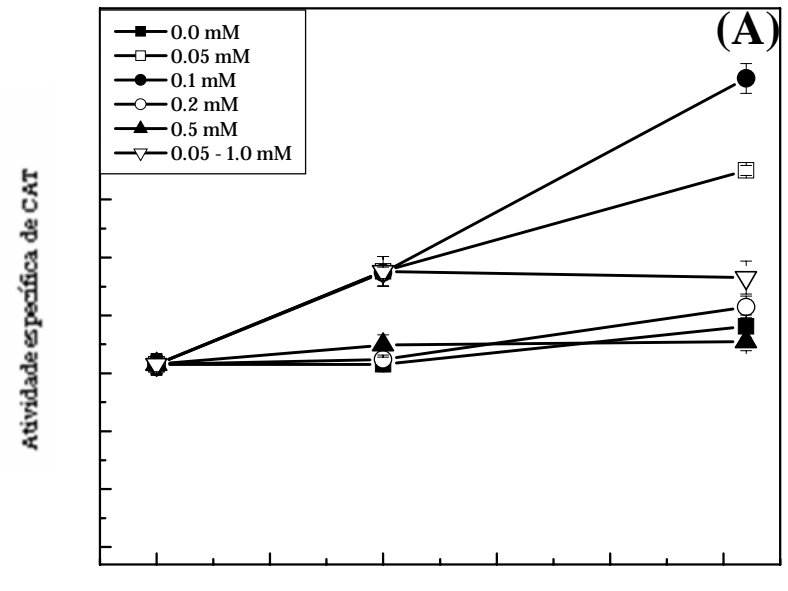

Tempo (dias)

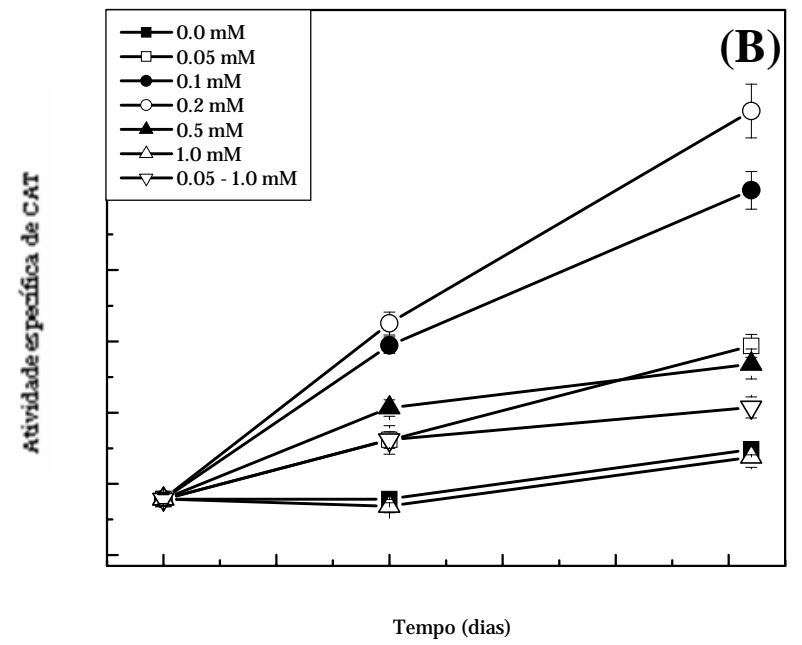

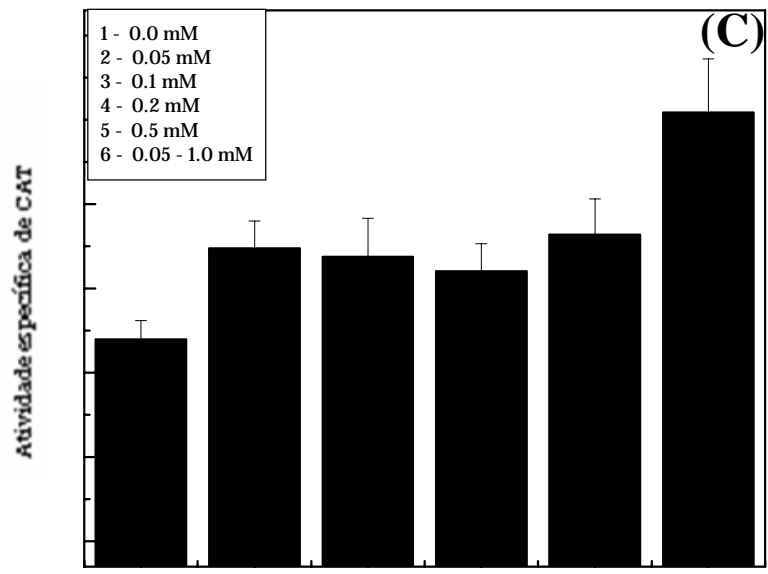

Concentrações de Cd (mM)

Figura 4.3 - Atividade específica de CAT ( $\mu$ mol $\mathrm{min}^{-1} \mathrm{mg}^{-1}$ proteína) em raízes (A); folhas (B) e frutos (C).

A atividade da GPOX foi também determinada em plantas de tomate expostas ao Cd. A atividade da GPOX foi imediatamente estimulada nas raízes pela concentração de 0,5 mM Cd quando comparadas aos controles, aos quais foram seguidas por um rápido decréscimo de atividade após 40 dias de exposição (Figura 4.4). Em folhas submetidas a 0,5 mM Cd, a atividade de GPOX não seguiu o mesmo padrão apresentado pelas raízes (Figura 4.4). Em contraste, nas 
plantas submetidas às concentrações crescentes $(0,0 \mathrm{mM}-1,0 \mathrm{mM} \mathrm{Cd})$, o metal induziu o aumento mais expressivo nos frutos, quando este foram comparados aos controles (Figura 4.4).

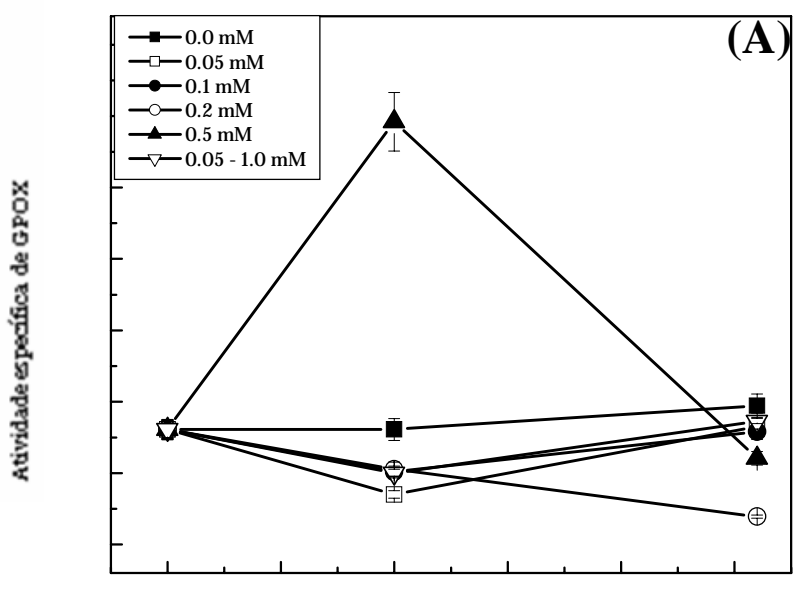

Tempo (dias)

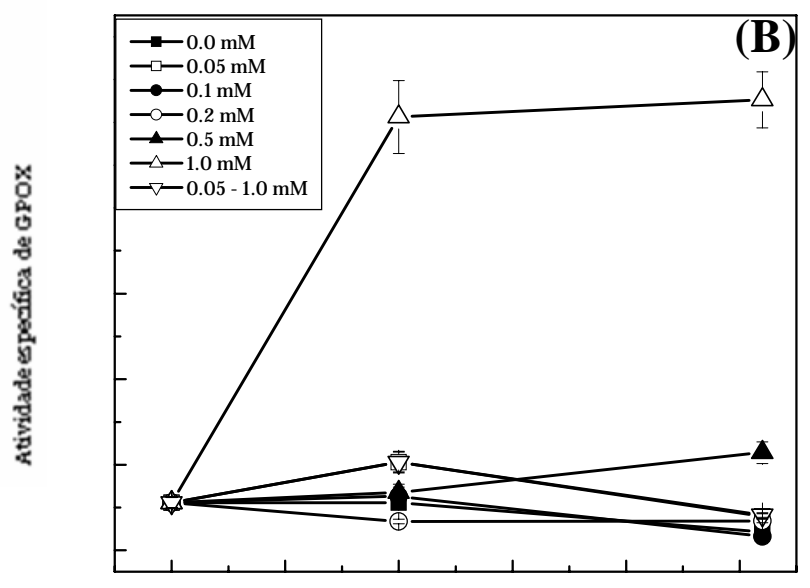

Tempo (dias)

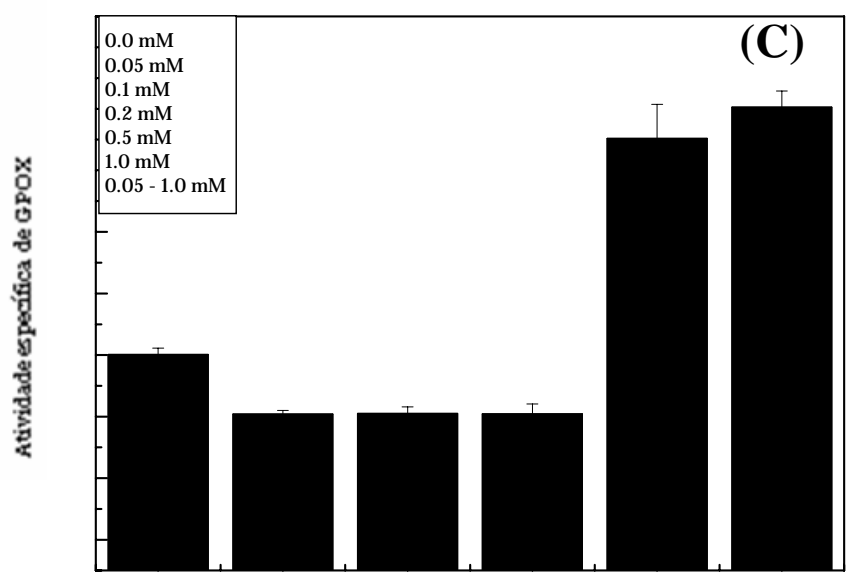

Concentrações de $\mathrm{Cd}(\mathrm{mM})$

Figura 4.4 - Atividade específica de GPOX (u) em raízes (A); folhas (B) e frutos (C).

Após um rápido aumento da atividade de GR nos 40 dias de crescimento, a atividade desta enzima decresceu nas raízes submetidas a 0,5 $\mathrm{mM} \mathrm{CdCl}_{2}$ comparadas ao controle (Figura 4.5). Por outro lado, a atividade de GR nas folhas submetidas a $0,5 \mathrm{mM} \mathrm{CdCl} 2$ permaneceu próxima a atividade do controle nos 40 dias, decrescendo após este período (Figura 4.5). Nos frutos, o máximo de atividade de GR foi observado nas plantas submetidas às concentrações 


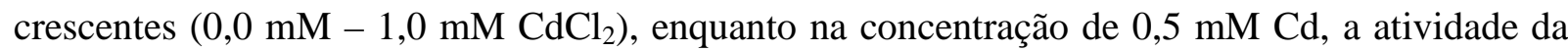
GR foi similar para as concentrações de 0,1 e 0,2 mM Cd (Figura 4.5).
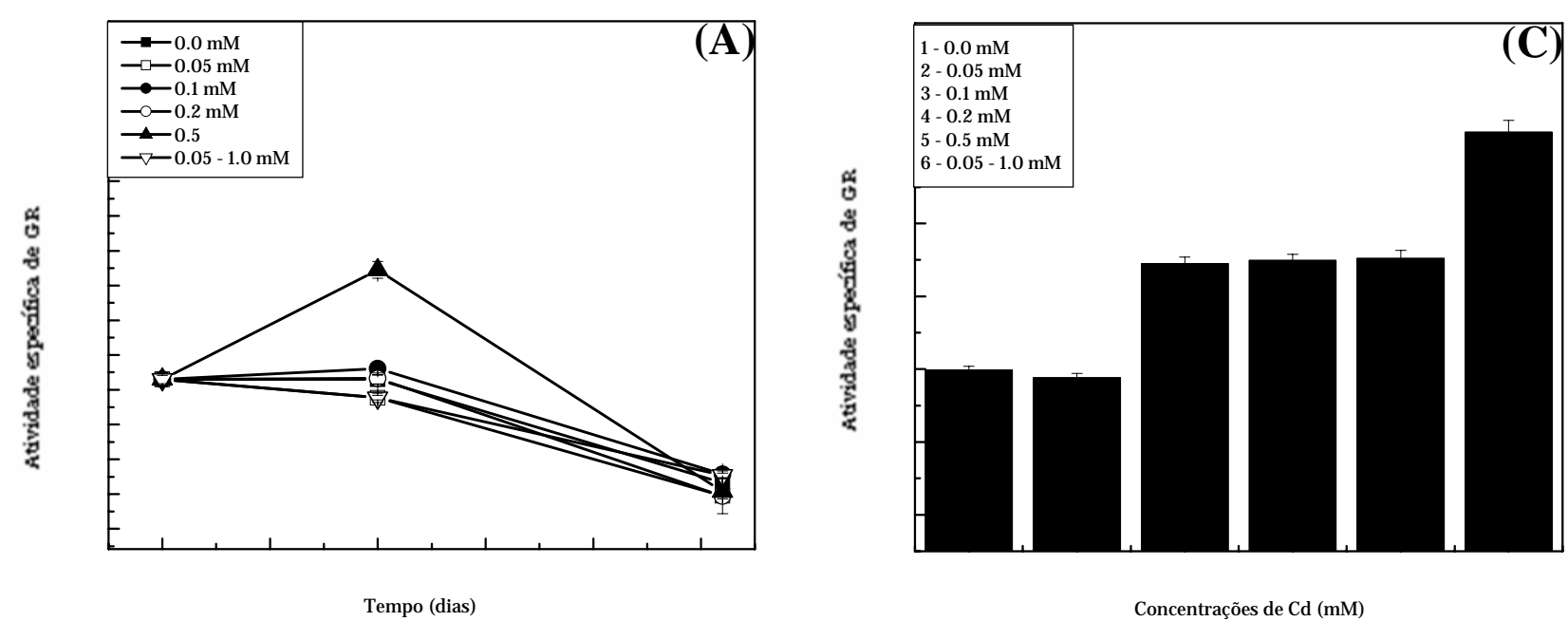

Concentrações de $\mathrm{Cd}(\mathrm{mM})$

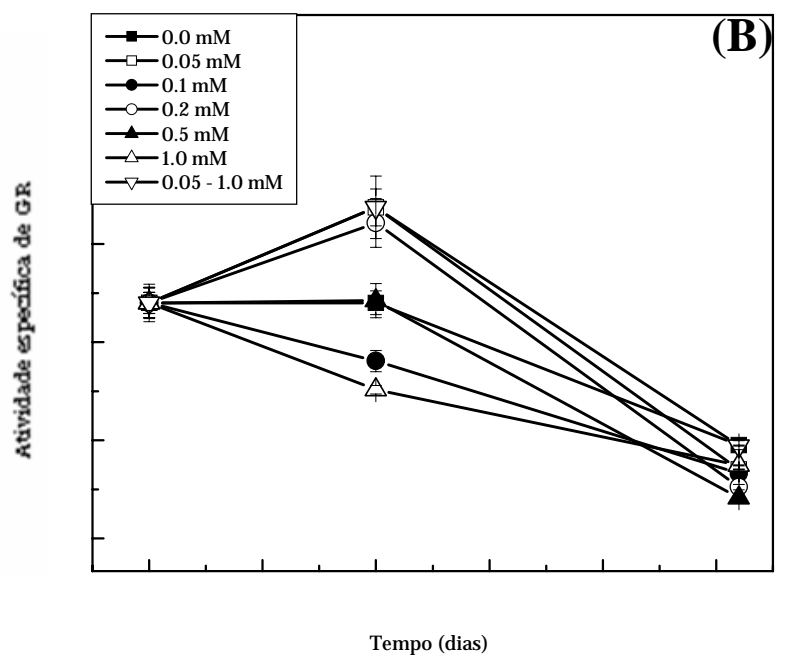

Figura 4.5 - Atividade específica de GR ( $\mu \mathrm{mol} \mathrm{min}^{-1} \mathrm{mg}^{-1}$ proteína) em raízes (A); folhas (B) e frutos (C)

As bandas da atividade de SOD representam a presença de isoenzimas que foram observadas seguindo técnicas de revelação de um PAGE nativo. Embora as análises densitoméricas não tenham sido realizadas, foi possível observar claramente diferenças de intensidade entre as isoenzimas em resposta ao $\mathrm{Cd}$.

A atividade de SOD revelou a existência de três isoenzimas nas folhas (bandas I, II e III) (Figura 4.6). Duas destas isoenzimas (bandas I e III) exibiram um decréscimo de intensidade em resposta a 0,2, 0,5 e 1,0 mM Cd, enquanto a banda II exibiu aumento de intensidade para as 
concentrações de 0,2, 0,5 e 1,0 mM de Cd (Figura 4.6). No caso das plantas submetidas às concentrações crescentes de metal (0,0 mM - 1,0 mM Cd), a intensidade das bandas I e III foram similares ao controle e da concentração mais baixa do metal aplicada.

Diferente ao observado nas folhas, a atividade da SOD revelou a presença de duas isoenzimas nas raízes (bandas I e II) e frutos (bandas I e II) (Figura 4.6). Nas raízes, as bandas I e II exibiram decréscimos de atividade nas concentrações de 0,2 and 0,5 mM Cd, em contraste ao obervado nos frutos, onde uma banda (a mais eletropositiva) pereceu responder especificamente ao Cd, decrescendo sua atividade nas concentrações de 0,2 e 0,5 mM Cd (Figura 4.6). Com relação às plantas submetidas às concentrações crescentes de metal $(0,0 \mathrm{mM}-1,0 \mathrm{mM} \mathrm{Cd})$, as atividades das duas bandas, tanto nas raízes quanto nos frutos foram mais intensas do que as concentrações de 0,2 mM e 0,5 mM Cd (Figura 4.6).

Como já mencionado, a concentração de 1,0 mM de Cd foi apenas utilizada para as análises de folhas. Essa concentração não foi utilizada para os outros tecidos (raízes e frutos) para análises comparativas das enzimas antioxidantes, mas a informação disponível neste trabalho sobre esta concentração nas folhas não deixa de ser importante para o entendimento dos mecanismos envolvidos na toxicidade do metal em um sistema modelo importante como o Micro-Tom. Além disso, estas informações serão utilizadas no projeto principal que está sendo conduzido por nosso laboratório com mutantes hormonais já disponíveis neste cultivar. Estes mutantes serão submetidos ao crescimento na presença do Cd com o objetivo de investigar a provável integração dos sinais externos (ambientais) e endógenos (hormonais) na fitotoxicidade e resistência a fatores de estresse. 

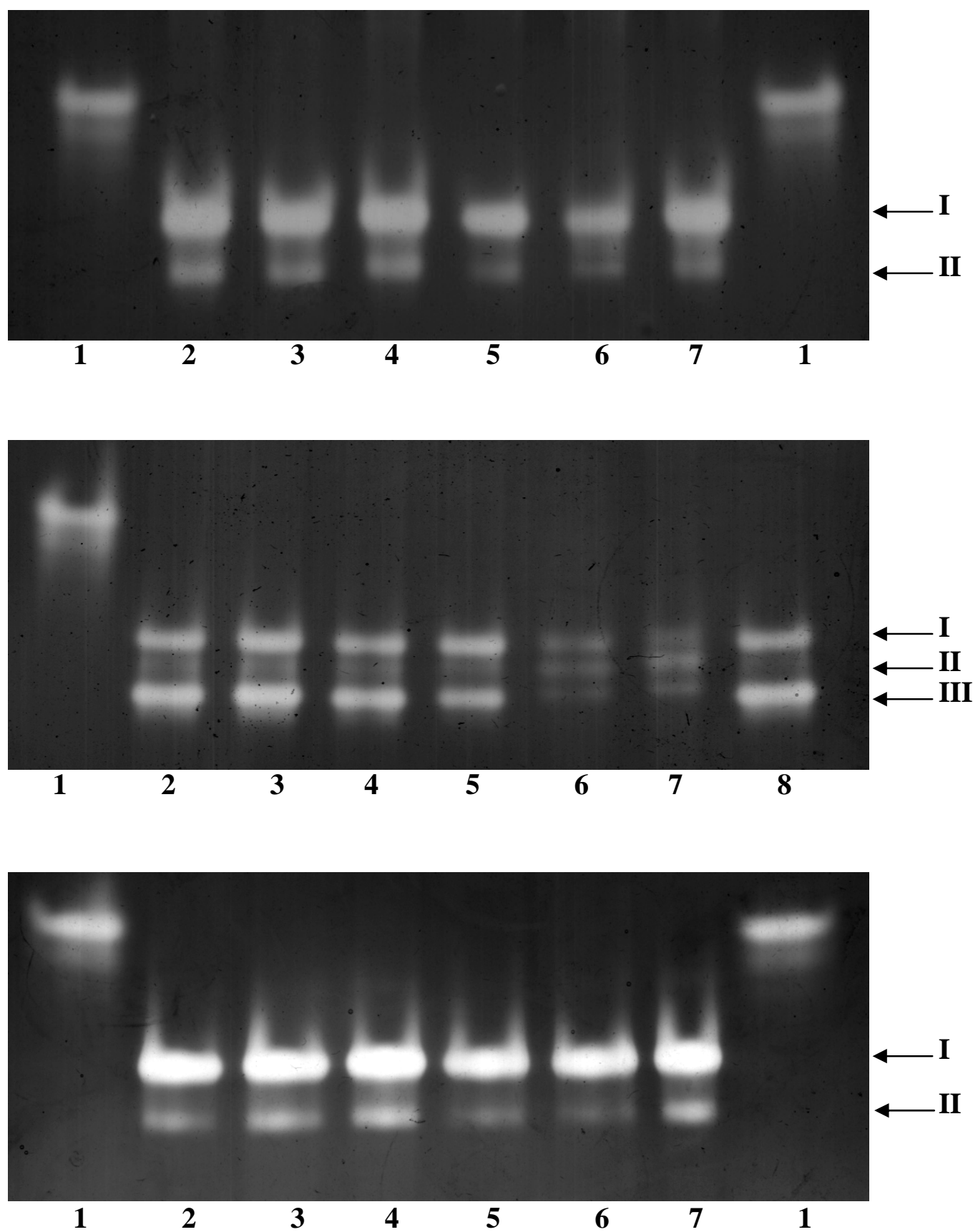

Figura 4.6 - Atividade de SOD seguindo o PAGE native de extratos de raízes (A), folhas (B) e frutos (C) durante o perídodo de 104 dias: (A) Linha 1, padrão de SOD bovina; linha 2, controle (zero $\mathrm{CdCl}_{2}$ ); linha 3, $0.05 \mathrm{mM} \mathrm{CdCl}_{2}$; linha 4, $0.1 \mathrm{mM} \mathrm{CdCl}_{2}$; linha 5, $0.2 \mathrm{mM} \mathrm{CdCl}_{2}$; linha 6, 0.5 $\mathrm{mM} \mathrm{CdCl}_{2}$; linha 7, $0.0 \mathrm{mM}$ - $1.0 \mathrm{mM} \mathrm{CdCl}_{2}$. (B) Linha 1, padrão de SOD bovino; linha 2, control (zero $\mathrm{CdCl}_{2}$ ); linha 3, $0.05 \mathrm{mM} \mathrm{CdCl}_{2}$; linha 4, $0.1 \mathrm{mM} \mathrm{CdCl}_{2}$; linha 5, $0.2 \mathrm{mM}$ $\mathrm{CdCl}_{2}$; linha 6, $0.5 \mathrm{mM} \mathrm{CdCl}_{2}$; linha 7, $1.0 \mathrm{mM} \mathrm{CdCl}_{2}$; e linha 8, $0.0 \mathrm{mM}-1.0 \mathrm{mM} \mathrm{CdCl}_{2}$. (C) Linha 1, padrão de SOD bovina; linha 2, controle (zero $\mathrm{CdCl}_{2}$ ); linha 3, $0.05 \mathrm{mM} \mathrm{CdCl}_{2}$; linha 4, $0.1 \mathrm{mM} \mathrm{CdCl}_{2}$; linha 5, $0.2 \mathrm{mM} \mathrm{CdCl}_{2}$; linha 6, $0.5 \mathrm{mM} \mathrm{CdCl}_{2}$; linha 7, $0.0 \mathrm{mM} \mathrm{-} 1.0$ $\mathrm{mM} \mathrm{CdCl} 2$ 


\subsection{Discussão}

Neste estudo, o crescimento das plantas de Micro-Tom foi inibido quando estas foram expostas às altas concentrações de Cd (Figura 4.1), também demonstrado através da peroxidação lipídica (Figura 4.2). As quantidades de Cd que são normalmente encontradas no ambiente são baixas, entretanto estas concentrações podem ser significativamente altas pela forte pressão antropogênica (GRATÃO et al., 2005). O Cd é um elemento não essencial na nutrição de plantas que pode inibir o crescimento (MEDIOUNI et al., 2006; LIU et al., 2007) e estimular a produção de EAOs, o que resulta em várias perturbações metabólicas (YAKIMOVA et al., 2006; DURCEKOVA et al., 2007).

De acordo com os resultados, as concentrações de Cd induziram estresse oxidativo através do aumento da quantidade de TBARS (Figura 4.2), especialmente nas concentrações mais altas testadas. A indução da peroxidação lipídica é um dos maiores efeitos decorrente do aumento das EAOs e funciona como um indicador de estresse oxidativo (DEWIR et al., 2006). O Cd parece não gerar radicais livres diretamente, mas pode elevar a peroxidação lipídica contribuindo para o processo de danos celulares (GRATÃO et al., 2006b).

O malondialdeído (MDA) é um dos metabólitos que reage ao ácido 2-tiobabitúrico (TBA), sendo um dos compostos de baixo peso molecular formados via decomposição dos produtos primários e secundários da peroxidação lipídica (DEWIR et al., 2006). O Cd pode induzir aumentos nos níveis de $\mathrm{H}_{2} \mathrm{O}_{2}$, que consequentemente aumenta os níveis de MDA em folhas de arroz (HSU; KAO, 2007), plântulas de tomate (MEDIOUNI et al., 2006), Phaseolus coccineus (SKORYNSKA-POLIT; KRUPA, 2006), Bacopa monnieri L (MISHRA et al., 2006), Lemna polyrrhiza (JOHN et al., 2007) e Brassica juncea (MOBIN; KHAN, 2007).

A toxicidade das EAOs explica a evolução do complexo arranjo de mecanismos de desintoxicação não enzimáticos e enzimáticos que contribuem para evitar a dissipação dos elétrons (PAULY et al., 2006). Entre os complexos sistemas antioxidantes enzimáticos, as peroxidases pertencem a uma importante família de enzimas envolvidas nas reações de oxidação do ascorbato, lignificação, defesa à patógenos, elongação da parede celular, etc (PASSARDI et al., 2007). A CAT representa o maior constituinte da matriz de peroxissomos nos tecidos fotossintéticos (REUMANN; WEBER, 2006). Entretanto, sua presença na mitocôndria de plantas é ainda foco de questionamentos (NOCTOR et al., 2007). Neste estudo, a atividade de CAT nas plantas de tomate variou entre as concentrações de Cd utilizadas (Figura 4.3). Além disso, a 
resposta da $\mathrm{CAT}$ ao $\mathrm{Cd}$ foi similar àquela observada nas raízes e folhas, com o aumento predominante sob baixas concentrações. A CAT pode ser regulada pelos níveis de $\mathrm{H}_{2} \mathrm{O}_{2}$ e a atividade aumentada observada sob condições de estresse sugere que para as concentrações de Cd analisadas, alterações significantes na geração de $\mathrm{H}_{2} \mathrm{O}_{2}$ ocorreram e que provavelmente, outros sistemas antioxidantes estavam envolvidos com a resposta ao estresse para as altas concentrações do metal. A quantidade de $\mathrm{H}_{2} \mathrm{O}_{2}$ e outras EAOs não foram mensuradas neste estudo, mas pode-se dizer que provavelmente houve aumento destes compostos provavelmente em função das respostas das enzimas antioxidantes observadas.

As enzimas antioxidantes variam nas respostas ao estresse oxidative induzida por metais. A atividade de CAT aumentou em resposta ao Cd em Allium sativum (ZHANG et al., 2005), Triticum aestivum L. (LIN et al. 2007), plântulas de cevada (DEMIREVSKA-KEPOVA et al., 2006). Por outro lado, decréscimos na atividade desta enzima também foram observados em Bacopa monnieri L. (MISHRA et al., 2006), Pisum sativum L. (RODRIGUEZ-SERRANO et al., 2006) e Miscanthus sinensis (SCEBBA et al., 2006).

Outra peroxidase, a GPOX, utiliza doadores elétrons como a guaiacol e pirogalóis como substratos (ASADA, 1999). Aumentos na atividade de GPOX nas plantas de tomate foram detectadas na resposta ao Cd particularmente na concentração mais alta (Figura 4.4). O papel desta enzima no metabolismo das plantas não está claro, sendo que a resposta desta enzima pode variar consideravelmente dependendo da espécie. Neste estudo, o Cd provavelmente afetou diretamente este sistema enzimático nas raízes, relacionado ao severo efeito das concentrações deste metal cujas atividades foram fortemente inibidas. Provavelmente, neste caso, CAT e enzimas relacionadas ao ciclo ascorbaro -glutationa, como APX, GR e glutationa-S-transferase (GST), parecem ser os principais mediadores nas respostas defensivas ao estresse oxidativo. A resposta desta enzima mostrou-se bastante responsiva em Bacopa monnieri L. (MISHRA et al., 2006), Miscanthus sinensis (SCEBBA et al., 2006) submetidas ao Cd, contrariamente ao observado em Pisum sativum L. (RODRIGUEZ-SERRANO et al., 2006).

O ciclo ascorbato-glutationa, também referido como 'Asada-Foyer-Halliwell', envolve sucessivas oxidaçãos e reduções do ascorbato, glutationa e NADPH pelas enzimas APX, GR, dehidroascorbato redutase (DHAR, EC 1.8.5.1), e monodehidroascorbato redutase (MDHAR, EC 1.6.5.4) (GRATÃO et al., 2005; MOLLER et al., 2007). O aumento na atividade de GR pode estar relacionado com a manutenção da glutationa na forma reduzida para sua incorporação em 
fitoquelatinas (PCs), ou no ciclo ascorbato-glutationa, na desintoxicação das EAOs induzidas por metais.

Nos resultados apresentados em Micro-Tom, a atividade de GR foi afetada significativamente entre os tecidos analisados (Figura 4.5). O aumento da atividade desta enzima foi relatado em espécies como Bacopa monnieri L. (MISHRA et al., 2006) e raízes de plantas de trigo (YANNARELLI et al., 2007), entre outras. Entretanto, a atividade desta enzima foi reduzida em Pisum sativum (RODRIGUEZ-SERRANO et al., 2006).

A SOD é largamente distribuída entre os organismos que consomem $\mathrm{O}_{2}$, sendo responsável pela dismutação do $\mathrm{O}_{2}{ }^{\bullet-}$ em $\mathrm{H}_{2} \mathrm{O}_{2}$, que influencia as concentrações de $\mathrm{O}_{2}{ }^{\bullet-}$ e $\mathrm{H}_{2} \mathrm{O}_{2}$ (SEM RAYCHAUDHURI; DENG, 2000).

As isoenzimas de SOD são compartimentalizadas em plantas superiores e três tipos distintos foram detectados em plantas, classificadas de acordo com o cofator metálico; Mn, Fe e Cu/Zn (ALSCHER et al., 2002). As Mn-SODs estão localizadas nas mitocôndrias e peroxissomos e foram identificdas em várias espécies como ervilha, melancia, pepino, tomate e outras espécies (DEL RIO et al., 2002; DEL RIO et al., 2003). As Fe-SODs estão associadas com os cloroplastos (ALSCHER et al., 2002), enquanto as Cu;Zn-SODs estão localizadas no citosol, cloroplastos e peroxissomos (DEL RIO et al., 2002). Recentemente uma classe distinta de SOD que contem Ni (Ni-SOD) foi identificada em cianobactérias e Streptomyces (BARONDEAU et al., 2004).

A atividade total de SOD foi claramente afetada em todos os tecidos analisados neste estudo, em especial para as concentrações mais altas nas folhas (Figura 4.6). A resposta da SOD a metais tóxicos varia entre espécies, tecidos, estágios de desenvolvimento e tempo de exposição. O aumento da atividade desta enzima é um importante mecanismo para evitar o estresse oxidativo causado por Cd. Este aumento já foi relatado em várias espécies como S. tuberosum (STROINSKI; KOZLOWSKA, 1997), H. vulgare (GUO et al., 2004), A. thaliana (SKORZYNSKA-POLIT et al., 2006), Triticum aestivum L. (LIN et al. 2007), Lemna polyrrhiza (JOHN et al. 2007) e plantas hiperacumuladoras do gênero Alyssum (SCHICKLER; CASPI, 1999).

De acordo com os resultados, a ação tóxica do Cd aumentou a peroxidação lipídica, conduzindo ao aumento das enzimas analisadas. As respostas enzimáticas variaram dependendo da concentração do metal. A CAT parece agir contra o $\mathrm{H}_{2} \mathrm{O}_{2}$ produzido por concentrações baixas em raízes e folhas, enquanto a GPOX parece agir na concentração mais alta. Entretanto, a GR, diferentemente das duas peroxidases, CAT e GPOX, exibiu a menor atividade nas raízes para as 
concentrações baixas do metal e a mais alta atividade, nas folhas. No caso dos frutos, as atividades de CAT, GPOX e GR foram maiores nas plantas submetidas às concentrações crescentes do metal. No caso da SOD, as concentrações mais altas foram tóxicas para esta enzima em todos os tecidos analisados.

Entretanto, os resultados que chamam mais a atenção são aqueles relacionados às plantas submetidas às concentrações crescentes do metal $\left(0,0 \mathrm{mM}-1,0 \mathrm{mM} \mathrm{CdCl}_{2}\right)$. No caso destas plantas, a peroxidação lipídica permaneceu próxima aos valores do controle e das menores concentrações do metal. Neste caso, a eficiência do sistema enzimático e outros compostos antioxidantes estariam envolvidos com uma provável adaptação destas plantas a esta condição de estresse. Este comportamento pode estar relacionado à forma de aplicação do metal, ou seja, sob doses crescentes ao longo do tempo.

Há diferenças entre os efeitos de estresse a curto e longo prazo, que pode ser parcialemente compensados pela aclimatação, adaptação e mecanismos de reparo. Além disso, os eventos de um estresse crônico causam danos consideráveis e podem eventualemente conduzirem a morte das plantas (LICHTENTHALER, 1996). No início do estresse quando as plantas são repentinamente confrontadas com uma situação crítica, com consequente declínio de várias atividades fisiológicas, elas ativam mecanismos metabólicos de reparo e adaptações metabólicas e morfológicas a longo prazo (MCKERSIE; LESHEM, 1994), sendo conduzidas a uma síndrome geral de aclimatação (GAS) ou síndrome geral de adaptação, que representa um esforço geral do organismo para se adaptar a novas condições (LESHEM; KUIPER, 1996).

Muitas questões relacionadas aos papéis de proteção da EAOs e sua modulação na rede de sinalização como processos biológicos que contralam o crescimento, desenvolvimento, resposta ao estresse, adaptação e morte celular programada ainda permanecem não esclarecidas (GECHEV et al., 2006). Todos estes processos dependem das respostas biológicas a da identidade química das EAOs, da intensidade dos sinais, pontos de produção das EAOs, estágio de desenvolvimento das plantas, estresse prévios e interações com outras moléculas sinalizadoras como óxido nítrico, mensageiros lipídicos e fitohormônios (GECHEV et al., 2006).

Baseado em todas as informações disponíveis na literatura, espera-se que seja dado especial atenção a este tipo de experimento em que plantas são submetidas a concentrações crescentes do metal, no intuito de compreender os mecanismos de defesa envolvidos. Este tipo de informação ganha atenção nos estudos que envolvem a integração da genética bioquímica e o melhoramento de plantas. Esta integração envolve a produção de plantas tolerantes ao estresse na 
utilização de programas de fitorremediação de ambientes poluídos por metais pesados, em particular, o Cd.

Nossos resultados colaboram para o entendimento de vários mecanismos básicos da toxicidade provocada pelo Cd. Um estudo mais compreensivo neste aspecto está sendo conduzido por nosso grupo de trabalho com mutantes hormonais do sistema modelo de estudo, o MicroTom. Estes mutantes representam a possibilidade do estudo da integração de sinais ambientais e endógenos na fitotoxicidade e resitência aos fatores de estresse. 


\section{Referências}

ALSCHER, R.G., ERTURK, N., HEATH, L.S. Role of superoxide dismutases (SODs) in controlling oxidative stress in plants. Journal of Experimental Botany, Oxford, v. 53, p. 13311341, 2002.

ASADA, K. The water cycle in chloroplast: scavenging of active oxygens and dissipation of excess photons. Annual Review of Plant Physiology and Plant Molecular Biology, Palo Alto, v. 50, p. 601-639, 1999.

AZEVEDO R.A., ALAS, R.M., SMITH, R.J., LEA, P.J. Response of antioxidant enzymes to transfer from elevated carbon dioxide to air and ozone fumigation, in the leaves and roots of wild-type and a catalase-deficient mutant of barley. Physiologia Plantarum, Oxford, v. 104, p. 280-292, 1998.

AZEVEDO, J.A., AZEVEDO, R.A. Heavy metals and oxidative stress: where do we go from here? Communications in Biometry and Crop Science, Poland, v. 2, p. 135-138, 2006.

BARONDEAU, D.P., KASSMANN, C.J., BRUNS, C.K., TAINER, J.A., GETZOFF, E.D. Nickel superoxide dismutase structure and mechanism. Biochemistry, Madri, v. 43, p. 80388047, 2004.

BENAVIDES, M.P., GALLEGO, S.M., TOMARO, M.L. Cadmium toxicity in plants. Brazilian Journal of Plant Physiology, Piracicaba, v. 17, p. 21-34, 2005.

BRADFORD,.M.M. A rapid and sensitive method for the quantitation of microgram quantities of protein utilizing the principle of protein-dye binding. Analytical Biochemistry, San Diego, v. 72, p. 248-59, 1976.

DEL RIO, L.A., CORPAS, F.J., SANDALIO, L.M., PALMA, J.M., GÓMEZ, M., BARROSO, J.B. Reactive oxygen species, antioxidant systems and nitric oxide in peroxisomes. Journal of Experimental Botany, Oxford, v. 53, p. 1255-1272, 2002.

DEL RIO, L.A., SANDALIO, L.M., ALTOMARE, D.A., ZILINSKAS, B.A. Mitochondrial and peroxisomal manganese superoxide dismutase: differential expression during leaf senescence. Journal of Experimental Botany, Oxford, v. 54, p. 923-933, 2003.

DEMIREVSKA-KEPOVA, K., SIMOVA-STOILOVA, L., STOYANOVA, Z.P., FELLER, U. Cadmium stress in barley: Growth, leaf pigment, and protein composition and detoxification of reactive oxygen species. Journal of Plant Nutrition, Philadelphia, v. 29, p.451-468, 2006.

DEWIR, Y.H, CHAKRABARTY, D., ALI, M.B., HAHN, E.J., PAEK, K.Y. Lipid peroxidation and antioxidant enzyme activities of Euphorbia milii hyperhydric shoots. Environmental and Experimental Botany, Paris, v. 58, p. 93-99, 2006. 
DURCEKOVA, K., HUTTOVA, J., MISTRIK, I., OLLE, M., TAMAS, L. Cadmium induces premature xylogenesis in barley roots. Plant and Soil, Dordretch, v. 290, p.:61-68, 2007.

GECHEV, T.S., VAN BREUSEGEM, F., STONE, J.M., DENEV, I., LALOI, C. Reactive oxygen species as signals that modulate plant stress responses and programmed cell death. Bioessays, Hoboken, v. 28, p. 1091-1101, 2006.

GOMES-JUNIOR, R.A., GRATAO, P.L., GAZIOLA, S.A., MAZZAFERA, P., LEA, P.J., AZEVEDO, R.A. Selenium-induced oxidative stress in coffee cell suspension cultures. Functional Plant Biology, Collingwood, v. 34, p. 449-456, 2007.

GOMES-JUNIOR, R.A., MOLDES, C.A., DELITE, F.S., POMPEU, G.B., GRATAO, P.L., MAZZAFERA, P., LEA, P.J., AZEVEDO, R.A. Antioxidant metabolism of coffee cell suspension cultures in response to cadmium. Chemosphere, Geneva, v. 65, p. 1330-1337, 2006.

GRATÃO, P.L., POLLE, A., LEA, P.J., AZEVEDO, R.A. Making the life of heavy metalstressed plants a little easier. Functional Plant Biology, Collingwood, v. 32, p. 481-94, 2005.

GRATÃO, P.L., GOMES-JUNIOR, R.A., DELITE, F.S., LEA, P.J., AZEVEDO, R.A. Antioxidant Stress Responses of Plants to Cadmium. In: KHAN, N.A; SAMIULLAH. (Ed.). Cadmium Toxicity and Tolerance in Plants. New Delhi: Narosa Publishers, 2006a. chap. 6, p. 1-34.

GRATÃO, P.L., POMPEU, G.B., CARDOSO, P.F., LEA, P.J., AZEVEDO, R.A. Plant antioxidant responses to toxic elements. Current Topics in Biochemical Research, New Delhi, v. 8, p. 40-70, 2006b.

GUO, T.R., ZHANG, G.P., ZHOU, M.X., WU, F.B., CHEN, J.X. Effects of aluminum and cadmium toxicity on growth and antioxidant enzyme activities of two barley genotypes with different Al resistance. Plant and Soil, Dordretch, v. 258, p. 241-248, 2004.

HEATH, R.L., PACKER, L. Photoperoxidation in isolated chloroplast. I. Kinetics and stoiichiometry of fatty acid peroxidation. Archives in Biochemistry Biophysics, Dusseldorf, v. 125, p. 2141-2145, 1968.

HOAGLAND, D., ARNON, D.I. The water culture method for growing plants without soil.In: . The water culture method for growing plants without soil. Berkeley: University California Agricultural Experiment Station, 1950. 34p.

HSU, Y.T., KAO, C.H. Cadmium-induced oxidative damage in rice leaves is reduced by polyamines. Plant and Soil, Dordretch, v. 291, p. 27-37, 2007.

IGAMBERDIEV, A.U., LEA, P.J. The role of peroxisomes in the integration of metabolism and evolutionary diversity of photosynthetic organism. Phytochemistry, Oxford, v. 60, p. 651-674, 2002. 
JOHN, R., AHMAD, P., GADGIL, K., SHARMA, S. Antioxidantive response of Lemna polyrrhiza L. To cadmium stress. Journal of Experimental Biology, Bern, v. 28, p. 583-589, 2007.

LESHEM, Y.Y., KUIPER, P.J.C. Is there a GAS (general adaptation syndrome) response to various types of environmental stress? Biologia Plantarum, Netherlands, v. 38, p. 1-18, September, 1996.

LICHTENTHALER, H.K. Vegetation stress: Na introduction to the stress concept in plants. Journal of Plant Physiology, Jena, v. 148, p. 4-14, 1996.

LIMA, J.E., CARVALHO, R.F., TULMANN NETO, A., FIGUEIRA, A., PERES, L.E.P.: MicroMsk: a tomato genotype miniature size, short life cycle and improved in vitro shoot regeneration. Plant Science, Ireland, v. 167, p. 753-757, 2004.

LIN, R.Z., WANG, X.R., LUO, Y., DU, W.C., GUO, H.Y., YIN, DQ. Effects of soil cadmium on growth, oxidative stress and antioxidant system in wheat seedlings (Triticum aestivum L.). Chemosphere, Geneva, v. 69, p. 89-98, 2007.

LIU, C.P., SHEN, Z.G., LI, X.D. Accumulation and detoxification of cadmium in Brassica pekinensis and B. chinensi. Biologia Plantarum, Netherlands, v. 51, p. 116-120, 2007.

MCKERSIE, B.D., LESHEM, Y.Y. Stress and Stress Coping in Cultivated Plants. In:

Stress and Stress Coping in Cultivated Plants. Dordrecht: Kluwer Academic Publishers, 1994. p. 1-256.

MEDIOUNI, C., BENZARTI, O., TRAY, B., GHORBEL, M.H., JEMAL, F. Cadmium and copper toxicity for tomato seedlings. Agronomical and Sustainable Development, Paris, v. 26 , p.227-232, 2006.

MEISSNER, R., JACOBSON, Y., MELAMED, S., LEVYATUV, S., SHALEV, G., ASHRI, A., ELKIND, Y, LEVY, A. A new model system for tomato genetics. - Plant Journal, Oxford, v. 12, p. 1465-1472, 1997.

MISHRA, S., SRIVASTAVA, S., TRIPATHI, R.D., GOVINDARAJAN, R., KURIAKOSE, S.V., PRASAD, M.N.V. Phytochelatin synthesis and response of antioxidants during cadmium stress in Bacopa monnieri L. Plant Physiology and Biochemistry, Paris, v. 44, p. 25-37, 2006.

MOBIN, M., KHAN, N.A. Photosynthetic activity, pigment composition and antioxidative response of two mustard (Brassica juncea) cultivars differing in photosynthetic capacity subjected to cadmium stress. Journal of Plant Physiology, Jena, v. 164, p. 601-610, 2007.

MOLLER, I.M., JENSEN, P..E, HANSSON, A. Oxidative modifications to cellular components in plants. Annual Review in Plant Biology, Oxford, v. 58, p. 459-481, 2007.

NOCTOR, G., DE PAEPE, R., FOYER, C.H. Mitochondrial redox biology and homeostasis in plants. Trends in Plant Science, London, v.;12, p. 125-134, 2007. 
PASSARDI, F., THEILER, G., ZAMOCKY, M., COSIO, C., ROUHIER, N., TEIXERA, F., MARGIS-PINHEIRO, M., IOANNIDIS, V., PENEL, C., LAND DUNAND, C. PeroxiBase: The peroxidase database. Phytochemistry, Oxford, v. 68, p. 1605-1611, 2007.

PAULY, N., PUCCIARIELLO, C., MANDON, K., INNOCENTI, G., JAMET, A., BAUDOUIN, E., HEROUART, D., FRENDO, P., PUPPO, A. Reactive oxygen and nitrogen species and glutathione: key players in the legume - Rhizobium symbiosis. Journal of Experimental Botany, Oxford, v. 57, p. 1769-1776, 2006.

PITZSCHKE, A., FORNAZI, C., HIRT H. Reactive oxygen species signalling in plants. Antioxidants \& Redox Signalling, Columbus, v. 8, p. 1757-1764, 2006.

PRZEDPELSKA, E., WIERZBICKA, M. Arabidopsis arenosa (Brassicaceae) from a lead-zinc waste heap in southern Poland - a plant with high tolerance to heavy metals. Plant and Soil, Dordrecht, v. 299, p. 43-53, 2007.

REUMANN, S, WEBER, A.P.M. Plant peroxisomes respire in the light: some gaps of the photorespiratory C-2 cycle have become filled - others remain. Biochimica et Biophysic Acta, Frankfurt, v. 1763, p. 1496-510, 2006.

RODRIGUEZ-SERRANO, M., ROMERO-PUERTAS, M.C., ZABALZA, A., CORPAS, F.J., GÓMEZ, M., DEL RIO, L.A., SANDALIO, L.M. Cadmium effect on oxidative metabolism of pea (Pisum sativum L.) roots. Imaging of reactive oxygen species and nitric oxide accumulation in vivo. Plant, Cell \& Environment, Oxford, v. 29, p. 1532-44, 2006.

SAKIHAMA, Y., COHEN,.M.F., GRACE, S.C., YAMASAKI, H. Plant phenolic antioxidant and prooxidant activities: phenolics-induced oxidative damage mediated by metals in plants. Toxicology, Duluth, v. 177, p. 67-80, 2002.

SCEBBA, F., ARDUINI, I., ERCOLI, L., SEBASTIANI, L. Cadmium effects on growth and antioxidant enzymes activities in Miscanthus sinensis. Biologia Plantarum, Netherlands, v. 50, p. 688-692, 2006.

SCHICKLER, H., CASPI, H. Response of antioxidative enzymes to nickel and cadmium stress in hyperaccumulator plants of the genus Alyssum. Physiologia Plantarum, Oxford, v. 105, p. 3944, 1999.

SEN RAYCHAUDHURI, S., DENG, X.W. The role of superoxide dismutase in combating oxidative stress in higher plants. The Botanical Review, New York, v. 66, p. 89-98, 2000.

SKORZYNSKA-POLIT, E., KRUPA, Z. Lipid peroxidation in cadmium-treated Phaseolus coccineus plant. Archives of Environmental Contamination and Toxicology, New York, v. 50, p. 482-487, 2006.

STROINSKI, A., KOZLOWSKA, M. Cadmium-induced oxidative stress in potato tuber. Actae Societatis Botanicae Poloniae, v. 66, p. 189-195, Oxford, 1997. 
SUN, H.J., UCHII S., WATANABE S., EZURA H. A high efficient transformation protocol for Micro-Tom, a Model cultivar for tomato functional genomics. Plant and Cell Physiology, Oxford, v. 47, p. 426-431, 2006.

VINCENT, J.M. Manual practico de rizobiologia. In: Manual practico de rizobiologia Buenos Aires: Hemisfério Sur, 1975. 200p.

VITÓRIA, A.P., LEA, P.J., AZEVEDO, R.A. Antioxidant enzymes responses to cadmium in radish tissues. Phytochemistry, Oxford, v. 57, p. 701-710, 2001.

WAHID, A, GHANI, A. Varietal differences in mung bean (Vigna radiata) for growth, yield, toxicity symptoms and cadmium accumulation. Annals of Applied Biology, Oxford, 2007, in press.

YAKIMOVA, E.T., KAPCHINA-TOTEVA, V.M., LAARHOVEN, L.J., HARREN, F.M., WOLTERING, E.J. Involvement of ethylene and lipid signaling in cadmium-induced programmed cell death in tomato suspension cells. Plant Physiology and Biochemistry, Paris, v. 44, p. 581-589, 2006.

YANNARELLI, G.G., FERNANDEZ-ALVAREZ , A.J., SANTA-CRUZ, D.M., TOMARO, M.L. Glutathione reductase activity and isoforms in leaves and roots of wheat plants subjected to cadmium stress. Phytochemistry, Oxford, v. 68, p. 505-512, 2007.

ZHANG, H.Y., JIANG, Y.N., HE, Z.Y., MA, M. Cadmium accumulation and oxidative burst in garlic (Allium sativum). Journal of Plant Physiology, Jena, v. 162, p. 977-984, 2005. 


\section{MUDANÇAS ULTRAESTRUTURAIS EM MUTANTES HORMONAIS DE TOMATE EXPOSTOS AO CÁDMIO}

\section{Resumo}

Entre os metais pesados, o cádmio (Cd) é provavelmente um dos mais danosos para as espécies de plantas. Folhas de mutantes hormonais de tomate foram analisadas através da microscopia óptica, microscopia eletrônica de varredura e de transmissão para a caracterização das mudanças estruturais causadas por $1,0 \mathrm{mM} \mathrm{CdCl} 2$ durante 40 dias. Os efeitos do metal na estrutura das folhas foram observados nos cloroplastos que exibiram mudanças no aspecto da organela, desorganização interna dos plastídeos, assim como dos sistemas de tilacóides e estroma. O Cd induziu diferentes alterações nos espaços intercelulares e aumento no tamanho das células do mesófilo entre os mutantes, quando estes foram comparados com plantas controle. Sugere-se que as mudanças estruturais observadas nas folhas tratadas com $\mathrm{Cd}$ como o fechamento estomático, estariam relacionadas à pressão osmótica. O acúmulo de material osmiofílico adjacentes as pilhas do grana (plastoglóbules) foram observados nas células das plantas tratadas com Cd. Uma análise comparativa entre estes diferentes materiais foi conduzida para que a importância das mudanças causadas pelo Cd e a relação com os processos metabólicos deste elemento tóxico pudessem ser esclarecidas.

Palavras chave: Cádmio; Cloroplasto; Tomate; Estroma; Mutantes hormonais; Estômato 


\title{
5 ULTRASTRUCTURAL CHANGES OF TOMATO HORMONAL MUTANTS EXPOSED TO CADMIUM
}

\begin{abstract}
Among the metals, cadmium (Cd) is probably the most damaging to plant species. Leaves of tomato hormonal mutants were analysed by light, scanning and transmission electron microscopy to characterize the structural changes caused by $1.0 \mathrm{mM} \mathrm{CdCl} 2$ for 40 days. The effects of Cd on leaf ultrastructure were observed in chloroplasts which exhibited changes in the organelle shape, internal disorganization of plastids, well as of thylakoids systems and stroma. Cd induced different alterations in intercellular spaces, as well as increase in the size of mesophyll cells among mutants, when compared to those of control plants. It is suggested that the structural changes observed in leaves treated with $\mathrm{Cd}$ such as stomatal closure, were mainly caused by a Cd-induced decrease in water uptake. The accumulation of dense spots of osmiophilic material located adjacent to the grana stack (plastoglobuli) were observed in plant cells treated with Cd. A comparative analysis that we carried out can illustrate the importance of tissue changes caused by $\mathrm{Cd}$ and the metabolic processes of this toxic element.
\end{abstract}

Keywords: Cadmium; Chloroplast; Tomato; Stroma; Hormonal Mutants; Stomata 


\subsection{Introdução}

A contaminação de solos, sedimentos e água por elementos tóxicos, tornou-se um sério problema frente a grande industrialização do mundo atual. Entre estes elementos tóxicos, o cádmio (Cd) está entre os mais perigosos poluentes para os humanos, animais e plantas mesmo sob baixas concentrações (GRATÃO et al., 2005; GRATÃO et al., 2006; MOBIN; KHAN, 2007; WAHID; GHANI, 2007). O Cd pode interferir no metabolimso da planta, afetando processos como o transporte de água, a fosforilação oxidativa nas mitocôndrias, fotossíntese e alterações nos conteúdos de clorofila (VASSILEV et al., 2003; DJEBALI et al 2005; VITÓRIA et al., 2006), embora a intensidade deste efeito dependa sempre das espécies, concentração do metal e o tempo de exposição (BENAVIDES et al., 2005).

O Cd é um elemento não essencial e as mudanças estruturais são alguns dos efeitos provocados por este elemente nas plantas (VITÓRIA et al., 2004). Algumas destas mudanças estão relacionadas à desorganização da estrutura foliar, espaços intercelulares reduzidos, alterações drásticas nos cloroplastos e disrupções nos tilacóides (ARAVIND; PRASAD, 2005; DJEBALI et al., 2005). Além disso, o Cd pode causar disrupção no envelope nuclear, plasmalema e membranas mitocondriais (STOYANOVA; TCHAKALOVA, 1997), severa plasmólise, condensação do citoplasma e da cromatina (LIU; KOTTKE, 2004).

O uso de vários sistemas modelos tornou-se muito importante para o estudo de complexas redes de fatores que influenciam o desenvolvimento, como os metais pesados. O cultivar miniatura de tomate (Micro-Tom) é usado como modelo genético baseado no seu pequeno tamanho e produção de frutos e sementes viáveis em vasos com 50-100 mL de substrato, com um ciclo de vida curto, entre 70 e 100 dias (MEISSNER et al., 1997). Além disso, vários mutantes hormonais já foram introduzidos no sistema modelo Micro-Tom, o que representa modelos de estudos complementares apresentando sensibilidade a hormônios. Para a classe das auxinas, o mutante diageotrópica (dgt) apresenta alterações na via de transdução de sinal da auxina (KELLY; BRADFORD, 1986). Por outro lado, um gene defectivo no receptor do etileno ocorre no mutante Never ripe $(\mathrm{Nr})$, que apresenta por sua vez, amadurecimento incompleto dos frutos (WILKINSON et al., 1995).

Assim, o objetivo deste estudo foi determinar as mudanças estruturais que ocorreram nas células foliares dos mutantes hormonais de tomate que crescream na presença do Cd. A informação disponível neste trabalho pode contribuir para o entendimento de alguns dos 
mecanismos básicos relacionados aos danos causados pelo Cd e a provável integração de sinais ambientais e endógenos envolvidos na fitotoxicidade e resistência a fatores de estresse.

\subsection{Material e métodos}

\subsubsection{Material}

As sementes de Micro-Tom dgt e $\mathrm{Nr}$ foram semeadas em caixas contendo uma mistura de substrato orgânico inerte (Plantmax HT Eucatex, Brazil) e vermiculita, na proporção 1:1, suplementado com $1 \mathrm{~g}$ de NPK 10. 10.10 por litro de substrato e 4 g de calcário dolomítico (Ca + Mg) por litro de substrato.

Posteriormente, o trasplantio foi realizado com plântulas contendo pelo menos um par de folhas bem desenvolvidas, além das cotiledonares. As plântulas foram transplantas para vasos de Leonard (VINCENT, 1975), preenchidos com areia e isopor (na proporção de 4:3, repectivamente) e solução nutritiva de Hoagland (HOAGLAND; ARNON, 1950). Após trinta dias, plantas uniformes foram selecionadas para o crescimento na mesma solução contendo $0 \mathrm{mM}$ (controle) e 1.,0 mM CdCl 2 A solução foi trocada sempre a cada 6 dias, mantendo os níveis da concentração do metal e da evaporação constantes. Após 1, 12 e 40 de exposição ao metal, pedaços de folhas foram coletados e submetidos imediatamente às soluções fixadoras.

\subsubsection{Microscopia Eletrônica de Varredura (M.E.V.)}

Para a observação do material vegetal (folha) em M.E.V., realizou-se a fixação das amostras em fixador Karnovsky (KARNOWSKY, 1965), modificado - glutaraldeído 2\% em tampão cacodilato de sódio 0,1 M. Desta forma, formou-se pontes entre as moléculas em função de dois grupamentos aldeídicos nas extremidades do glutaraldeído, criando assim uma trama tridimensional. O material permaneceu neste fixador por alguns dias em geladeira. A pós-fixação foi realizada com tetróxido de ósmio $\left(\mathrm{OsO}_{4}\right)$ lavando-se a amostra pré-fixada em aldeído com três passagens de cerca de 10 minutos em tampão cacodilato 0,05 M pH 7,2 e imersão em uma solução de $\mathrm{OsO}_{4} 1 \%$ em tampão cacodilato $0,05 \mathrm{M} \mathrm{pH} 7,2$ por 1 hora, à $25^{\circ} \mathrm{C}$ em uma capela (VITÓRIA et al., 2004). O OsO 4 (ou ácido ósmico) funciona como fixador devido aos oito 
agrupamentos ativos que possue, os quais ao reagir com proteínas, ácidos nucléicos, polissacarídeos e lipídeos, resultam em uma trama tridimensional estabilizando a estrutura da célula. Além disso, na M.E.V., o $\mathrm{OsO}_{4}$ funciona como emissor de elétrons secundários, melhorando a qualidade da imagem gerada. Após a pós-fixação com $\mathrm{OsO}_{4}$, a amostra foi lavada com água destilada rapidamente por três vezes e a seguir passada em soluções de concentração crescente de acetona (30, 50, 70, 90 e 100\%), permanecendo cerca de 10 minutos em cada uma. Posteriroemente após o processo de desidratação, as amostras foram secas em ponto crítico com $\mathrm{CO}_{2}$. O material biológico foi acondicionado em "stubs" (suporte próprio para observação em M.E.V.) e em seguida recebeu uma cobertura de ouro de cerca de 100-200 A por um processo conhecido como "sputtering". Após estes preparos, as amostras foram visualizadas em um Microscópio Eletrônico de Varredura modelo DSM 940A da Zeiss, instalado no Núcleo de Apoio à Pesquisa em Microscopia Eletrônica Aplicada à Pesquisa Agropecuária (NAP/MEPA) na ESALQ-USP.

\subsubsection{Microscopia Óptica (M.O.)}

As amostras (folha) foram coletadas e fixadas em solução Karnowsky (KARNOWSKY, 1965). Após a fixação, o material foi submetido à desidratação em séria alcoólica e emblocado em historresina JB-4. O material foi seccionado em micrótomo manual proporcionando cortes de 5 a $6 \mu \mathrm{m}$. Para uma análise geral, foi utilizada a coloração pelo azul de toluidina $(0,05 \%)$ em Tampão Fosfato de Potássio pH 4,7 durante 5 minutos. Em seguida o material foi lavado rapidamente em água destilada e secos ao ar (VITÓRIA et al., 2004). As lâminas permanentes foram montadas em PERMOUT. As observações foram realizadas em microscópio óptico (Zeiss, Jena, Germany) instalado no Núcleo de Apoio à Pesquisa em Microscopia Eletrônica Aplicada à Pesquisa Agropecuária (NAP/MEPA) na ESALQ-USP.

\subsubsection{Microscopia Eletrônica de Transmissão (M.E.T.)}

Pequenas porções de tecido (folhas) $(1 \mathrm{x} 2 \mathrm{~mm})$ foram fixadas em solução de Karnovsky modificado: glutaraldeído 2\%, paraformaldeído 4\%, cloreto de cálcio $5 \mathrm{mM}$ em tampão cacodilato de sódio $(0,1 \mathrm{M} \mathrm{pH} 7,2)$ por 48 horas, lavadas em tampão cacodilato $0,1 \mathrm{M}(3 \mathrm{x} 15$ 
min.) e pós-fixadas por 1 hora com tetróxido de ósmio e 1\% em tampão cacodilato de sódio 0,2M. Após rápidas lavagens com solução salina $0,9 \%$, as amostras foram coradas "in bloco" com acetato de uranila 2,5\% em água durante uma noite e desidratadas com séries crescentes de acetona em água (25,50,75\%) por 5 minutos, seguidas por 2 tratamentos de 10 minutos cada um com acetona $90 \%$ e 3 tratamentos de 20 minutos com acetona pura. Posteriormente, as amostras foram incluídas em resina Epon 812 a $70{ }^{\circ} \mathrm{C}$ por 48 horas. Os cortes ultrafinos (60-90 nm) foram depositados em grades de cobre recobertas com formvar, contrastados com acetato de uranila 2,5\% e citrato de chumbo (VITÓRIA et al., 2006). As detecções foram observadas a $80 \mathrm{kV}$ utilizando um microscópio eletrônico de varredura (Zeiss Em 900) instalado no Núcleo de Apoio à Pesquisa em Microscopia Eletrônica Aplicada à Pesquisa Agropecuária (NAP/MEPA) na ESALQ-USP.

\subsection{Resultados}

Os resultados estão relacionados a 40 dias de exposição ao metal, em função da não observação de alterações estruturais foliares das plantas de tomate nos tempos de 1 e 12 dias de exposição (dados não mostrados).

As análises da microscopia eletrônica de varredura (M.E.V) demostraram que as células epidérmicas dos lados abaxiais das folhas dos três controles (Micro-Tom, $\mathrm{Nr}$ e $d g t$ ) analisados apresentavam estômatos abertos (Figuras 5.1, 5.2 e 5.3), contrariamente ao observado nas células epidérmicas do Micro-Tom submetido ao metal, cujos estômatos estavam fechados (Figura 5.1). Entretanto, a maior parte dos estômatos dos mutantes $N r$ (Figura 5.2) e dgt (Figura 5.3) tratados com o metal, permaneceu aberta. 

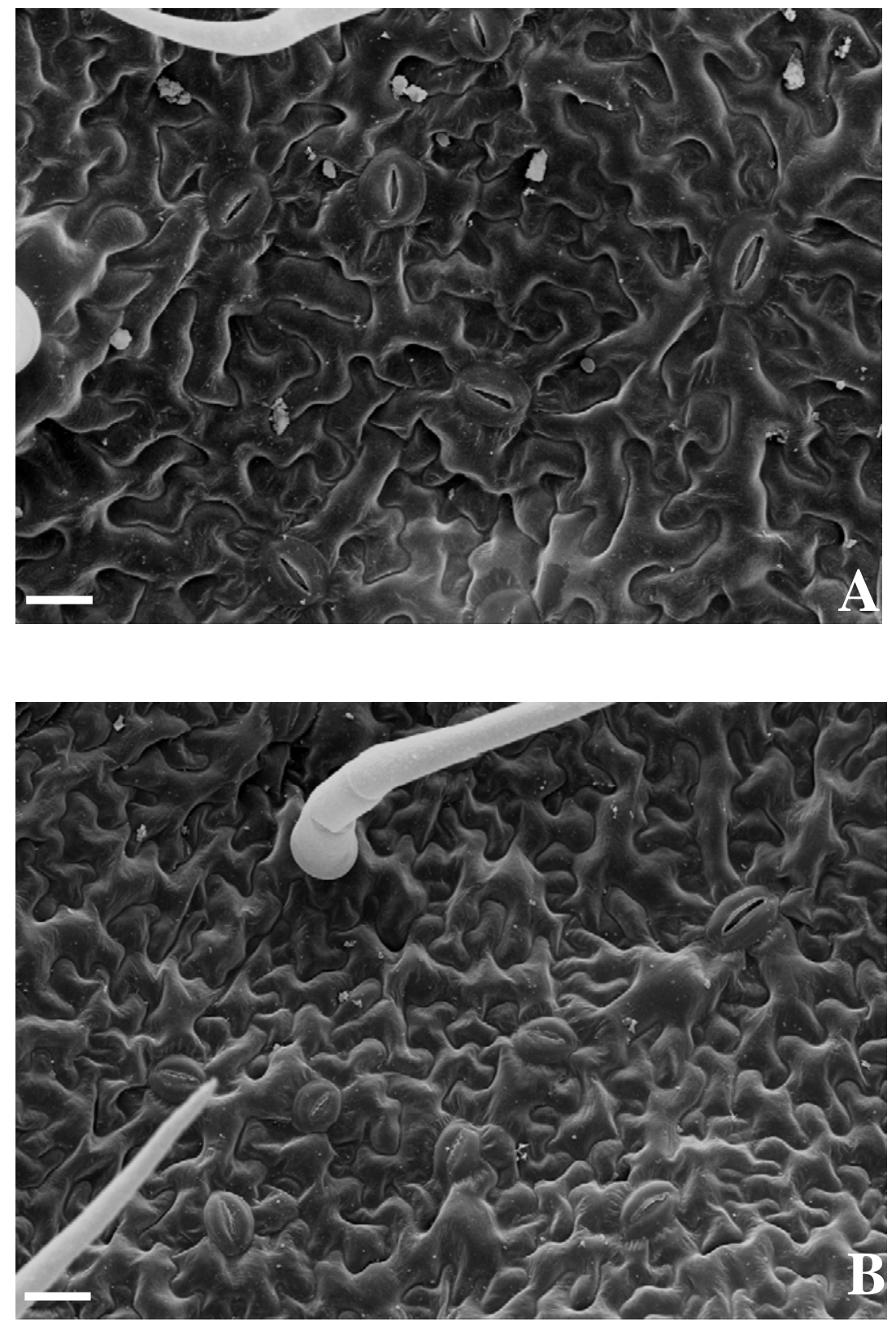

Figura 5.1 - Microscopia eletrônica de varredura da epiderme foliar de Micro-Tom. A - controle; B -1,0 $\mathrm{mM} \mathrm{CdCl}{ }_{2}$ Barras= $20 \mu \mathrm{m}(\mathrm{A}, \mathrm{B})$ 

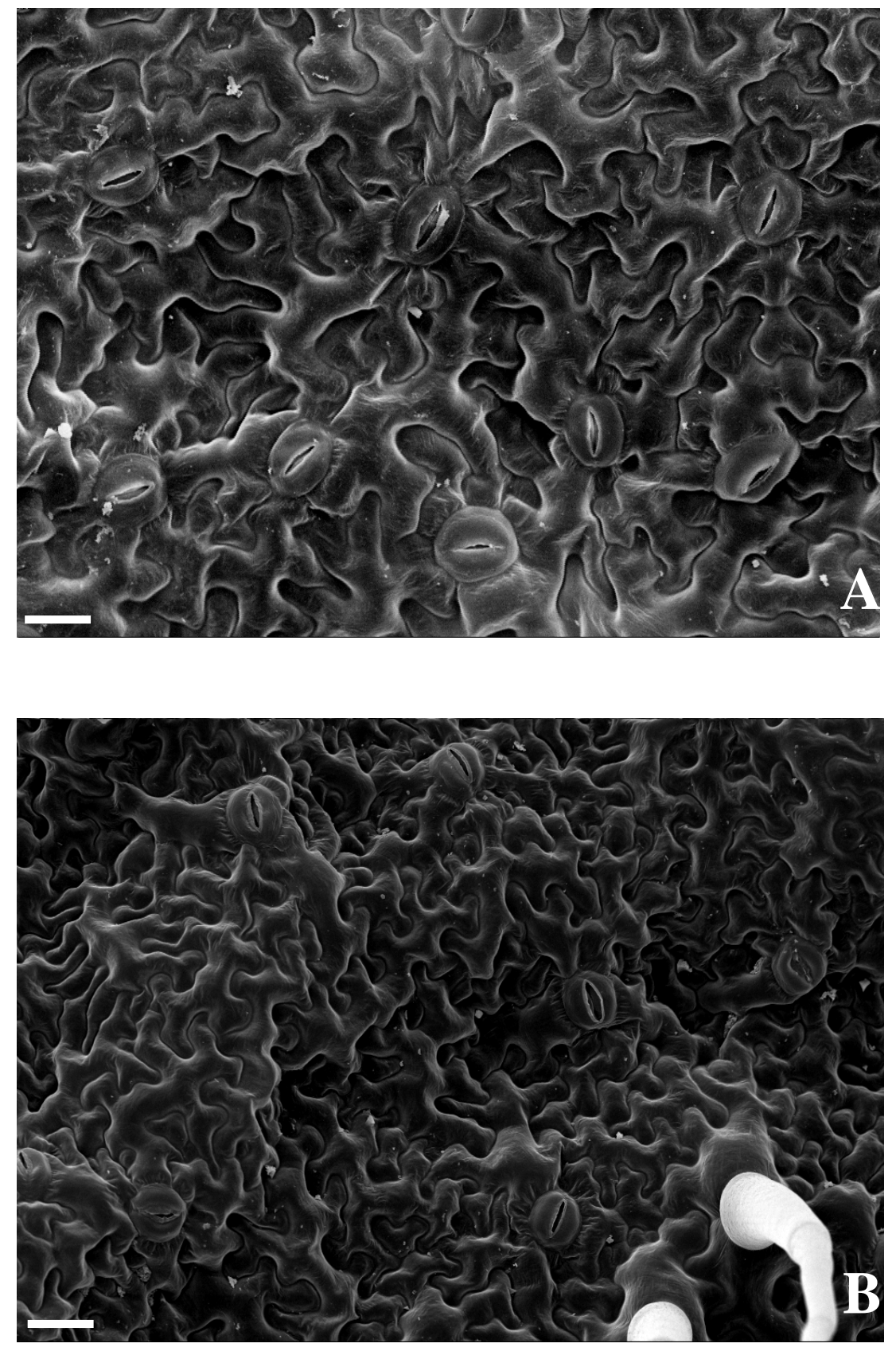

Figura 5.2 - Microscopia eletrônica de varredura da epiderme foliar de $\mathrm{Nr}$. A - controle; B -1,0 mM CdCl 2 Barras $=20 \mu \mathrm{m}(\mathrm{A}, \mathrm{B})$ 

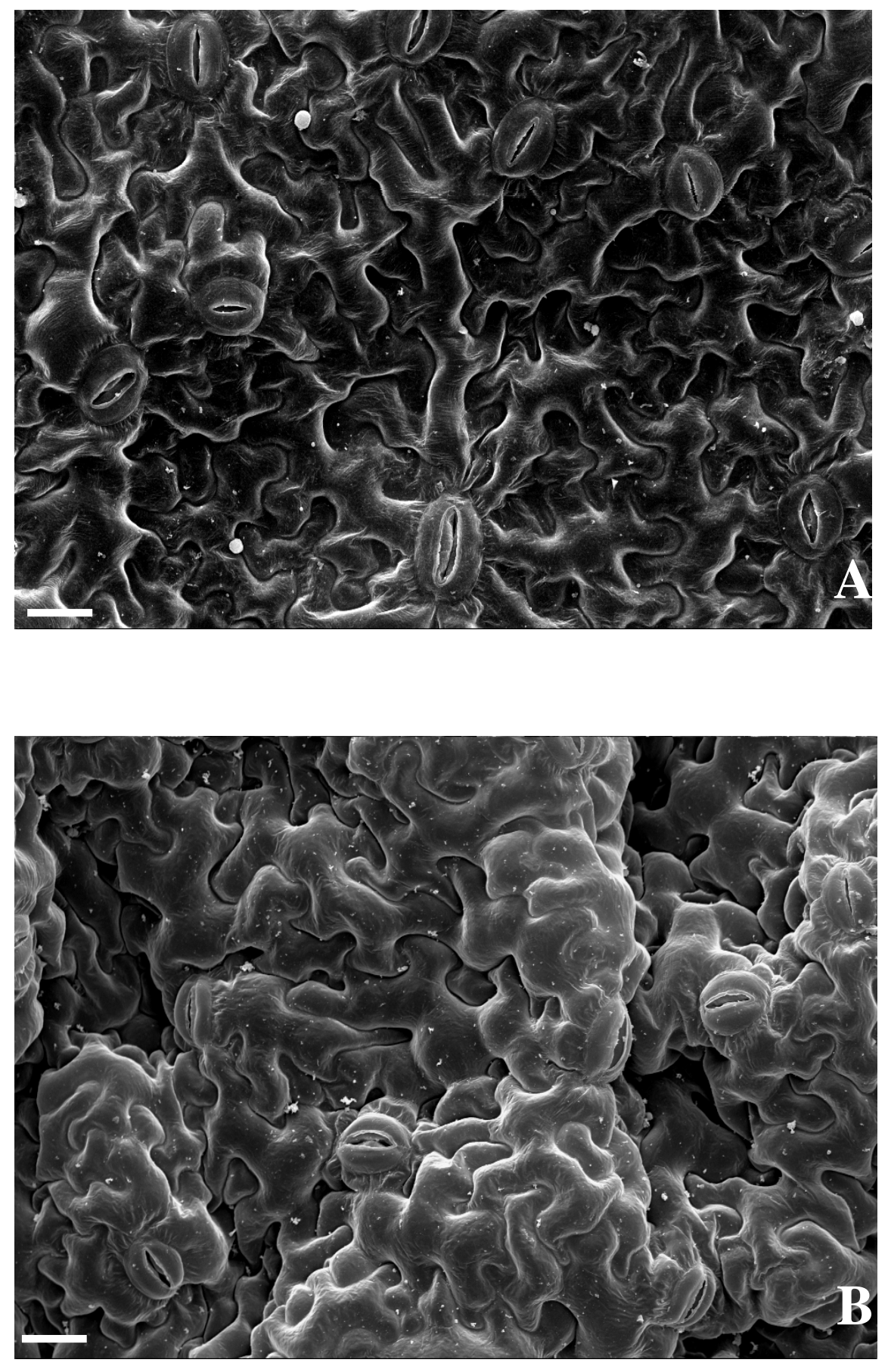

Figura 5.3 - Microscopia eletrônica de varredura da epiderme foliar de dgt. A - controle; B -1,0 mM $\mathrm{CdCl}_{2}$ Barras $=20 \mu \mathrm{m}(\mathrm{A}, \mathrm{B})$ 
Através da microscopia óptica, as análises histológicas revelaram importantes diferenças anatômicas entre os mutantes expostos ao Cd, comparados aos respectivos controles. Foram observadas modificaçãoes na densidade foliar, arranjo celular, aumento no tamanho das células paliçádicas (Figura 5.4, 5.5 e 5.6) e decréscimo do número de cloroplastos (Figura 5.5 e 5.6). Os resultados mostraram que o tratamento com o Cd induziu aumento nos espaços intercelulares nas folhas de $\mathrm{Nr}$ (Figura 5.5), contrariamente ao observado para o mutante dgt (Figura 5.6). 

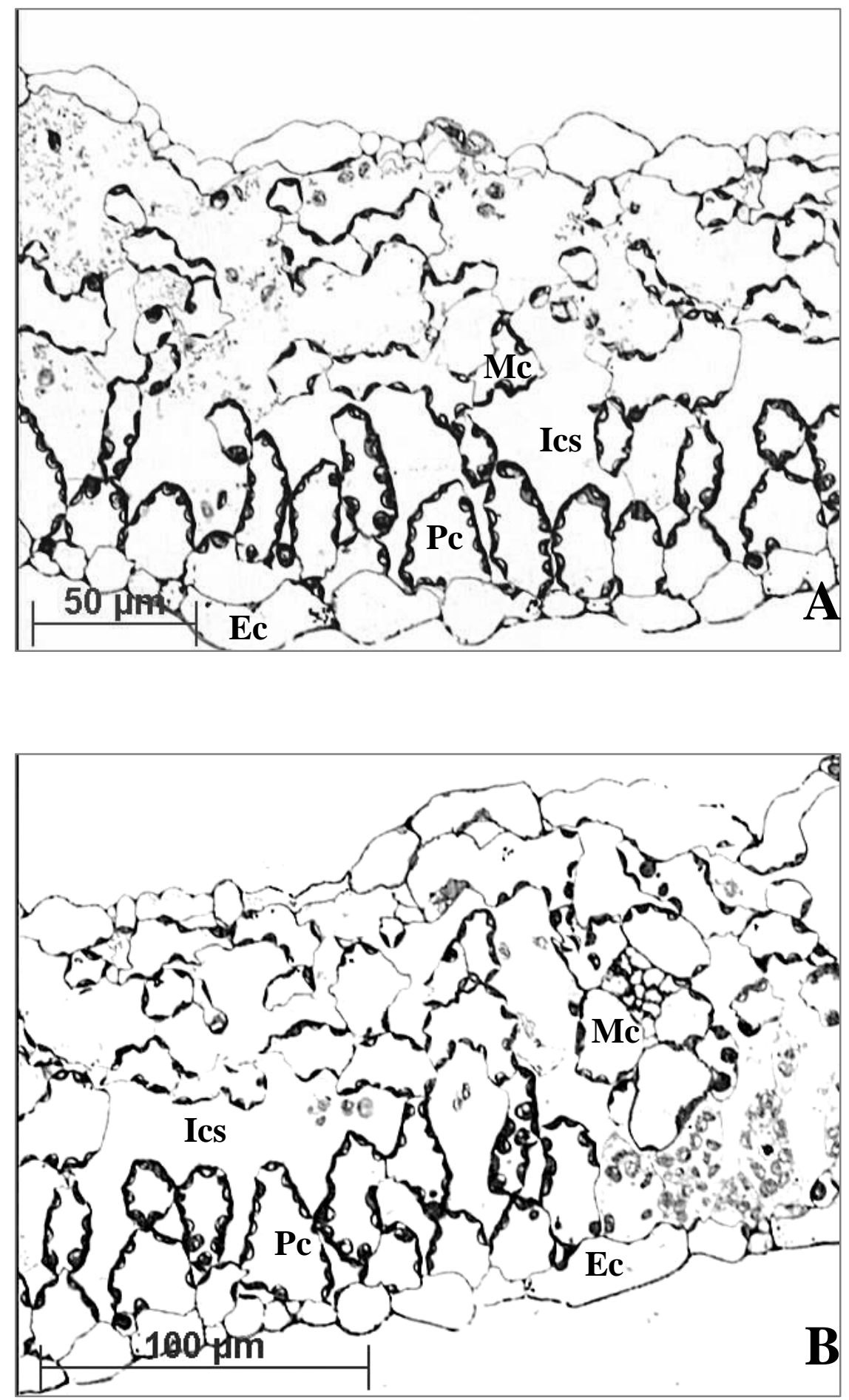

Figura 5.4 - Corte transversal do tecido foliar de Micro-Tom. A - controle; B - $1 \mathrm{mM} \mathrm{CdCl}$. Ec, célula epidérmica; Pc, célula paliçádica; Mc, célula do mesófilo; Ics, espaço intercelular 

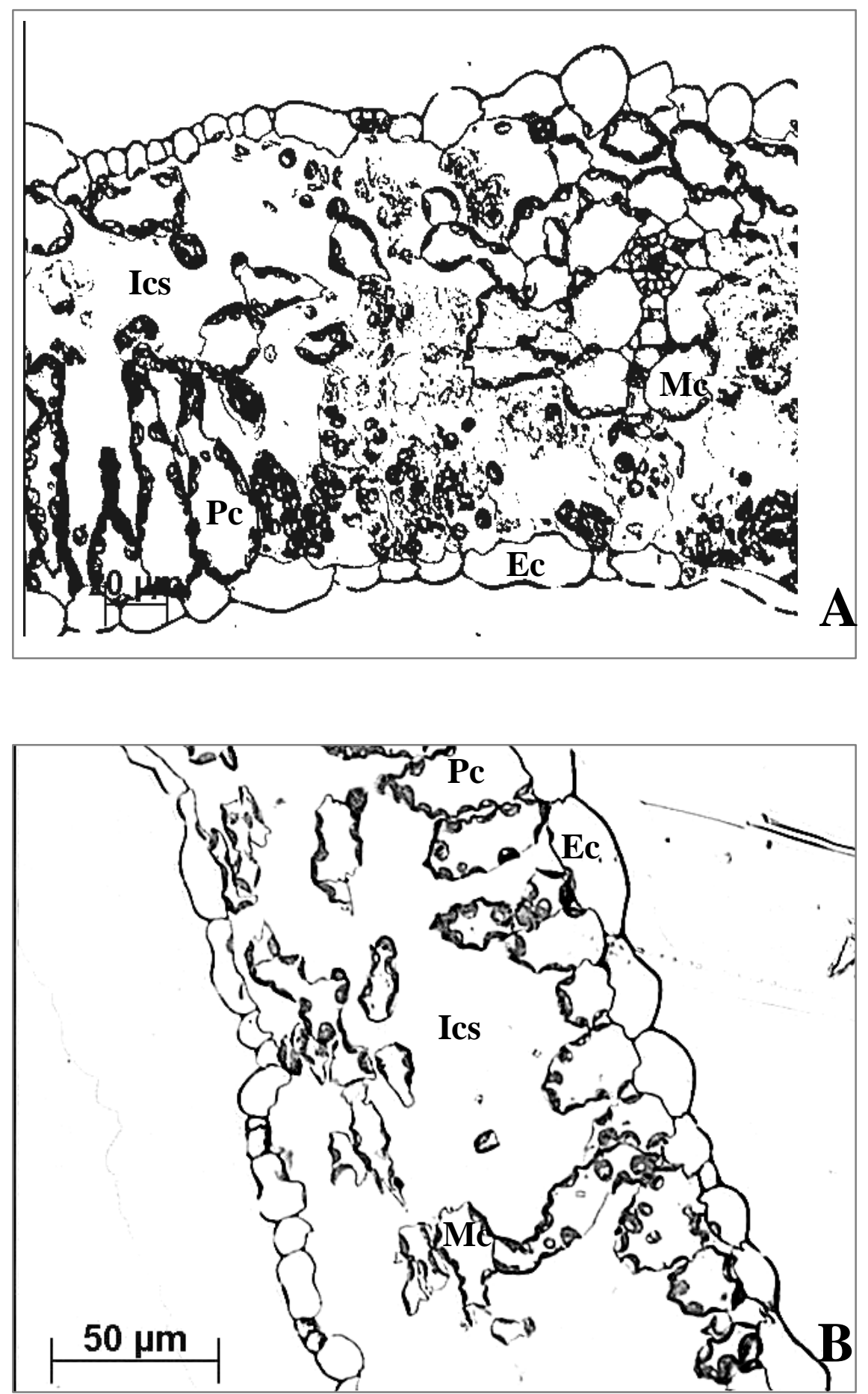

Figura 5.5 - Corte transversal do tecido foliar de $\mathrm{Nr}$. A - controle; B - $1 \mathrm{mM} \mathrm{CdCl}_{2}$. Ec, célula epidérmica; Pc, célula paliçádica; Mc, célula do mesófilo; Ics, espaço intercelular 

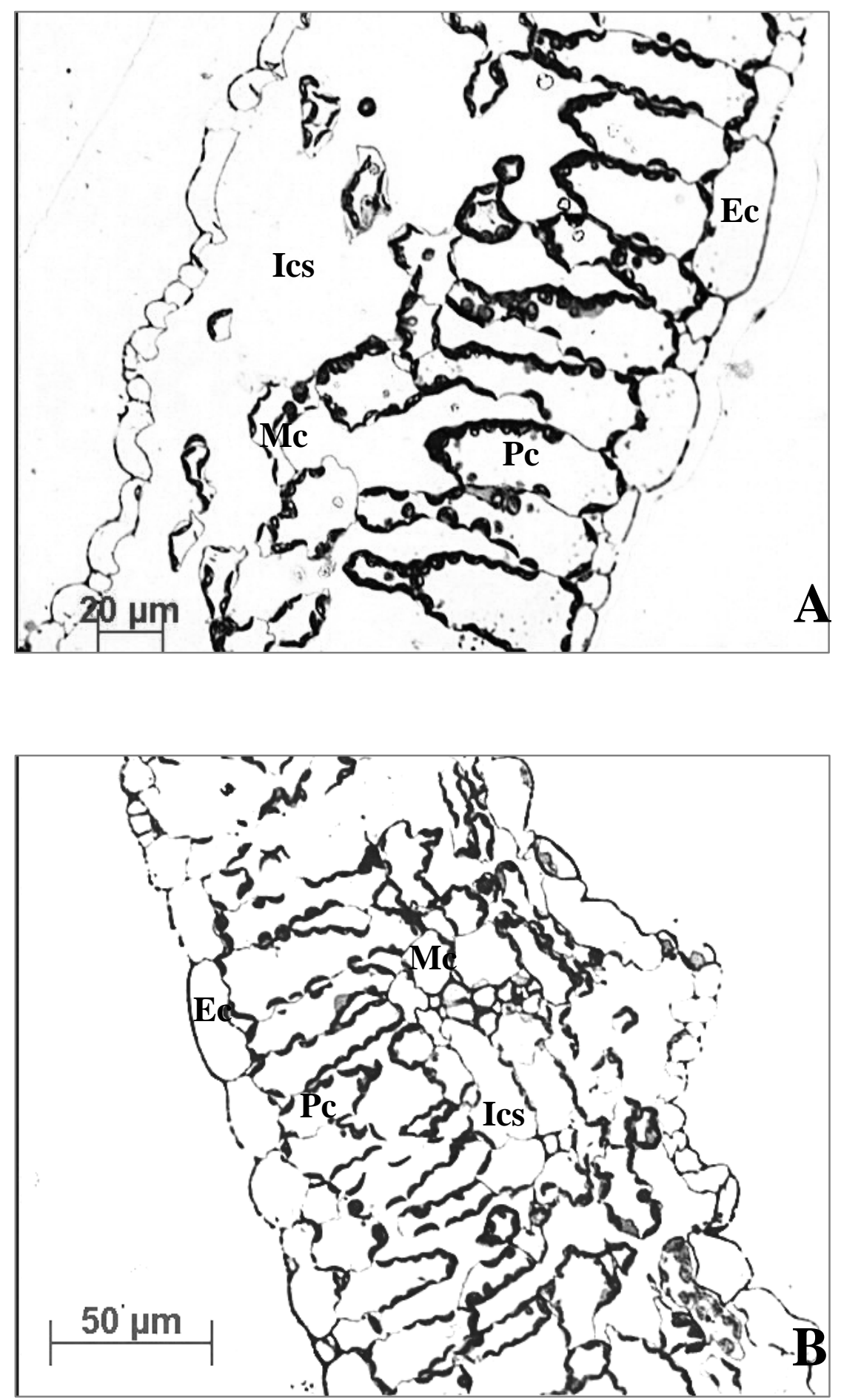

Figura 5.6 - Corte transversal do tecido foliar de dgt. A - controle; B - $1 \mathrm{mM} \mathrm{CdCl}_{2}$. Ec, célula epidérmica; Pc, célula paliçádica; Mc, célula do mesófilo; Ics, espaço intercelular 
As análises através da microscopia eletrônica de transmissão (M.E.T.) demonstraram diferenças na estrutura dos cloroplastos entre todos os materiais analisados. Nos controles de Micro-Tom, os cloroplastos estavam alongados e com um arranjamento típico de granum e estroma (Figura 5.7). Nas controles do mutante $\mathrm{Nr}$ (Figura 5.9) e das folhas de $d g t$ tratadas com Cd (Figura 5.12), os cloroplastos continham abundantes grãos de amido. Curiosamente, nos controles foliares do mutante dgt (Figura 5.11), foram observados efeiros degenerativos nos cloroplastos que claramente exibiram intensa degradação e disrupção, similares àqueles observados para os materiais submetidos ao metal.

As observações através da M.E.T. nas folhas de Micro-Tom, $\mathrm{Nr}$ e dgt submetidas a 1,0 mm $\mathrm{CdCl}_{2}$ mostraram desorganização interna de plastídeos, assim ocomo desorganização dos tilacóides e estroma (Figura 5.8, 5.10 e 5.12) quando comparadas as plantas controle (Figura 5.7, 5.9 e 5.11). Observou-se também, um contorno irregular das pilhas dos grana. Além disso, o tamanho e a quantidade dos grãos de amido no mutante $N r$ tratado com metal foi drasticamente reduzido (Figura 5.10) quando comparados ao controle. Em folhas de Micro-Tom, $\mathrm{Nr}$ e dgt submetidos ao metal, observou-se o acúmulo de material denso adjacente a pilha do grana (plastoglóbulo) nos cloroplastos (Figura 5.8, 5.10 e 5.12).

A principal alteração observada entre os mutantes está relacionada à distorção da membrana dos cloroplastos e ao desarranjo do tilacóide. Em folhas de Micro-Tom e dgt tratadas com Cd foram observadas extensiva degradação e desorganização dos grana, além do acúmulo de peroxissomos e mitocôndrias (Figura 5.8 e 5.12). 

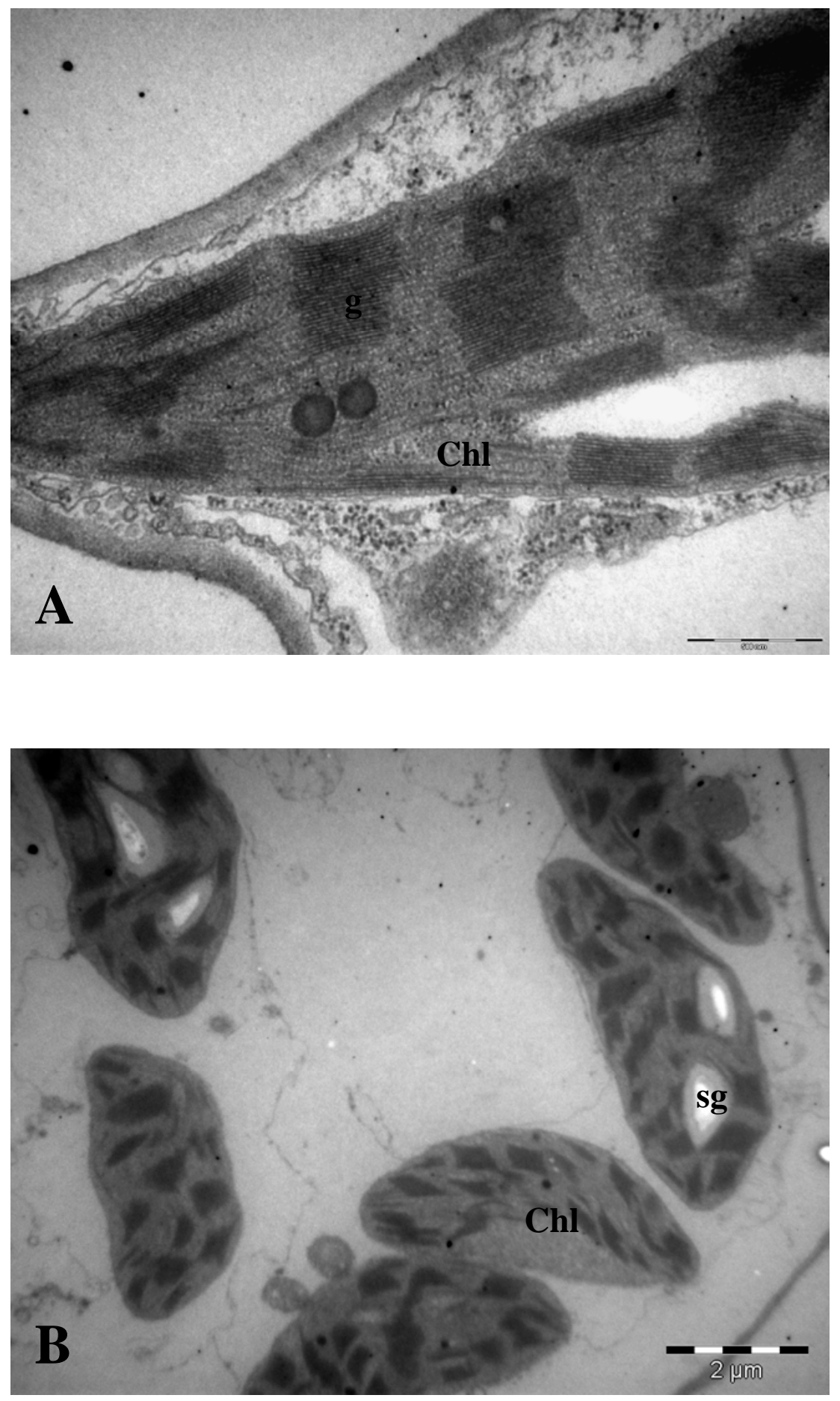

Figura 5.7 - Microscopia eletrônica ilustra a morfologia dos cloroplastos. A, B - controle foliar do MicroTom. Chl, cloroplasto; g, grana; Sg, grão de amido 

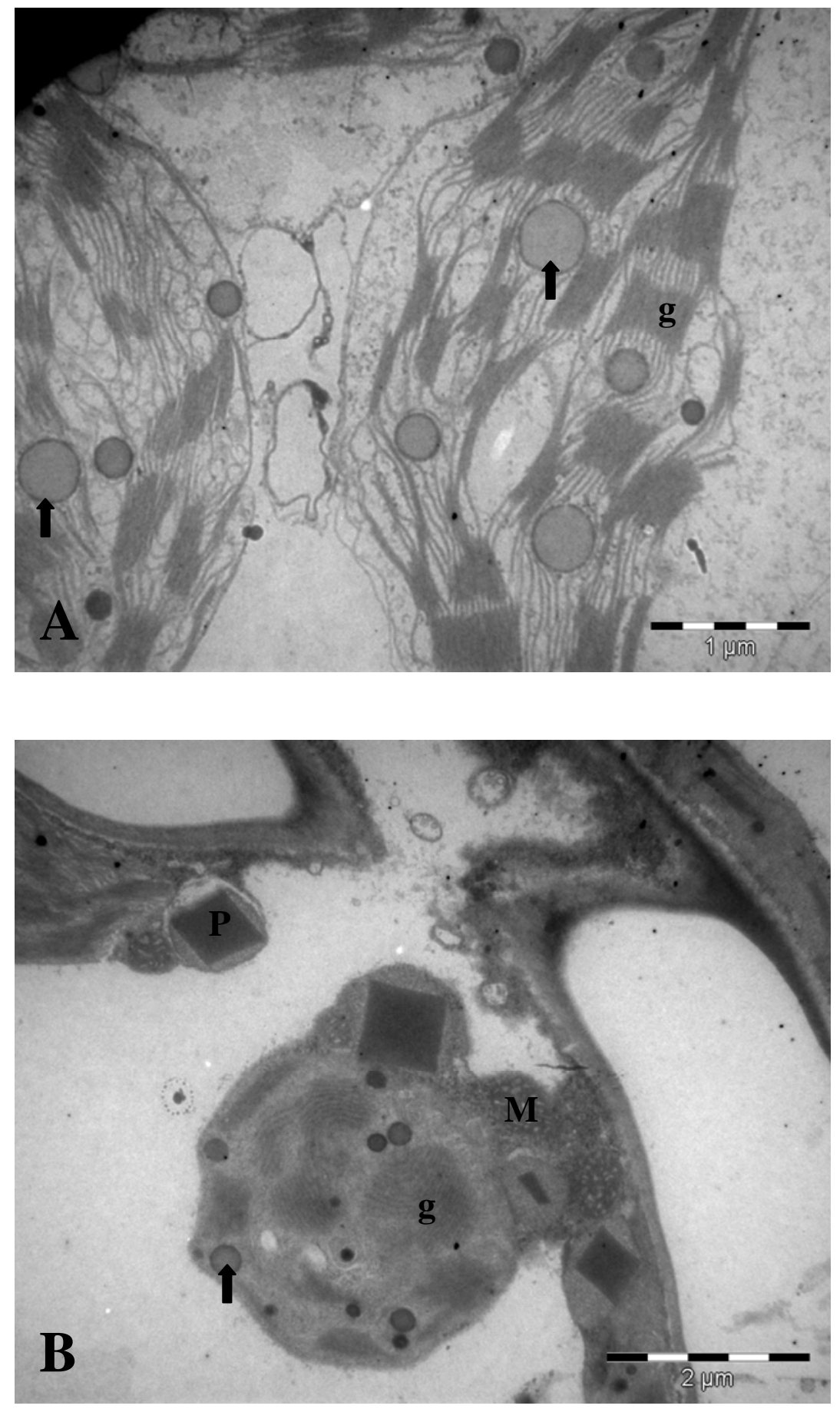

Figura 5.8 - Microscopia eletrônica ilustra a morfologia dos cloroplastos. A, B - exposição do Micro-Tom à 1,0 mM CdCl 2 . g, grana; M, mitocôndria; P, peroxissomo. Setas indicam plastoglóbulos 

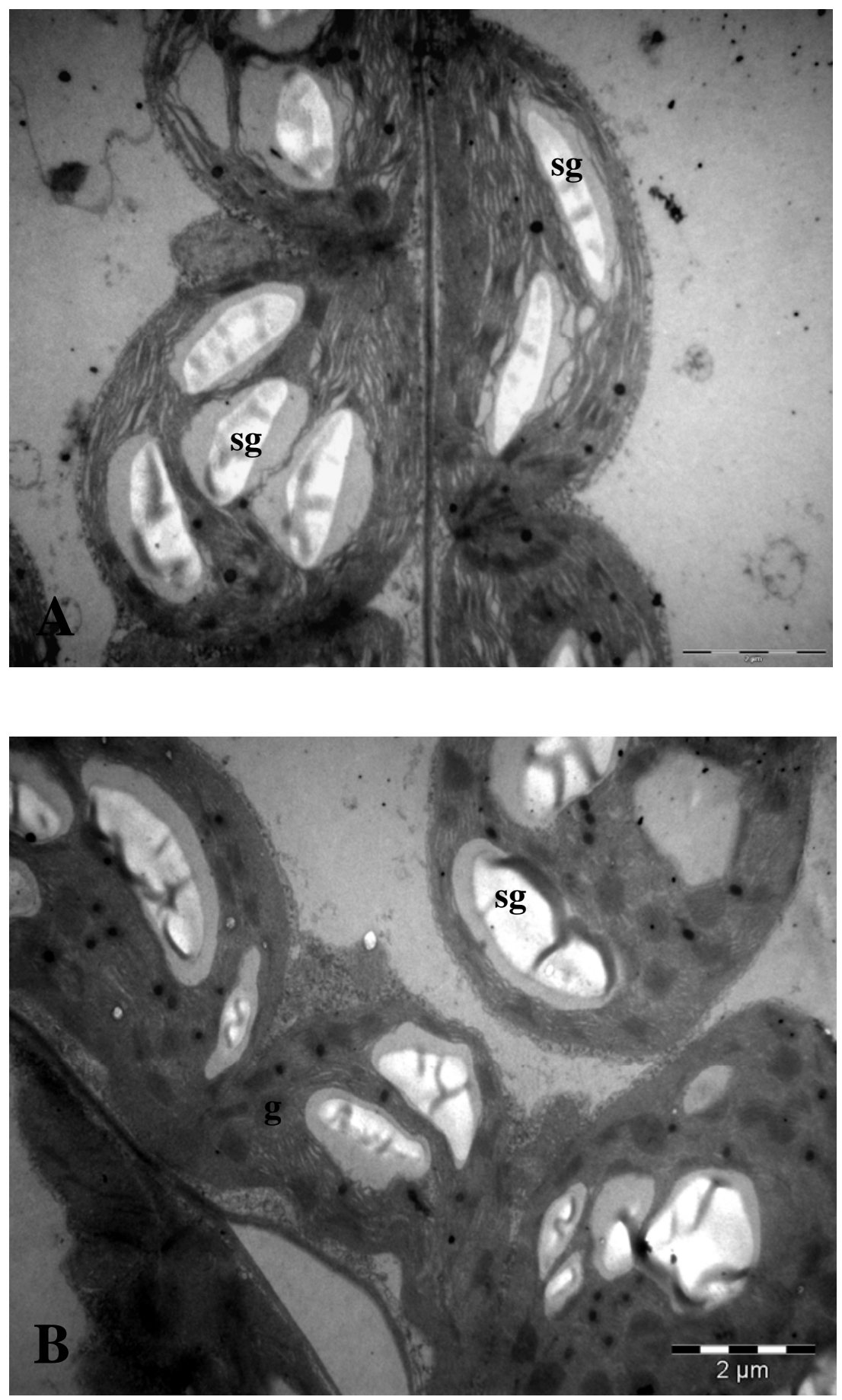

Figura 5.9 - Microscopia eletrônica ilustra a morfologia dos cloroplastos. A, B - controle do Nr. g, grana; Sg, grão de amido 

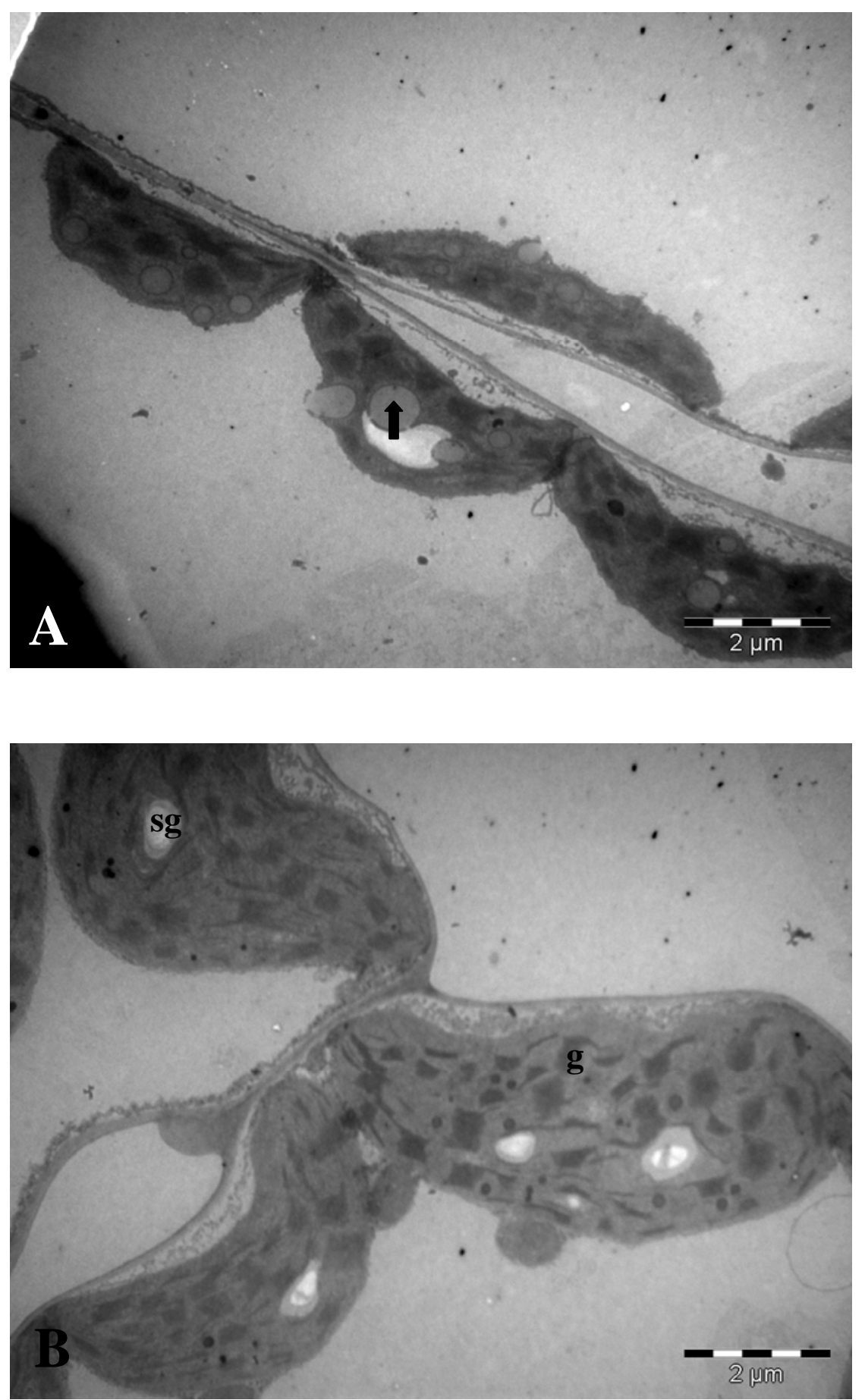

Figura 5.10 - Microscopia eletrônica ilustra a morfologia dos cloroplastos. A, B - exposição do $\mathrm{Nr}$ à 1,0 mM CdCl 2 . g, grana; Sg, grão de amido. Setas indicam plastoglóbulos 

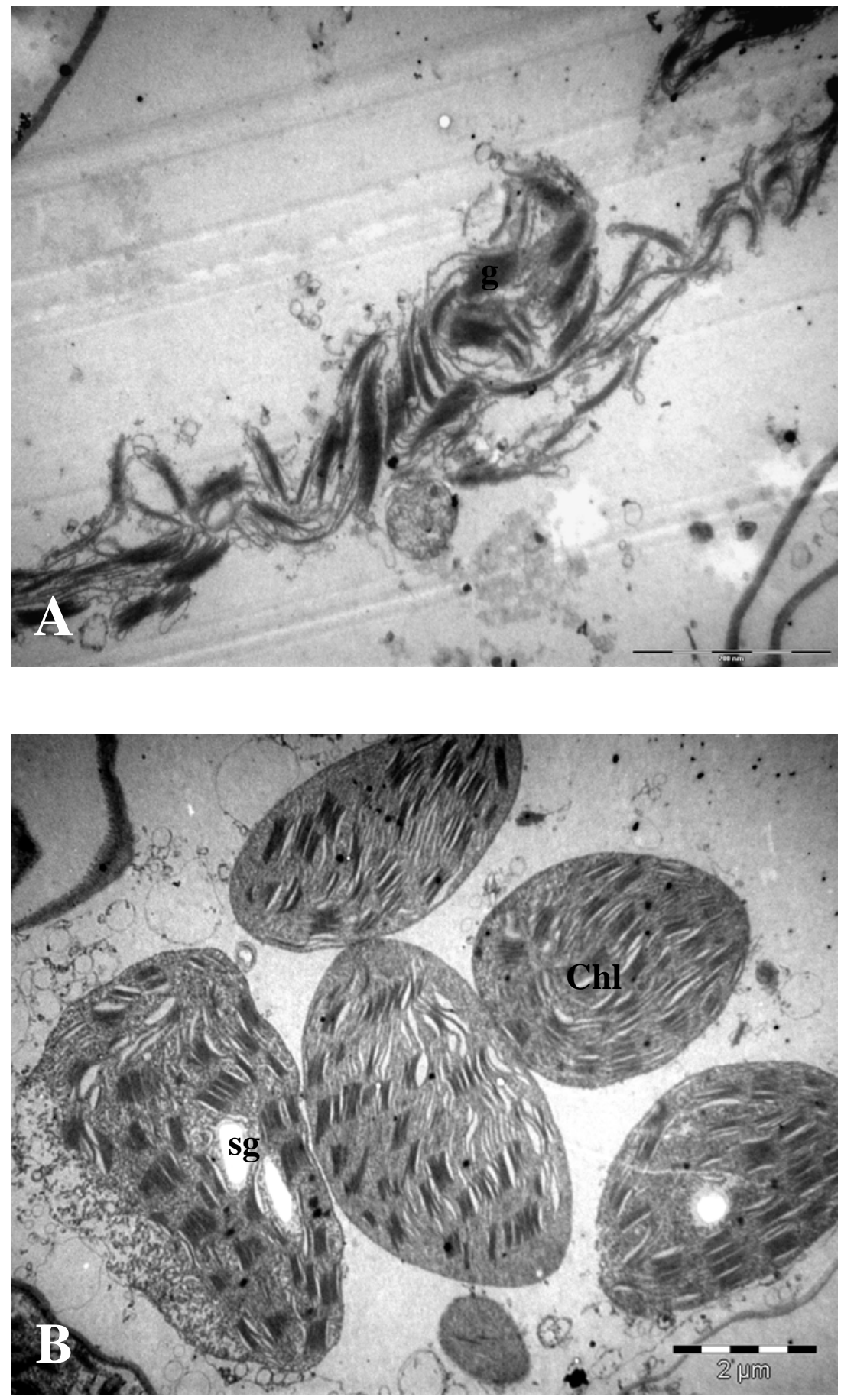

Figura 5.11 - Microscopia eletrônica ilustra a morfologia dos cloroplastos. A, B - controle do dgt. Chl, cloroplasto; g, grana; Sg, grão de amido 

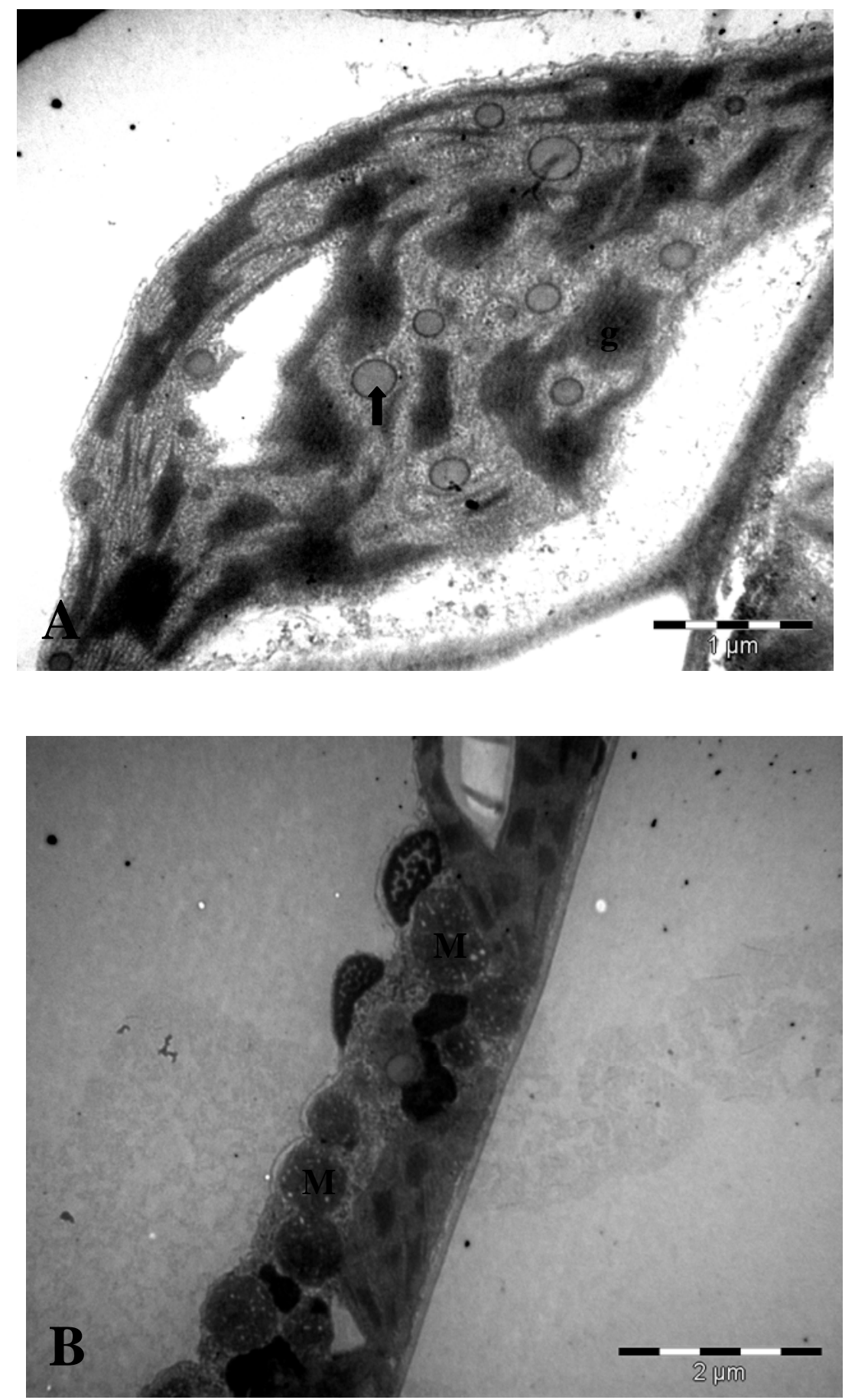

Figura 5.12 - Microscopia eletrônica ilustra a morfologia dos cloroplastos. A, B - exposição do dgt à 1,0 $\mathrm{mM} \mathrm{CdCl}_{2}$. g, grana; $\mathrm{M}$, mitocôndria. Setas indicam plastoglóbulos 


\subsection{Discussão}

Plantas expostas a severas condições de estresses exibem várias respostas morfogenéticas consideradas alterações genéricas induzidas pelo estresse, que reflete processos comuns como transporte e metabolismo alterados de fitormônios e aumento na produção de EAOs (FRANCIA et al., 2007; POTTERS et al., 2007).

Fitormônios como auxina e etileno, assim como EAOs intermediam importante papel nos caminhos de transdução de sinais, permitindo que plantas se confrontem com vários estresses (FOREMAN et al., 2003; KLEE, 2004; TORRES, DANGL, 2005). Os sinais transducionais induzidos pelo estresse não são bem conhecidos, mas a similaridades entre as respostas aos estresses abióticos podem indicar a relação das EAOs na responsividade ao hormônio (PASTERNACK et al., 2005).

O uso de mutantes com disrupção em uma resposta específica aos hormônios ou sinais ambientais são frequentemente usados para mostrar ou excluir possíveis interações na transdução de sinais (COENEN, LOMAX, 1998; POLANSKA et al., 2007). A auxina está relacionada com quase todos os aspectos do desenvolvimento de plantas, que abrange desde a dominância apical e diferenciação vascular nos caules à iniciação dos órgãos laterais e gravitropismo nas raízes, sendo o ácido indol acético (IAA), a maior forma da auxina descrita em plantas superiores (SWARUP et al., 2000). Sobre o etileno, este fitormônio está relacionado a importantes processos fisiológicos nas plantas, com importante papel na transdução de sinais associados com estresses bióticos e abióticos (BLEECKAR; KENDE, 2000; MUNNÉ-BOSH et al., 2004; KWAK et al., 2006; VAN LOON et al., 2006). O etileneo pode estar associado a outros hormônios como auxina, citocinina, ácido abcísico (ABA), ácido salicílico e jasmonato, relacionados ao seu caminho de sinalização aos estresses biótico e abiótico nas plantas (GUO; ECKER, 2004; ETHERIDGE et al., 2006).

O etileno é um componente crítico de vários processos como germinação de sementes, amadurecimento de frutos, abscisão e senescência. Além disso, estímulos bióticos e abióticos podem conduzir a síntese de etileno (KLEE, 2004; MONTOYA et al., 2005; BARRY; GIOVANNONI, 2007). Alguns metais como o Cd interferem na síntese de etileno, estimulando a atividade da ACC sintase, enzima chave para a biossíntese de etileno. Este aumento na atividade enzimática está associado com o efeito indireto através de sinais de células adjacentes que são 
diretamente afetadas pelo Cd (FUHRER, 1982). Entretanto, este contato direto entre o Cd e a proteína da ACC sintase in vitro resulta na inibição da atividade enzimática (FUHRER 1982).

Os resultados da M.E.V. mostraram variação na abertura/fechamento estomático relacionado aos diferentes mutantes de tomate expostos ao Cd (Figura 5.1, 5.2 e 5.3). A baixa absorção de água de plantas de tomate expostos ao Cd pode ser um importante fator para explicar as alterações estruturais observadas. Em resposta as condições de estresse induzida pelo Cd, a planta pode ser capaz de induzir mecanismos para prevenir a perda de água, como fechamento estomático e aumento da capacidade da absorção de água (BARYLA et al., 2001; VITÓRIA et al., 2004). Todas estas alterações dependem de fatores como concentração do metal, período de exposição e grau de sensibilidade das espécies ao metal (PRASAD, 1995).

Auxinas e citocininas são bem conhecidas por antagonizarem os efeitos do ácido abcísico (ABA) no movimento estomático, inibindo o fechamento estomático induzido pelo ABA através das modulação da biossíntese do etileno (TANAKA et al., 2006). Em adição, o etileno pode inibir a redução da pressão osmótica nas células guarda induzida pelo ABA (TANAKA et al., 2006). O mecanismo de fechamento estomático induzido pelo ABA está relacionado ao decréscimo do turgor da célula guarda em função do efluxo de $\mathrm{K}^{+}$ânions associados, como o $\mathrm{Cl}^{-}$e/ou malato, que pode funcionar por um aumento nas concentrações citoplasmáticas de $\mathrm{Ca}^{2+}$ (TANAKA et al. 2005). O fitormônio etileno pode estar relacionado com a elevação do $\mathrm{Ca}^{2+}$ através da ativação dos canais permeáveis de $\mathrm{Ca}^{2+}$ na membrana plasmática da célula guarda (ZHAO et al., 2007). Além disso, o etileno pode estimular o influxo de Cd através dos canais permeáveis de $\mathrm{Ca}^{2+}$ da membrana plasmática, levando a morte celular (YAKIMOVA et al., 2006).

Há algumas indicações sobre a ligação entre o etileno e as EAOs, como a indução do fechamento estomático em Arabidopsis pelo etileno, dependente de peróxido de hidrogênio nas células guarda (DESIKAN et al., 2005; DESIKAN et al., 2006). Entretanto, os receptores de etileno dos mutates etr1-1 e etr1-3 são insensíveis ao etileno relacionado ao fechamento estomático e produção do peróxido de hidrogênio (DESIKAN et al., 2006). O envolvimento do etileno na regulação da abertura estomática não está clara. Em algumas espécies, o etileno mediado pela auxina pode induzir a abertura estomática, enquanto em outras espécies, ele pode induzir o fechamento (DESIKAN et al., 2006). Em Arabidopsis thaliana, o etileno pode modular o ácido abscísico (ABA), induzindo o fechamento estomático (TANAKA et al., 2005). Alguns dados indicam que o fechamento estomático induzido pelo peróxido de hidrogênio precisa do 
receptor de etileno ETR1, implicando na ligação entre o peróxido de hidrogênio e o sinal de transdução do etileno (DESIKAN et al., 2005).

A auxina pode estar relacionada com a regulação do comportamento estomático (XIAOPING; XI-GUI, 2006). Além disso, a indução da abertura estomática através da auxina pode estar relacionada à exclusão do $\mathrm{H}^{+}$através da membrana plasmática. A auxina pode afetar o bombeamento do $\mathrm{H}^{+}$através da membrana plasmática que precede a elongação induzida pela auxina e células guarda (COENEN et al., 2002).

Em contraste a outros metais, nenhum sistema de entrada do Cd na célula por transportadores metálicos e também via canais de Ca são conhecidos (POLLE; SCHÜTZENDÜBEL, 2003). Além disso, uma ligação cruzada pode existir entre o metal pesado e os caminhos de sinalização do estresse abiótico. Neste sentido, as citocininas agem como antagonistas do Cd indicando que o fitormônio pode afetar a tolerância ao metal pesado (POLLE; SCHÜTEZENDÜBEL, 2003). Entretanto, o fechamento estomático pode ser a causa da interação direta do efeito tóxico do $\mathrm{Cd}$ nas células gurada. O aumento da resistência estomática pode também ser uma conseqüência do efeito tóxico do Cd de outros tecidos de plantas, conduzindo ao decréscimo da disponibilidade de água nas folhas e na regulção estomática (PERFUSBARBEOCH et al., 2002). A aplicação do Cd pode induzir o decréscimo na condutância foliar e a na absorção do $\mathrm{CO}_{2}$. Este decréscimo pode ser parcialmente relacionado à difusão do $\mathrm{CO}_{2}$ para pontos de carboxilação resultando no fechamento estomático (PERFUS-BARBEOCH et al., 2002).

O Cd pode também interpor diretamente com a sinalização do Ca tão logo os íons de Cd tenham habilidade de trocar o Ca na regulação da calmodulina (PERFUS-BARBEOCH et al., 2002). O Cd pode ter efeito pleiotrópico, sua difusão pode iniciar na célula guarda através dos íons de Ca resultando na perturbação da sinalização do Cd (ALLEN et al., 2000).

De acordo com os resultados apresentados pela M.O., o aumento dos espaços intercelulares nas folhas de $\mathrm{Nr}$ (Figura 5.5) nas plantas submetidas ao Cd pode estar relacionado ao aumento da aeração ocasionado pela morte celular (BEHBOODI; SAMADI, 2004). Entretanto, o tamanho celular reduzido e os espaços intercelulares pequenos observados nas folhas do dgt (Figura 5.6) podem indicar que o Cd afetou a expansão celular. Essa alteração pode estar relacionada com efeitos deletérios no potencial de turgor e na plasticidade celular (BARCELÓ et al., 1988). Em plantas de ervilha e tomate, análises ultraestruturais das folhas 
mostraram distúrbios caracterizados pelo aumento do tamanho da célula do mesófilo e redução dos espaços intercelulares (SANDALIO et al., 2001; DJEBALI et al. 2005).

A presença de altas concentrrações de EAOs no ambiente celular pode impor danos oxidativos nas estruturas e funções celulares (CHOUDHURY; PANDA, 2005). De acordo com os resultados observados na M.E.T., as alterações observadas nos cloroplastos pode ser devido ao aumento na produção de EAOs. As EAOs são tóxicas, causando uma cascata de reações oxidativas que resultam na quebra do DNA, proteínas e degradação de pigmentos, inativação de enzimas e peroxidação lipídica (GRATÃO et al., 2005; GRATÃO et al., 2006). Os efeitos mais danosos das EAO estão relacionados à peroxidação dos lipídeos de membrana essenciais no plasmalema ou organelas intracelulares (SCANDALIOS, 2005).

De acordo com os resultados, as folhas de Micro-Tom e dgt tratadas com Cd apresentaram proliferação de peroxissomos e mitocôndrias (Figura 5.8 e 5.12). O estresse oxidativo pode causar proliferação de peroxissomos que possuem um eficiente sistema de defesa contra as EAOs, especialmente $\mathrm{H}_{2} \mathrm{O}_{2}$ (IGAMBERDIEV; LEA, 2002). As mitocôndrias e os peroxissomos são organelas metabolicamente ligadas (SCHRADER; YOON, 2007) e através das análises ultraestrururais, as populações de peroxissomos e mitocôndrias, mediados pelas EAOs, teriam papel nos mecanismos da senescência foliar (PASTORI; DEL RIO, 1993). Além disso, de acordo com estudos ultraestruturais, o estresse oxidativo pode induzir a proliferação de cinco a duas vezes a população de peroxissomos e mitocôndrias em plantas, respectivamente (PALMA et al., 1991).

Os peroxissomos de plantas têm um importante papel em numerosos processos fisiológicos e são capazes de se adaptarem a mudanças ambientais alterando seu conteúdo, morfologia e abundância (HU, 2007). Em plantas, um grande número de peroxissomos estão envolvidos na mobilização de lipídeos através da ß-oxidação e do ciclo do glioxilato, fotorespiração, metabolismo de nitrogênio, síntese e metabolismos de hormônios e geração e de EAOs (HU, 2007).

O Cd pode estimular o estresse oxidativo, mas em contraste com outros metais tóxicos, não parece estimular a produção de EAOs diretamente (SCHÜTZENDÜBEL et al., 2001; BOOMINATHAN; DORAN, 2002). Além disso, o Cd pode conduzir a redução do crescimento foliar, morte celular, clorose foliar que ocorre como uma conseqüência da inibição de água e de nutrientes, destruição da função do cloroplasto e senescência foliar, mostrando cloroplastos com número e tamanho alterados (HUTTOVÁ et al., 2006). 
Neste estudo, o Cd afetou a ultrastrutura dos cloroplastos, dos grãos de amido e aumento no número e tamanho de plastoglóbulos (Figura 5.8, 5.10. 5.12). Estas mudanças estão relacionadas pricipalmente com a desorganização das membranas dos tilacóides (VIJARANAKUL et al., 2001; BORGES et al. 2004). Alterações estruturais nos cloroplastos ocorrem quando altas concentrações de Cd são usadas, (RASCIO et al., 1993; CARGINALE et al., 2004), induzindo distorções nos tilacóides e o aumento no número e tamanho de plastoglóbulos e vesículas periféricas (HAKMAOUI et al., 2007). O número e tamanho de plastoglóbulos no cloroplasto está relacionado a síntese e reciclagem de produtos lipofílicos do metabolismo oxidativo durante condições de estresse (OLMOS et al., 2006;YATTERBERG et al., 2006). Em plantas de ervilha, análises ultraestruturais mostraram que o Cd produziu desorganização da estrutura dos cloroplastos, com aumento no número de plastoglóbulos e a formação de vesículas nos vacúolos (MACCARTHY et al., 2001).

Com relação ao grão de amido, o Cd pode danificar os cloroplastos causando a inativação e promovendo o decréscimo do conteúdo de clorofila e aumento nos grãos de amido e lipídeos (BEHBOODI; SAMADI, 2004). Os efeitos do Cd na estrutura dos cloroplastos diferem daqueles de outros metais como niquel (Ni), colbalto (Co) e zinco ( $\mathrm{Zn}$ ) que pode induzir o acúmulo de amido (DJEBALI et al., 2005). Entretanto, a ausência ou decréscimo no número de amido nos cloroplastos pode estar relacionado com a inibição da fotossíntese (DJEBALI et al., 2005). Além disso, sabe-se também que o etileno pode estar relacionado com mudanças no metabolismo do amido (KUZNETSOV et al., 2001).

Em nosso resultados, curiosamente tanto nas plantas submetidas ao Cd como naquelas controles do mutante dgt, foi observado características do fenômeno de autólise (Figura 5.11). Durante a autólise, fortes desorganização do citoplasma, plasmólise e alterações como quebra e desintegração do núcleo, retículo endoplasmático, aparato do Golgi são observadas (OLIVEIRA; BISALPUTRA, 1977; OUYANG et al., 1999; BENNICI; TANI, 2004).

Durante a autólise, ocorre a degeneração autolítica das células que passam por uma série de eventos que resultam na desorganização e desaparecimento de todos os componentes protoplasmáticos, sendo o núcleo e o plasmalema os últimos a desaparecerem (OUYANG et al., 1999). Em plântulas de milho, análises ultrastruturais das células do mesófilo mostraram extensiva desorganização do cloroplasto, principalmente afetando as membrans do tilacóide (RASCIO et al., 1993; SOUZA et al., 2005). Em Elodea canadensis, o Cd causou alterações na forma da organela e no arranjo dos tilacóides, aparecimento de muitas vesículas citoplasmáticas 
e desorganização da perede celular (DALLA VECHIA et al., 2005; ESPOSIT et al., 2007). Em trigo o Cd mostrou causar danos na estrutura dos cloroplastos de trigo, manifestado pela dilatação das membranas dos tilacóides. Estas mudanças estruturais sugerem que o $\mathrm{Cd}$ provavelmente induziu senescência prematura (OUZOUNIDOU et al., 1997).

Obervações ultrastruturais em Hydrilla verticillata mostraram dispersão dos dictiossomos, desintegração do retículo endoplasmático, vesiculação dos cloroplastos e cristas mitocondriais, assim como o desaparecimento dos ribossomos, aglutinação da cromatina e núcleo, dispersão do nucléolo, disrupção da membrana nuclear, desintegração dos cloroplastos e mitocôndria e colapso do plasmodemata (SHI et al., 2000).

A informação disponível neste trabalho é um passo importante para o entendimento das mudanças estruturais causadas por metais pesados assim como os processos metabólicos envolvidos com os elementos tóxicos. Assim, através dos estudos da integração de sinais endógenos e danos causados nas estruturas das células, torna-se possível inferir estratégias para manter a função vital das plantas sujeitas a fatores de estresse. 


\section{Referências}

ALLEN, G.J., CHU, S.P., SCHUMACHER, K., SHIMAZAKI, C.T., VAFEADOS, D., KEMPER, A., HAWKE, S.D., TALLMAN, G., TSIEN, R.Y., HARPER, J.F., CHORY, J., SCHROEDER, J.I. Alteration of stimulus-specific guard cell calcium oscillations and stomatal closing in Arabidopsis det3 mutant. Science, Washington, v. 289, p. 2338-2342, 2000.

ARAVIND, P., PRASAD, M.N.V. Cadmium-Zinc interactions in a hydroponic system using Ceratophyllum demersum L.: adaptive ecophysiology, biochemistry and molecular toxicology. Brazilian Journal of Plant Physiology, Piracicaba, v. 17, p. 3-5, 2005.

BARCELÓ, J., VÁSQUES, M.D., POSCHENRIEDER, C. Structural and ultrastructural disorders in cadmium-treated bush bean plants (Phaseolus vulgaris L.). New Phytologist, London, v. 108, p. 37-49, 1988.

BARRY, C.S., GIOVANNONI, J.J. Ethylene and Fruit Ripening. Journal of Plant Growth Regulation, Netherlands, v. 26, p. 143-159, 2007.

BARYLA, A., CARRIER, P., FRANCK, F., COULOMB, C., SAHUT, C., HAVAUX, M. Leaf chlorosis in oilseed rape plants ( Brassica napus ) grown on cadmium-polluted soil: causes and consequences for photosynthesis and growth. Planta, New York, v. 212, p. 696-709, 2001.

BEHBOODI, B.S.H., SAMADI, L. Detection of apoptotic bodies and oligonucleosomal DNA fragments in cadmium-treated root apical cells of Allium cepa Linnaeus. Plant Science, Clare, v. 167, p. 411-416, 2004.

BENAVIDES, M.P., GALLEGO, S.M., TOMARO, M.L. Cadmium toxicity in plants. Brazilian Journal of Plant Physiology, Piracicaba, v. 17, p. 21-34, 2005.

BENNICI, A., TANI, C. Anatomical and ultrastructural study of the secretory cavity development of Citrus sinensis and Citrus limon: evaluation of schizolysigenous ontogeny. Flora, New York, v. 199, p. 464-475, 2004.

BLEECKER, A.B., KENDE, H. Ethylene: a gaseous signal molecule in plants. Annual Review of Cell and Developmental Biology, Palo Alto, v. 16, p. 1-16, 2000.

BOOMINATHAN, R., DORAN, P.M. Ni-induced oxidative stress in roots of the Ni hyperaccumulator, Alyssum bertolonii. New Phytologist, London, v. 156, p. 205-215, 2002.

BORGES, R., MIGUEL, E.C., DIAS, J.M.R., DA CUNHA, M., RICARDO, E.B.S., OLIVEIRA, J.G., SOUZA FILHO, G.A. Ultrastructural, physiological and biochemical analyses of chlorote toxicity on rice seedlings. Plant Science, Clare, v. 166, p. 1057-1062, 2004.

CARGINALE, V., SORBO, S., CAPASSO, C., TRINCHELlA, F., CAFIERO, G., BASILE, A. Accumulation, localization, and toxic effects of cadmium in the liverwort Lunularia cruciata. Protoplasma, Leipzig, v. 223, p. 53-61, 2004. 
CHOUDHURY, S., PANDA, S.K. Toxic effects, oxidative stress and ultrastructural changes in moss Taxithelium nepalense (Schwaegr.) Broth. under chromium and lead phytotoxicity. Water, Air, and Soil Pollution, Dordrecht, v. 167, p. 73-90, 2005.

COENEN, C., BIERFREUND, N., LÜTHEN, H., NEUHAUS, G. Developmental regulation of $\mathrm{H}^{+}$-ATPase-dependent auxin responses in the diageotropica mutant of tomato (Lycopersicon eesculentum). Physiologia Plantarum, Copenhagen, v. 114, p. 461-471, 2002.

COENEN, C., LOMAX, T.L. The Diageotropica Gene Differentially Affects Auxin and Cytokinin Responses throughout Development in Tomato. Plant Physiology, Rockville, v. 117, p. 63-72, 1998.

DALLA VECHIA, F., LA ROCCA, N., MORO, I., DE FAVERI, S.,ANDREOLI, C., RASCIO, N. Morphogenetic, ultrastructural and physiological damages suffered by submerged leaves of Elodea canadensis exposed to cadmium. Plant Science, Clare, v. 168, p. 329-338, 2005.

DESIKAN, R., HANCOCK, J.T., BRIGHT, J., HARRISON, J., WEIR, I., HOOLEY, R., NEIL, S.J. A role for ETR1 in hydrogen peroxide signaling in stomatal guard cells. Plant Physiology, Rockville, v. 137, p. 831-834, 2005.

DESIKAN, R., LAST, K., HARRETT-WILlIAMS, R., TAGLIAVIA, C., HARTER, K., HOOLEY, R., HANCOCK, J.T., NEIL, S.J. Ethylene-induced stomatal closure in Arabidopsis occurs via AtrbohF-mediated hydrogen peroxide synthesis. Plant Journal, Oxford, v. 47, p. 907916, 2006.

DJEBALI, W., ZARROUK, M., BROUQUISSE, R., EL KAHOUI, S., LIMAM, F., GHORBEL, M.H., CHAIBI, W. Ultrastructure and lipid alterations induced by cadmium in tomato (Lycopersicon eesculentum) chloroplast membranes. Plant Biology, New York, v. 7, p. 358-368, 2005.

ESPOSIT, S., COBIANCHI, R.C., SORBO, S., CONTE, B., BASILE, A. Ultrastructural alterations and HSP 70 induction in Elodea canadensis Michx. Exposed to heavy metals. Caryologia, Florence, v. 60, p. 115-120, 2007.

ETHERIDGE, N., HALL, B.P., SCHALLER, G.E. Progress report: ethylene signaling and responses. Planta, New York, v. 223, p. 387-391, 2006.

FOREMAN, J., DEMIDCHIK, V., BOTHWELL, J.H.F. Reactive oxygen species produced by NADPH oxidase regulate plant cell growth. Nature, London, v. 422, p. 442-446, 2003.

FRANCIA, D., DAMARIA, D., CALDERINI, O., FERRARIS, L., VALENTINO, D., ARCIONI, S., TAMIETTI, G., CARDINALE, F. Wounding induces resistance to pathogens with different lifestyles in tomato: role of ethylene in cross-protection Plant, Cell and Environment, Oxford, v. 30, p. 1357-1365, 2007.

FUHRER, J. Ethylene Biosynthesis and Cadmium Toxicity in Leaf Tissue of Beans (Phaseolus vulgaris L.). Plant Physiology, Rockville, v. 70, p. 162-167, 1982. 
GRATÃO, P.L., POLLE, A., LEA, P.J., AZEVEDO, R.A. Making the life of heavy metalstressed plants a little easier. Functional Plant Biology, Collingwood, v. 32, p. 481-494, 2005.

GRATÃO, P.L., POMPEU, G.B., CARDOSO, P.F., LEA, P.J., AZEVEDO, R.A. Plant antioxidant responses to toxic elements. Current Topics in Biochemical Research, New Delhi, v. 8, p. 40-70, 2006.

GUO, H., ECKER, J.R. The ethylene signalling pathway: new insights. Current Opinion in Plant Biology, London, v. 7, p. 40-49, 2004.

HAKMAOUI, A., ATER, M., BOKA, K., BARON, M. Cooper and cadmium tolerance, uptake and effect on chloroplast ultrastructure. Studies on Salix purpurea and Phragmites australis. Zeitschrift fur Naturforschung C-A Journal of Biosciences, Tubingen, v. 62, p. 417-426, 2007.

HOAGLAND, D., ARNON, D.I. The water culture method for growing plants without soil.In: . The water culture method for growing plants without soil. Berkeley: University California Agricultural Experiment Station, 1950. 34p.

HU, J. Plant peroxisome multiplication: highly regulated. Journal of Integrative Plant Biology. Califórnia, v. 49, p.1112-1118, 2007.

HUTTOVÁ, J., MISTRÍK, I. , OLLÉ-ŠIMONOVIÈOVÁ, M., TAMÁS, L. Cadmium induced changes in cell wall peroxidase isozyme pattern in barley root tips. Plant Soil Environment, Oxford, v. 52, p. 250-253, 2006.

IGAMBERDIEV, A.U., LEA, P.J. The Role of peroxisomes in the integration of metabolism and evolutionary diversity of photosynthetic organism. Phytochemistry, Oxford, v. 60, p. 651-674, 2002.

KARNOWSKY, M.J. A formaldehyde-glutaraldehyde fixative of high osmolarity for use in electron microscopy . Journal of Cell Biology, New York, v. 27, p.137A, 1965.

KELLY, M.O., BRADFORD, K.J. Insensitivity of the. diageotropica tomato mutant to auxin.Plant Physiology, Rockville, v. 82, p. 713-717, 1986.

KLEE, H.J. Ethylene Signal Transduction. Moving beyond Arabidopsis. Plant Physiology, Rockville, v. 135, p. 660-667, 2004.

KUZNETSOV, O.A., BROWN, C.S., LEVINE, H.G., PIASTUCH, W.C., SANWOLEWANDOWSKI, M.M., HASENSTEIN, K.H. Composition and physical properties of starch in microgravity-grown plants. Advances in Space Research, Oxford, v. 28, p. 651-658, 2001.

KWAK, J.M., NGUYEN, V., SCHROEDER, J.I. The role of reactive oxygen species in hormonal responses. Plant Physiology, Rockville, v. 141, p. 323-329, 2006. 
LIU, C.P., SHEN, Z.G., LI, X.D. Accumulation and detoxification of cadmium in Brassica pekinensis and B. chinensi. Biologia Plantarum, Netherlands, v. 51, p. 116-120, 2007.

MCCARTHY, I., ROMERO-PUERTAS, M.C., PALMA, J.M., SANDALIO, L.M., CORPAS, F.J., GÓMEZ, M., DEL RIO, L.A. Cadmium induces senescence symptoms in leaf peroxisomes of pea plants. Plant, Cell and Environment, Oxford, v. 24, p. 1065-1073, 2001.

MEISSNER, R., JACOBSON, Y., MELAMED, S., LEVYATUV, S., SHALEV, G., ASHRI, A., ELKIND, Y., LEVY, A. A new model system for tomato genetics. Plant Journal, Oxford, v. 12, p. 1465-1472, 1997.

MOBIN, M., KHAN, N.A. Photosynthetic activity, pigment composition and antioxidative response of two mustard (Brassica juncea) cultivars differing in photosynthetic capacity subjected to cadmium stress. Journal of Plant Physiology, Stuttgart, v. 164, p. 601-610, 2007.

MONTOYA, T., NOMURA, T., YOKOTA, T., FARRAR, K., HARRISON, K., JONES, J.G.D., KANETA, T., KAMIYA, Y., SZEKERES, M., BISHOP, G.J. Patterns of Dwarf expression and brassinosteroid accumulation in tomato reveal the importance of brassinosteroid synthesis during fruit development. Plant Journal, Oxford, v. 42, p. 262-269, 2005.

MUNNÉ-BOSCH, S., PEÑUELAS, J., ASENSIO, D., LLUSIÀ, J. Airborne ethylene may alter antioxidant protection and reduce tolerance of holm Oak to heat and drought stress. Plant Physiology, Rockville, v. 136, p. 2937-2947, 2004.

OLIVEIRA, L., BISALPUTRA, T. Ultrastructural Studies in the Brown Alga Ectocarpus in Culture: Autolysis. New Phytologist, London, v. 78, p. 139-145, 1977.

OLMOS, E., KIDDLE, G., PELLNY, T.K., KUMAR, S., FOYER, C.H. Modulation of plant morphology, root architecture, and cell structure by low vitamin C in Arabidopsis thaliana. Journal of Experimental Botany, Oxford, v. 57, p. 1645-1655, 2006.

OUYANG, X.Z., XIE, S.P., HE, Z.M. Ultrastructural study on the degenerative processes of procambial cells in maize leaf blades. Acta Botanica Sinica, New York, v. 41, p. 570-575, 1999.

OUZOUNIDOU, G., MOUSTAKAS, M., ELEFTHERIOU, E.P. Physiological and ultrastructural effects of cadmium on wheat (Triticum aestivum L.) leaves. Archives of Environmental Contamination and Toxicology,Oxford, v. 32, p. 154-160, 1997.

PALMA, J.M., GARRIDO, M., RODRIGUEZ GARCIA, M.I., DEL RIO, L.A. Peroxisome proliferation and oxidative stress mediated by activated oxygen species in plant peroxisomes. Archives in Biochemistry Biophysics, Dusseldorf, v. 287, p. 68-74, 1991.

PASTERNAK, T., POTTERS, G., CAUBERGS, R., JANSEN, M.A.K. Complementary interactions between oxidative stress and auxins control plant growth responses at plant, organ, and cellular level. Journal of Experimental Botany, Oxford, v. 56, p. 1991-2001, 2005. 
PASTORI G.M., DEL RIO, L.A. An activated-oxygen-mediated role for peroxisomes in the mechanism of senescence of Pisum sativum L. leaves. Planta, New York, v. 193, p. 385-391, 1993.

PERFUS-BARBEOCH, L., LEONHARDT, N., VAVASSEUR, A., FORESTIER, C. Heavy metal toxicity: cadmium permeates through calcium channels and disturbs the plant water status. Plant Journal, Oxford, v. 32, p. 539-548, 2002.

POLANSKA, L., VICANKOVA, A., NOVAKOVA, M., MALBECK, J., DOBREV, P.I., BRZOBOHATY, B., VANKOVA, R., MACHACKOVA, I. Altered cytokinin metabolism affects cytokinin, auxin, and abscisic acid contents in leaves and chloroplasts, and chloroplasts ultrastructure in transgenic tobacco. Journal of Experimental Botany, Oxford, v. 58, p. 637649, 2007.

POLLE, A., SCHÜTZENDÜBEL, A. Heavy metal signalling in plants: linking cellular and organismic responses. Topics in Current Genetics, Berlin, v. 4, p. 187-215, 2003.

POTTERS, G., PASTERNAK, T.P., GUISEZ, Y., PALME, K.J., JANSEN, M.A.K. Stressinduced morphogenic responses: growing out of trouble? Trends in Plant Science, London, v. 12, p. 98-105, 2007.

PRASAD, M.N.V. Cadmium toxicity and tolerance in vascular plants. Environmental and Experimental Botany, Oxford, v. 35, p. 525-545, 1995.

RASCIO, N., DALLA VECHIA, F., FERRETTI, M., MERLO, L., CHISI, R. Some effects of cadmium on maize plants. Archives of Environmental Contamination and Toxicology, New York, v. 25, p. 244-249, 1993.

SANDALIO, L.M., DALURZO, H.C., GOMEZ, M., ROMERO-PUERTAS, M.C., DEL RIO, L.A. Cadmium-induced changes in the growth and oxidative metabolism of pea plants. Journal of Experimental Botany, Oxford, v. 52, p. 2115-2126, 2001.

SCANDALIOS, J.G. Oxidative stress: molecular perception and transduction of signals triggering antioxidant gene defenses. Brazilian Journal of Medical Biology Research, Ribeirão Preto, v. 38, p. 995-1014, 2005.

SCHRADER, M., YOON, Y. Mitochondria and peroxisomes: Are the "Big Brother" and the " Little Sister' closer than assumed? BioEssays, Wiley, v. 29, p. 1105-1114, 2007.

SCHÜTZENDÜBEL, A., SCHWANZ, P., TEICHMANN, T., GROSS, K., LANGENFELDHEYSER, R., GODBOLD, D.L., POLLE, A. Cadmium-induced changes in antioxidant systems, hydrogen peroxide content and differentiation in Scots pine roots. Plant Physiology, Rockville, v. 127, p. 887-898, 2001.

SHI, G.X., DU, K.U., XIE, K.B., DING, X.Y., CHANG, F.C., CHEN, G.X. Ultrastructural study of leaf cells damaged from $\mathrm{Hg}^{2+}$ and $\mathrm{Cd}^{2+}$ pollution in Hydrilla verticillata. Acta Botanica Sinica, New York, v. 42, p. 373-378, 2000. 
SOUZA, J.F., DOLDER, H., CORTELLAZZO, A.L. Effect of excess cadmium and zinc ions on roots and shoots of maize seedlings. Journal of Plant Nutrition, Philadelphia, v. 28, p. 19231931, 2005.

STOYANOVA, D.P., TCHAKALOVA, E.S. Cadmium-induced ultrastructural changes in chloroplasts of the leaves and stems parenchyma in Myriophyllum spicatum L. Photosynthetica, Praha, v. 34, p. 241-248, 1997.

SWARUP, R., MARCHANT, A., BENNETT, M.J. Auxin transport: providing a sense of direction during plant development. Biochemical Society Transactions, London, v. 28, p. 481485, 2000.

TANAKA, Y., SANO, T., TAMAOKI, M., NAKAJIMA, N., KONDO, N., HASEZAWA, S. Ethylene Inhibits Abscisic Acid-Induced Stomatal Closure in Arabidopsis. Plant Physiology, Rockville, v. 138, p. 2337-2343, 2005.

TANAKA, Y., SANO, T., TAMAOKI, M., NAKAJIMA, N., KONDO, N., HASEZAWA, S. Cytokinin and auxin inhibit abscisic acid-induced stomatal closure by enhancing ethylene production in Arabidopsis. Journal of Experimental Botany, Oxford, v. 57, p. 2259-2266, 2006.

TORRES, M.A., DANGL, J.L. Functions of the respiratory burst oxidase in biotic interactions, abiotic stress and development. Current Opinion in Plant Biology, London, v. 8, p. 397-403, 2005.

VAN LOON, L.C., GERAATS, B.P.J., LINTHORST, H.J.M. Ethylene as a modulator of disease resistance in plants. Trends in Plant Science, London, v. 11, p. 184-191, 2006.

VASSILEV, A., LIDON, F., CAMPOS, P.S., RAMALHO, J.C., BARREIRO, M.G., YORDANOV, I. Cu-induced changes in clhoroplast lipids and photosystem 2 activity in barley plants. Bulgarian Journal Plant Physiology, Oxford, v. 29, p. 33-43, 2003.

VIJARANAKUL, U., JAYASWAL, R.K., NADAKAVUKAREN, M.J. Alteration in chloroplast ultrastructure of suspension cultured Nicotiana tabacum cells by cadmium. Science Asia, Bangkok, v. 27, p. 227-231, 2001.

VINCENT, J.M. Manual practico de rizobiologia. In: Manual practico de rizobiologia Buenos Aires: Hemisfério Sur, 1975. 200p.

VITÓRIA, A.P., DA CUNHA, M., AZEVEDO, R.A. Ultrastructural changes of radish leaf exposed to cadmium. Environmental and Experimental Botany, Oxford, v. 58, p. 47-52, 2006.

VITÓRIA, A.P., RODRIGUEZ, A.P.M., CUNHA, M., LEA, P.J., AZEVEDO, R.A. Structural changes in radish seedlings exposed to cadmium. Biologia Plantarum, Netherlands, v. 47, p. 561-568, 2004. 
WAHID, A, GHANI, A. Varietal differences in mung bean (Vigna radiata) for growth, yield, toxicity symptoms and cadmium accumulation. Annals of Applied Biology, Oxford, 2007, in press.

WILKINSON, J.Q., LANAHAN, M.B., YEN, H.C., GIOVANNONI, J.J., KLEE, H.J. An ethylene inducible component of signal transduction encoded by Never ripe. Science, Washington, v. 270, p. 1807-1809, 1995.

XIAO-PING, S., XI-GUI, S. Cytokinin- and auxin-induced stomatal opening is related to the change of nitric oxide levels in guard cells in broad bean. Physiologia Plantarum, Copenhagen, v. 128, p. 569-579, 2006.

YAKIMOVA, E.T., KAPCHINA, V.M., LAARHOVEN, L.J., HARREN, F.M., WOLTERING, E.J. Involvement of ethylene and lipid signaling in cadmium-induced programmed cell death in tomato suspension cells. Plant Physiology and Biochemistry, Paris, v. 44, p. 581-589, 2006.

YATTERBERG, A.J., PELTIER, J.B., VAN WIJK, K.J. Protein profiling of plastoglobules in chloroplasts and chromoplasts; a surprising site for didderential accumulation of metabolic enzymes. Plant Physiology, Rockville, v. 140, p. 984-997, 2006.

ZHAO, M.G., TIAN, Q.Y., ZHANG, W.H. Ethylene activates a plasma membrane $\mathrm{Ca}^{2+}-$ permeable channel in tobacco suspension cells. New Phytologist, London, v. 174, p. 507-515, 2007. 